\title{
Tigiversity of Glasgow
}

Krus, A. M. and Cobb, C. R. (2018) The Mississippian fin de siècle in the middle Cumberland region of Tennessee. American Antiquity, 83(2), pp. 302-319. (doi:10.1017/aaq.2018.1)

This is the author's final accepted version.

There may be differences between this version and the published version. You are advised to consult the publisher's version if you wish to cite from it.

http://eprints.gla.ac.uk/152419/

Deposited on: 29 November 2017

Enlighten - Research publications by members of the University of Glasgow http://eprints.gla.ac.uk 


\section{THE MISSISSIPPIAN FIN DE SIÈCLE IN THE MIDDLE CUMBERLAND REGION OF TENNESSEE}

Anthony M. Krus and Charles R. Cobb

Anthony M. Krus Scottish Universities Environmental Research Centre, Scottish Enterprise Technology Park, East Kilbride G75 0QF, UK (tony.krus@glasgow.ac.uk, corresponding author)

Charles R. Cobb Florida Museum of Natural History, University of Florida, Dickinson Hall, 1659 Museum Road, Gainesville, FL 32611, USA 


\begin{abstract}
Bayesian chronological modeling is used to investigate the chronology for a large-scale human depopulation event during the Mississippi period (A.D. 1000-1700) known as the Vacant Quarter phenomenon. The Middle Cumberland Region (MCR) of Tennessee is within the Vacant Quarter area and six villages from the final phase of Mississippian activity in the MCR have been subjected to radiocarbon dating. Complete radiocarbon datasets from these sites are presented within an interpretative Bayesian statistical framework. The results provide a unique history of each settlement and demonstrate that Mississippian occupations at each site likely terminated in the mid-to-late fifteenth- and possibly early sixteenth-centuries A.D., which is $50-100$ years later than the most recent estimate for the timing of the Vacant Quarter. Mississippian abandonment in the MCR was relatively quick, likely occurring over less than a century. The exact reasons for abandonment are not entirely clear but appear to be linked to climate change. A radiocarbon simulation experiment indicates that future robust radiocarbon dating with well selected samples could greatly improve the chronological precision for this late Mississippian activity. More broadly, this demonstrates that model-building with radiocarbon simulations can be used to address regional scale chronological issues within the American Southeast and beyond.
\end{abstract}




\section{SPANISH ABSTRACT}

A través del modelado Bayesiano se explora la cronología de un proceso de despoblación humana a gran escala que tuvo lugar durante el periodo Misisipi (A.D. 1000-1700) y que se conoce como el fenómeno "Vacant Quarter". Seis poblados del final de la fase de actividad misisipiana en la Región del Medio Cumberland (RMC) de Tennessee, insertadas a su vez dentro del área "Vacant Quarter", han sido objeto del programa de dataciones radiocarbónicas. Se presentan series completas de dataciones radiocarbónicas de estos yacimientos interpretadas mediante el análisis cronológico Bayesiano. Los resultados permiten trazar la propia historia de cada yacimiento y demuestran que las ocupaciones misisipianas finalizarían con probabilidad entre mediados y finales del siglo XV y posiblemente comienzos del siglo XVI d.C., lo que implica entre 50-100 años más tarde que la estimación cronológica más reciente del "Vacant Quarter". El abandono de la ocupación misisipiana en el RMC fue relativamente rápido, teniendo lugar probablemente durante menos de un siglo. Las causas del abandono no están completamente dilucidadas, pero parecen estar relacionadas con el cambio climático. Un experimento de simulación radiocarbónica indica que futuros programas de dataciones sobre muestras bien seleccionadas podrían mejorar de manera considerable la precisión cronológica para el final de la actividad misisipiana. En términos generales, esto demuestra el potencial de los modelos construidos mediante dataciones radiocarbónicas simuladas a la hora de abordar cuestiones cronológicas de escala regional tanto para el Sudeste americano, como para otras zonas. 
It was not that long ago, at least by radiocarbon date reckoning, that the so-called Vacant Quarter (Williams 1983, 1990) was viewed as somewhat of a demographic singularity (Figure 1): How and why could such a large portion of the mid-continent of North America be abandoned by sedentary, agricultural peoples comprising the Mississippian chiefdoms of the fifteenth-century A.D.? By Stephen Williams' (1990) estimation, most of the traditional Mississippian-period core area was "burned out" well before the arrival of Europeans on Native American soil. This kind of exodus is perhaps understandable in places like the American Southwest where pronounced oscillations in the scarcity and abundance of water fostered large-scale migrations (e.g., Hill et al. 2004; Lekson and Cameron 1995). While the timing of the Vacant Quarter seems to coincide with a period of pronounced droughts (Meeks and Anderson 2013), significant portions of the region are dissected by sizable drainages that we know did not dry up even in times of drought, not the least of which are the Mississippi and Ohio Rivers.

Suffice it to say, the jury is still out on the causes of the large magnitude movement of peoples. We think that this poses an even larger question than once was thought because it now appears that there were other contemporary regional abandonments elsewhere in eastern North America (Anderson 1994; Cable 2018; Johnson 1996; Williams 2001). Apparently, an extensive atmosphere of destabilization permeated a much larger region than just the Vacant Quarter in the fourteenth and fifteenth centuries A.D.

At this time, it is difficult to delineate the timing and tempo of the unfolding of the Vacant Quarter with precision or certainty. We argue that a better handle on chronology 
is an important first step toward addressing this phenomenon. A regional abandonment taking place over the course of 25 years potentially has very different causes and consequences than one taking place over a 200 year span. Although there now is a solid corpus of Mississippian radiocarbon dates from throughout the region (Meeks and Anderson 2013), they have not been collected with the express purpose of addressing issues of abandonment. Instead, they represent a compilation derived from decades of fieldwork across numerous archaeological sites.

By way of contrast, in the United Kingdom robust models for archaeological sites and regions have provided chronologies that have completely transformed understandings of archaeological histories (Bayliss 2009; 2015; Hamilton et al. 2015). Careful implementation of scientific dating and chronological modeling have allowed for the creation of site histories in Britain at generational scales. Corresponding syntheses of detailed regional archaeological narratives have brought new understandings to past phenomena. There has yet to be a project in North American archaeology on the same scale as this British chronological work (Hamilton and Krus 2018; Thompson and Krus 2018), in part because this kind of enterprise represents a daunting logistical and fiscal challenge. For example, the chronological modeling projects overseen by Alex Bayliss at Historic England have involved the careful selection and submission of thousands of samples for new radiocarbon dates (for example, see Bayliss et al. [2011], Denaire et al. [2017], Richards et al. [2016], Tasić et al. [2016], and Whittle et al. [2016]). 
With this in mind, we turn our attention to the Middle Cumberland Region (MCR) of Tennessee to demonstrate that the promise of this kind of effort merits the kind of chronological investments made by our colleagues across the Atlantic. Although our study sample includes radiocarbon dates from various unrelated projects, they can still serve as a robust foundation for exploring the timing of the Vacant Quarter in a similar manner to British archaeological projects driven by chronological modeling. In Stephen Williams' $(1983,1990)$ original formulation the MCR was considered part of the Vacant Quarter, and a later synthesis by Michael Moore and Kevin Smith (2009) further demonstrated that the area was depopulated sometime in the A.D. 1400s. However, a major question underlying the Vacant Quarter phenomenon has been, and continues to be, whether all the sub-regions experienced a population out-flow at approximately the same time, or whether there was any kind of time-lag involved that created more of a time-transgressive process?

By introducing Bayesian chronological modeling of the radiocarbon dates available from the late Thruston Phase settlements, the final phase of Mississippi period activity in the MCR (Beahm 2013:259-261; Moore and Smith 2009), we believe that we can begin to cast some initial light on issues surrounding the relative synchronicity of depopulation at multiple scales. The key questions that we address are: 1) Is it possible to evaluate whether the timing of population loss varies within the MCR?; 2) Does abandonment in this region vary significantly from other sub-regions in the Vacant Quarter?; 3) Is it possible to use a high-resolution chronology in the MCR to better understand the regional 
history at decadal-scales and to use these data to contextualize site-specific historicallycontingent reasons for social change?

\section{THE VACANT QUARTER AND OTHER REGIONAL ABANDONMENTS}

In his initial formulation of the Vacant Quarter hypothesis, Stephen Williams (1983, 1990) estimated that the abandonment occurred within the 100 year interval between A.D. 1450 and 1550 . His study was based on an insightful and panoramic melding of diagnostic horizon markers and radiocarbon dates. Dan and Phyllis Morse (1983) suggested the abandonment was perhaps 50 to 100 years earlier in the Central Mississippi Valley, whereas Cobb and Brian Butler (2002) argued that in the Lower Ohio Valley the last significant vestiges of population disappear around A.D. 1450.

As Scott Meeks and David Anderson (2013) have pointed out, this kind of variation has given the appearance — questionable in their opinion—-that the Vacant Quarter was a clinal phenomenon with some sub-regions depopulated well before others. After compiling a sample of 557 radiocarbon dates from five sub-regions throughout the Vacant Quarter, including the Middle Cumberland drainage, they argued that widespread, synchronic abandonment seems to have occurred by about A.D. 1420. They reached their conclusion by observing that the summed calibrated probability distributions of the radiocarbon dates for each of the sub-regions displayed a similar notable decline at the beginning of the fifteenth-century—a point which we will revisit. 
Widespread as it was, it now appears that the Vacant Quarter may not have been an isolated occurrence in the late prehistoric Southeast. David Anderson (1994) describes depopulation of a large portion of the Savannah River drainage in the 1400s; John Cable (2018) makes a similar argument for a large swath of the South Carolina coast and interior; Jay Johnson (1996) has posited that an abandonment of the Upper Tombigbee drainage may somehow be related to the Vacant Quarter phenomenon; and Stephen Williams (2001) was to later argue that the Yazoo Basin in the Lower Mississippi Valley also witnessed a massive population decline in the fifteenth-century. It should be noted that no one working on the Vacant Quarter or related abandonments has suggested that a complete evacuation of people occurred. It is possible that hamlets and encampments persisted up until the arrival of Europeans.

Scott Meeks and David Anderson (2013) have documented that the Vacant Quarter phenomenon generally correlates with a series of severe droughts beginning in the late A.D. 1200 s, as inferred through tree-ring proxies for precipitation. This presumes quite reasonably that there would be a time-lag between the onset of the first droughts and the eventual departure of populations under duress. John Cable (2018) makes a similar argument for ultimate climatological causation in his study of late Mississippian abandonment of the Carolina coastal region. Both studies are based on recent climatological reconstructions demonstrating significant and large-scale droughts over a significant portion of the Midwest and Southeast during the fifteenth and sixteenth centuries A.D. (Cook et al. 2007; Cook et al. 2014). Based on the same climatological data, Benson et al. (2009) suggest that an earlier series of droughts spanning A.D. 1100- 
1245 may also have played a role in the decline of Cahokia. Likewise, North Atlantic climatic fluctuations during the Mississippi period may have helped precipitate cultural and sociopolitical changes; for example, cooler temperatures during the onset of the Little Ice Age (about A.D. 1400) may have negatively impacted maize agricultural yields and increased the scarcity of food (Benson et al. 2007; 2009; Bird et al. 2017; Milner 1999; Milner et al. 2013).

Even if one does not subscribe to environmental or climatological determinism, it is difficult to accept that so many coeval regional depopulations were instigated throughout the Southeast solely by social factors. Nevertheless, it is important to consider climate within the context of cultural and social agency, particularly with regard to the various ways in which communities may respond to stress. For example, Meeks and Anderson (2013) posit that, over the course of time, significant declines in maize yields among Mississippian polities had political as well as demographic consequences - as the surpluses that underlay chiefdom political economies evaporated so did the power of those chiefs. The resulting broad scale social re-organization was accompanied by conflict and unrest that eventually led to wholesale population movements. Meghan Buchanan (2015) also sees warfare as playing a role in the large-scale exodus manifested by the Vacant Quarter, advancing a model whereby regional conflict was tightly integrated with a cultural landscape of spirits and otherworldly practices.

Although it is now widely accepted that the Mississippian Southeast was always in a state of flux, the Late Mississippi period during these centuries seems to have witnessed 
population movements on an unprecedented scale. Climate change clearly seems to have been one factor, if not the only one. We suggest that building detailed chronological models of sub-regions is a necessary step towards addressing the complex processes underlying large-scale population movements, as well as the consequences of those migrations.

\section{THE MIDDLE CUMBERLAND REGION}

A primary reason that we focus on the Middle Cumberland is that our recent assessment of the occupation span of one site in that region, Averbuch, did not quite square with Meeks and Anderson's (2013) chronology of abandonment. Whereas they have hypothesized that it occurred in the MCR around A.D. 1420, our Bayesian models of radiocarbon dates from Averbuch provided a site-closure estimate of about 25 to 50 years later (Cobb et al. 2015). Aside from statistical variation and overlap, numerous causes could account for this discrepancy. It is conceivable that the residents of Averbuch managed to persist for a few more decades after everyone else had departed. However, it is also possible that abandonments of the MCR deviated from the current expectations for the Vacant Quarter on a larger scale. This is an issue that can be addressed with more site-specific Bayesian chronological models for other MCR settlements.

Meeks and Anderson (2013) to their credit relied on a very large sample of 557 dates across 113 sites, which included 111 dates from 29 MCR sites. They developed sum probability distributions (using Calib 5.1) for each of five sub-regions in the Vacant 
Quarter to arrive at their early fifteenth-century estimate of abandonment. Their data revealed that there is a trickle of radiocarbon dates in each region that post-dates the midA.D. 1400s. At the same time, the summed probabilities displayed what they viewed as a "precipitous decline" (Meeks and Anderson 2013:75) in the probability distributions in the 1380-1420 interval, providing a basis for their A.D. 1420 widespread abandonment hypothesis.

Although we believe that they have correctly identified a larger abandonment event or process, interpreting patterns of calibrated radiocarbon probabilities based on visual evidence alone is an imprecise practice that can be refined with a strong degree of statistical rigor with the use of Bayesian modeling. For example, our study of the Averbuch site based on 18 radiocarbon dates provided a summed probability distribution that showed a steep decline in the fifteenth-century A.D. (Cobb et al. 2015). Based on these data, Bayesian modeling allow us to go one step further and to set probability estimates for the terminus of the site occupation at cal A.D. 1430-1500 at 95 percent probability, and cal A.D. 1440-1475 at 68 percent probability (Cobb et al. 2015: Figure 3).

To be fair, Meeks and Anderson's reliance on the probability distribution of radiocarbon dates is a common practice for approximating the establishment, occupation, and abandonment of sites and regions; in fact, Cobb and Butler (2002) used the same method for estimating the Ohio River Valley depopulation within the larger Vacant Quarter. However, the use of summed probabilities to interpret regional archaeological 
phenomena can be greatly skewed by calibration curve wiggles, non-proportional sampling, residual samples from post-depositional taphonomic processes, and from uncorrected radiocarbon offsets such as from the old-wood effect or from uncorrected fractionation (Contreras and Meadows 2014; Williams 2012). One of the advantages of Bayesian chronological models for human activity is that it can accommodate these biases within the chronological estimates of events with a given level of statistical probability (Bayliss 2009, 2015).

This is not to say that summed probability distributions have been rendered obsolete by Bayesian approaches. A number of studies have shown that summed probability distributions provide a very important initial perspective on general trends within the overall occupation of a site or region. Deviations or patterns of interest in these trends can subsequently be bracketed and explored with a high degree of resolution through Bayesian modeling (e.g., Inomata et al. 2014; Marsh 2015).

Given this background, we expanded our sample of sites in the MCR to evaluate whether Averbuch was either a late outlier in the Vacant Quarter, or else represented one example of a larger pattern of abandonment in the drainage that could be assigned to the mid to late A.D. 1400s. Rather than including all MCR radiocarbon dates in our analysis, we focused on sites with late Thruston Phase (A.D. 1350-1450) components, the final phase of Mississippian activity in the MCR (Beahm 2013:259-261; Moore and Smith 2009). There are six Mississippian sites in the MCR that have yielded both late Thruston Phase ceramic traits and sufficient numbers of radiocarbon samples with which to build an 
initial model of regional abandonment (Figure 2): Averbuch (40DV60), a palisaded village on a small drainage north of the Cumberland River (Cobb et al. 2015; Klippel et al. 1984); Brentwood Library (40WM210), a palisaded village on the Little Harpeth River (Moore 2005); East Nashville Mounds (40DV4), a large multi-mound site on the Cumberland River (Walling et al. 2000); Gordontown (40DV6), palisaded multi-mound town located on a tributary of Mill Creek (Moore and Breitburg 1998; Moore et al. 2006); Rutherford-Kizer (40SU15), a large and fortified multi-mound site on a tributary creek south of the Cumberland River (Moore and Smith 2001); and Sellars (40WI1), another site on a tributary creek south of the Cumberland River (Butler 1981).

Importantly, there are radiocarbon measurements from archaeological samples from each of these sites (Supplemental Materials Appendix A). This paper applies a Bayesian methodology (Bronk Ramsey 2009a) to date the timing of activity at each of the individual late Thruston Phase sites. Using a Bayesian framework, the chronology of this activity can be estimated not only by radiocarbon dating, but also by using the relative dating information provided by stratigraphy and feature groupings.

\section{METHODOLOGY}

The dataset used in this study includes all the available radiocarbon dates from late Thruston Phase (A.D. 1350-1450) sites in the MCR. This dataset consists of 65 radiocarbon dates, 13 from new measurements and 52 from the published literature. The new samples were obtained from curated archival materials held by the Tennessee 
Division of Archaeology (Supplemental Materials Appendix A). Samples were selected for new dating only if their context was securely associated with curatorial and excavation records. Of the 65 radiocarbon measurements, 58 were made on wood charcoal, four on nutshell, two on maize, and one on a sample of residue or soot.

The radiocarbon measurements are presented in Appendix A, where they are quoted in accordance with the Trondheim Convention (Stuiver and Kra 1986) as conventional radiocarbon ages (Stuiver and Polach 1977). Contextual and descriptive details for these samples are also provided in Appendix A. Calibrated date ranges were calculated using IntCal13 (Reimer et al. 2013) and OxCal v4.3. They are cited in the text as 95 percent confidence intervals, with the end points rounded outwards to 10 years. The technique used for Bayesian chronological modeling is a form of Markov Chain Monte Carlo sampling (Bronk Ramsey 2009a) and has been applied using the program OxCal v4.3 (http://c14.arch.ox.ac.uk/). The fit between the OxCal model and data is gauged with the $\mathrm{A}_{\text {model }}$ agreement index, and values higher than 60 indicate good agreement between the model parameters and the dates (Bronk Ramsey 2009a). Resulting posterior density estimates from OxCal are calendar years and presented in italics as probability ranges with end points rounded to the nearest five years. The algorithms used in the models can be derived from the model descriptions and OxCal code. Note that the posterior density estimates produced by modeling are not absolute. They are interpretative estimates, which can and will change as new data become available and as other researchers choose to model the existing data from different perspectives. 


\section{RESULTS}

Chronological models were constructed and run in OxCal, one for each late Thruston Phase site. The structure of each model is presented in the model descriptions (Supplemental Materials Appendix B) and the model code (Supplemental Materials Appendix E). The taphonomic relationships each radiocarbon sample possess with its corresponding archaeological context is described in Appendices A-B.

The Bayesian chronological models use charcoal outlier modeling as a strategy for accounting for the unknown inherent age offset in wood charcoal and soot samples (Bronk Ramsey 2009b). These models assume an exponential distribution, with an exponential constant $\tau$ of 1 taken over the range -10 to 0 , of the charcoal dates (following Bronk Ramsey 2009b). The shifts are then scaled by a common scaling factor that can lie anywhere between $10^{0}$ and $10^{3}$ years.

The models show good overall agreement between the radiocarbon dates and the assumptions of the models (Supplemental Materials Appendix B). Detailed results for these models are summarized in Table 1 and Figures 3-7. A model for Gordontown is not provided because only two radiocarbon dates are available from this site, which is not a robust enough sample to construct meaningful chronological model for the site occupation. As a result, Appendix B presents a review of the radiocarbon data from Gordontown and describes what can be inferred about the site chronology from the two existing dates. 
Alternative versions of each model were created as a sensitivity analysis by slightly modifying the primary models. Specifically, charcoal outlier modeling was not used in the alternative versions of each model. The alternative models show good overall agreement between the radiocarbon dates and the assumptions of the models (Supplemental Materials Appendix C). Overall, the posterior probabilities for the alternative models are mostly identical to the primary models, although a few are slightly older than the primary model counterparts, which was expected because the alternative models do not use charcoal outlier modeling and are thus much more sensitive to radiocarbon measurements from old wood. The results from the primary models are preferred because they account for the unknown inherent age offset in wood charcoal and a potential soot sample with charcoal outlier modeling (Bronk Ramsey 2009b).

We also took the additional step of running a simulation experiment in $\mathrm{OxCal}$ to determine the minimum number of additional radiocarbon dates that might be needed to achieve Bayesian chronological modeling results of much higher precision in the primary models for the start and end of activity at each site. This simulation experiment is described fully in the Supplemental Materials (Appendix D and Appendix E) and the results are summarized in Table 3 and Figure 7 . We believe that this approach is an important means of estimating the number of radiocarbon samples required to address specific chronological questions posed by research designs.

\section{DISCUSSION}


The Bayesian modeling provides posterior probabilities for the start and end of activity at each late Thruston Phase site (Figures 3-4, Table 1). When compared to the previous calendar year estimates for the chronology of these sites, the chronologies created with Bayesian modeling are more variable, demonstrating the unique history of each settlement (Table 1). Further, the chronologies created with Bayesian modeling are more useful than the previous chronological estimates (Table 1) because they provide an explicit chronological framework for the timing of human activity that is independent from relative artifact chronologies.

Appendix B describes the full details of the posterior probabilities; they estimate that activity at the sites lasted from around A.D. 1300-1550. The final activity at each settlement is estimated to have occurred around the originally defined time frame for the Vacant Quarter of A.D. 1450-1550 (Williams 1983, 1990), but activity at all of the sites likely lasted into the second-half of the fifteenth-century-which is later than Meeks and Anderson's (2013) hypothesized Vacant Quarter abandonment of A.D. 1420. Further, at 68 percent probability activity at East Nashville Mounds and Brentwood Library is estimated to have lasted potentially until A.D. 1525 (Figure 4, Table 1).

A matrix comparing the posterior probabilities for the end of activity at late Thruston Phase sites in the MCR was created to best determine the order of site abandonment (Table 2). At 68 percent probability, the earliest terminus at a site for human activity is at Rutherford-Kizer at cal A.D. 1400-1465 and the latest at Brentwood Library at cal A.D. 
1460-1525 (Tables 1-2). The estimated span of time between these two posterior probabilities is $15-115$ years at 68 percent probability (Figure 5), which provides an estimate for the rate of Mississippian abandonment in the MCR and demonstrates that regional abandonment likely unfolded in less than a century.

The estimate for the end of activity at Brentwood Library (cal A.D. 1460-1525, 68 percent probability, Table 1) provides the best current estimate for the final abandonment of the MCR. If the Meeks and Anderson (2013) model for other portions of the Vacant Quarter is accurate, then the MCR was depopulated about 50-100 years later than the other sub-regions. Nevertheless, if we treated the reservoir of dates examined by Meeks and Anderson (2013) to similar Bayesian analyses, then it is possible that a different perspective would emerge. It is conceivable, for example, that the Vacant Quarter represented a geographic time-transgressive phenomenon, with the MCR being vacated later than other sub-regions. Alternatively, each sub-region in the Vacant Quarter may have experienced very distinct histories. This possibility is reflected in the MCR where it appears that the abandonment of the last communities may have been a staggered process, itself a complex product of local social, ecological, and environmental variables. Our ability to hone in on these kinds of patterns with more precision is an important step toward addressing both the causes and consequences of the larger Vacant Quarter abandonment as well as sub-regional variations in depopulation.

Even if late fifteenth-century Thruston Phase instability was precipitated by droughts, other factors beyond climate clearly were at work. This is indicated by the estimates from 
the Bayesian chronological models for palisade construction and maintenance at the late Thruston Phase sites in the MCR, all of which seem to have been surrounded with fortifications (Figures 6-7, Table 1). These models provide the first definitive and precise estimates for Mississippian palisade construction and maintenance in the MCR and estimate that this activity continued at each late Thruston Phase site into the fifteenthcentury. At 68 percent probability, the final palisade maintenance activity took place at Brentwood Library at cal A.D. 1450-1500 (Figure 6). Bastions are present on the fortifications at each late Thruston Phase site in the MCR, except for Averbuch, suggesting considerable effort went into building the palisades at these sites so that they could inflict flanking fire on attackers (Keeley et al. 2007:67; Milner 1999, 2000, 2007; Milner et al. 2013). An attack from contemporaneous populations seems to have been a pervasive threat in the MCR in the fifteenth-century.

The chronological models indicate that the late Thruston Phase palisades were potentially maintained for multiple generations, possibly well over a century. Specifically, at 68 percent probability the palisade at Sellars is estimated to have been maintained for $1-160$ years, the palisade at Rutherford-Kizer is estimated to have been maintained for $110-210$ years, the palisade at Brentwood Library is estimated to have been maintained for 40-145 years, and the palisade at Averbuch is estimated to have been maintained for 40-105 years (Figure 7). Long-term Mississippian palisade use involved repairs and expansions, sometimes of massive character (Krus 2016), indicating that coordinated Mississippian workforces were present at the late Thruston Phase settlements in the fifteenth century to maintain these sizeable structures. 
Our next step is to design a project that aims to create high-resolution site-based chronologies for all known Mississippian settlements in the MCR, in part to better understand the exact timing and tempo of multi-scalar social changes that comprised the Vacant Quarter. Additionally, it may be possible to further refine the posterior probabilities estimated in this study to provide regional histories of a much higher precision, which was the goal of the simulation experiment (Supplemental Materials Appendix D). Table 3 and Figure 8 show the minimum number of simulated radiocarbon dates required to meet the simulation model parameters with posterior 68 and 95 percent probability confidence intervals spanning 50 years (or less) for the start and end of activity at each late Thruston Phase settlement. These simulations demonstrate that a minimum of 10-40 simulated radiocarbon dates are needed to achieve 68 percent probability confidence intervals spanning 50 years for the start and end of activity at a given late Thruston Phase settlement, and that a minimum of 35-150 simulated radiocarbon dates are needed to achieve 95 percent probability confidence intervals spanning 50 years.

The simulation experiment results demonstrate that dramatically more samples are needed to achieve 50 year confidence intervals for boundaries when the "true" start date defined by the experiment was within the A.D. 1300s, because of a calibration curve wiggle covering cal A.D. 1290-1410 (described in detail in Krus et al. 2015). Regardless, achieving 50 year confidence intervals for starting and ending boundaries for each site at 68 percent probability is possible with a more robust dating program for each site (Table 
3 and Figure 8). We advocate a stepped approach to future radiocarbon submissions, where 5-15 new dates from secure contexts are submitted for each site, with the simulation experiments re-run with the new results to determine how many additional dates are needed to achieve noticeably more precise probabilities for each site (following Bayliss and Bronk Ramsey [2004] and Hamilton and Krus [2018]).

\section{CONCLUSION}

In its initial inception, the geographic and temporal parameters of the Vacant Quarter were defined from a medley of radiocarbon dates with wide standard deviations (by modern standards), and from coarse phases tied to diagnostic artifacts. Further refinements to estimates of the regional abandonment have been based largely on summed probability distributions, that in turn have benefitted from the chronological refinements of accelerator mass spectrometry dating. However, even these assessments still have a sizable subjective component in their interpretation. Further, there is still a tendency for regional chronological analyses to rely on traditional periodizations that may bias data sample selection and reify existing interpretations. While Bayesian analyses support the findings from elsewhere in the mid-continent that the Vacant Quarter was largely a fifteenth-century A.D. phenomenon, they also emphasize that what may appear as a synchronous event at one scale may in fact have been comprised of numerous asynchronous mini-abandonments at the community level. The challenge remains as to how to explain the linkages of the different scales of abandonment. Our radiocarbon simulations indicate that future robust dating with well selected samples 
from the late Thruston MCR settlements could greatly improve the precision of the existing models.

If the Vacant Quarter depopulation occurred within the space of a century, in some respects this may be considered a temporal event that linked many Mississippian subregions. Our Bayesian modeling of site chronologies suggest that this event still may have had a time-transgressive character, even if fairly rapid, since the MCR abandonment estimates follow those of other regions by several decades. However, until Bayesian chronological models are applied to other sub-regions in the Vacant Quarter, direct comparisons are somewhat problematic. Nevertheless, we believe our results do provide some important lessons for researchers elsewhere who are attempting to construct detailed archaeological chronologies. Once the general boundaries of an archaeological target have been delineated, it is possible with Bayesian modeling to make an assessment of the number of dates required to estimate the temporal parameters with a given level of desired statistical confidence. In turn, these kinds of assessments should provide a much higher degree of resolution as to whether we are dealing with events, short-term processes, or generational kinds of changes - in other words, the type of information about the tempo of change necessary for developing models of explanation and causality.

Left unstated in the question of abandonment is the question of where did all the people go? All of the researchers pursuing this line of inquiry agree with Stephen Williams that these phenomena do not represent endemic demographic collapses; instead, communities on a very large scale seem to have decamped for what they perceived as greener pastures. 
Although we do not follow up on this specific issue here, there are intriguing data on sudden population arrivals as well as disappearances in the Southeast. Amanda Regnier (2014) has recently demonstrated that a large portion of the Alabama River drainage witnessed a major influx of peoples around A.D. 1450 after a long interval of near vacancy. Although it is not clear where the immigrants came from, the timing of their arrival with regional abandonments in surrounding regions is certainly suspicious. In eastern Tennessee, the argument has also been made that the late Mississippian Dallas and/or Mouse Creek phases may have incorporated pulses of population from the Middle Cumberland region, although the skeletal data (cf. Berryman 1980; Kelso 2013) used to support these arguments still seems to be somewhat equivocal. These kinds of findings emphasize that parallel research on population arrivals as well as population departures is clearly necessary to provide a balanced perspective on regional abandonments.

\section{Acknowledgments}

Our deep thanks to Mike Moore (Tennessee Division of Archaeology) and Kevin Smith (Middle Tennessee State University) for their ongoing assistance in selecting samples and interpreting the results from sites in the Middle Cumberland drainage. We would also like to thank three anonymous reviewers who provided helpful and thoughtful comments. Portions of this research have been funded by the National Science Foundation (BCS0852686) and the Wenner Gren Foundation (Grant No. 8477). 
Supplemental Materials. Appendices A-E are accessible as supplemental materials linked to the online version of the paper, which is accessible via the SAA member login at www.saa.org/members-login.

Appendix A. Radiocarbon data.

Appendix B. Description of Bayesian models and results.

Appendix C. Description of alternative Bayesian models and results.

Appendix D. Description of simulation experiments and results

Appendix E. Code for OxCal models. 


\section{REFERENCES CITED}

Anderson David G.

1994 The Savannah River Chiefdoms: Political Change in the Late Prehistoric Southeast. University of Alabama Press, Tuscaloosa.

Bayliss, Alex

2009 Rolling out revolution: using radiocarbon dating in archaeology. Radiocarbon 51(1):123-147.

2015 Quality in Bayesian chronological models in archaeology. World Archaeology 47(4):677-700.

Bayliss, Alex and Christopher Bronk Ramsey

2004 Pragmatic Bayesians: a Decade of Integrating Radiocarbon Dates into Chronological Models. In Tools for Constructing Chronologies: Crossing Disciplinary Boundaries, edited by Caitlin E. Buck and Andrew R. Millard, pp. 25-41. Springer-Verlag, London.

Bayliss, Alex, Johannes van der Plicht, Christopher Bronk Ramsey, Gerry McCormac, Frances Healy and Alasdair Whittle 2011 Towards generational time-scales: The quantitative Interpretation of Archaeological Chronologies. In Gathering Time: Dating the Early Neolithic 
Enclosures of Southern Britain and Ireland, edited by Alasdair Whittle, Frances Healy, and Alex Bayliss, pp. 17-59. Oxbow Books, Oxford.

Beahm, Emily Lynne

2013 Mississippian polities in the Middle Cumberland Region of Tennessee. Ph.D. Dissertation, Department of Anthropology, University of Georgia.

Benson, Larry V., Michael S. Berry, Edward A. Jolie, Jerry D. Spangler, David W. Stahle and Eugene M. Hattori

2007 Possible impacts of early-11th-, middle-12th-, and late-13th-century droughts on western Native Americans and the Mississippian Cahokians. Quaternary Science Reviews 26(3):336-350.

Benson, Larry V., Timothy R. Pauketat, and Edward R. Cook.

2009 Cahokia's Boom and Bust in the Context of Climate Change. American Antiquity $74: 467-83$.

Berryman, Hugh E.

1980 Mouse Creek, Dallas and Middle Cumberland: A Multivariate Approach. In Skeletal Biology of Aboriginal Populations in the Southeastern United States, edited by Patrick S. Willey and Fred H. Smith, pp. 1-14. Miscellaneous Papers 5. Tennessee Anthropological Association, Knoxville. 
Bird, Broxton W., Jeremy J. Wilson, William P. Gilhooly III, Byron A. Steinman and Lucas Stamps

2017 Midcontinental Native American population dynamics and late Holocene hydroclimate extremes. Scientific Reports 7:41628.

Bronk Ramsey, C.

1995 Radiocarbon Calibration and Analysis of Stratigraphy: The OxCal program. Radiocarbon 37(2):425-430.

1998 Probability and Dating. Radiocarbon 40(1):461-474.

2001 Development of the Radiocarbon Calibration Program. Radiocarbon 43(2A):355363.

2009a Bayesian Analysis of Radiocarbon Cates. Radiocarbon 51(1):337-360.

2009b Dealing with outliers and offsets in radiocarbon dating. Radiocarbon 51(3):10231045.

Buchanan, Meghan E.

2015 War-Scapes, Lingering Spirits, and the Mississippian Vacant Quarter. In Tracing the Relational: The Archaeology of Worlds, Spirits, and Temporalities, edited by Meghan E. Buchanan and B. Jacob Skousen, pp. 85-99. University of Utah Press, Salt Lake City.

Butler, Brian M.

1981 Sellars: A Small Mound Center in the Hinterlands. Tennessee Anthropologist 
6:37-60.

Cable, John S.

2018 Explaining the Mississippian Abandonment of the Central South Carolina Coast and its Implications for Understanding the Cultural and Natural Processes that Shape the Late Prehistory of the South Atlantic Slope. University of Alabama Press, Tuscaloosa (in press).

Cobb, Charles R., and Brian M. Butler

2002 The Vacant Quarter Revisited: Late Mississippian Abandonment of the Lower Ohio Valley. American Antiquity 67:625-641.

Cobb, Charles R., Anthony M. Krus, and Dawnie W. Steadman

2015 Bayesian Modeling of the Occupation Span of the Averbuch Site in the Middle Cumberland Drainage, Tennessee. Southeastern Archaeology 34:46-56.

Contreras, Daniel A., and John Meadows

2014 Summed Radiocarbon Calibrations as a Population Proxy: a Critical Evaluation using a Realistic Simulation Approach. Journal of Archaeological Science $52: 591-608$.

Cook, Edward R., Richard Seager, Mark A. Cane, and David W. Stahle 
2007 North American Drought: Reconstructions, Causes, and Consequences. EarthScience Reviews 81 (1-2):93-134.

Cook, Benjamin I., Jason E. Smerdon, Richard Seager and Edward R. Cook

2014 Pan-Continental Droughts in North America over the Last Millennium. Journal of Climate 27:383-397.

Denaire, Anthony, Philippe Lefranc, Joachim Wahl, Christopher Bronk Ramsey, Elaine Dunbar, Tomasz Goslar, Alex Bayliss, Nancy Beavan, Penny Bickle and Alasdair Whittle

2017 The Cultural Project: Formal Chronological Modelling of the Early and Middle Neolithic Sequence in Lower Alsace. Journal of Archaeological Method and Theory:1-78.

Deter-Wolf, Aaron, and Michael C. Moore

2016 Archaeological Excavations at the Rutherford-Kizer Site: A Mississippian Mound Center in Sumner County, Tennessee. Revised Electronic Edition, 2016. Research Series 13. Division of Archaeology, Tennessee Department of Environment and Conservation, Nashville.

Hamilton, William Derek, Colin Haselgrove and Chris Gosden

2015 The Impact of Bayesian chronologies on the British Iron Age. World Archaeology 47(4):642-660. 
Hamilton, William Derek, and Anthony M. Krus

2018 The Myths and Realities of Bayesian Chronological Modeling Revealed. American Antiquity 82: in press.

Hill, J. Brett, Jeffery J. Clark, William H. Doelle, and Patrick D. Lyons

2004 Prehistoric Demography in the Southwest: Migration, Coalescence, and Hohokam Population Decline. American Antiquity 69(4):689-716.

Inomata, Takeshi, Raúl Ortiz, Bárbara Arroyo, and Eugenia J. Robinson

2014 Chronological Revisions of Preclassic Kaminaljuyú: Implications for Social Processes in the Southern Maya Area. Latin American Antiquity 25(4):377-408.

Johnson, Jay K.

1996 The Nature and Timing of the Late Prehistoric Settlement of the Black Prairie in Northeast Mississippi: A Reply to Hogue, Peacock, and Rafferty. Southeastern Archaeology 15(2):244-249.

Keeley, Lawrence H., Marisa Fontana, and Russell Quick

2007 Baffles and Bastions: The Universal Features of Fortifications. Journal of Archaeological Research 15(1):55-95.

Kelso, Rebecca Kathleen Scopa 
2013 A Comparison of Mississippian Period Subadults from the Middle Cumberland and Eastern Regions of Tennessee to Assess Health and Past Population Interactions. Ph.D. dissertation, Department of Anthropology, The University of Tennessee, Knoxville.

Klippel, Walter E., and William M. Bass (editors)

1984 Averbuch: A Late Mississippian Manifestation in the Nashville Basin. Two volumes. Department of Anthropology, University of Tennessee, Knoxville. Submitted to the National Park Service, Atlanta.

Krus, Anthony M.

2016 The Timing of Precolumbian Militarization in the U.S. Midwest and Southeast. American Antiquity 81(2):375-388.

Krus, Anthony M., Robert Cook and Derek Hamilton

2015 Bayesian Chronological Modeling of SunWatch, a Fort Ancient Village in Dayton, Ohio. Radiocarbon 57(5):965-977.

Lekson, Stephen H., and Catherine M. Cameron

1995 The Abandonment of Chaco Canyon, the Mesa Verde Migrations, and the Reorganization of the Pueblo World. Journal of Anthropological Archaeology 14(2):184-202. 
Marsh, Erik J.

2015 The Emergence of Agropastoralism: Accelerated Cultural Change on the Andean Altiplano 3540-3120 cal BP. Environmental Archaeology 20(1):13-29.

Meeks, Scott C. and David G. Anderson

2013 Drought, subsistence stress, and population dynamics: assessing Mississippian abandonment of the Vacant Quarter. In Soils, Climate, \& Society: Archaeological Investigations in Ancient America, edited by John D. Wingard and Sue Eileen Hayes, pp. 61-83. University Press of Colorado, Boulder.

Milner, George R.

1999 Warfare in Prehistoric and Early Historic Eastern North America. Journal of Archaeological Research 7(2):105-151.

2000 Palisaded Settlements in Prehistoric Eastern North America. In City Walls, edited by James D. Tracy, pp. 46-70. Cambridge University Press, Cambridge, UK.

2007 Warfare, population, and food production in prehistoric Eastern North America. In North American Indigenous Warfare and Ritual, edited by Richard J. Chacon and Rubén G. Mendoza, pp. 182-201. University of Arizona Press, Tucson.

Milner, George R., George Chaplin, and Emily Zavodny

2013 Conflict and Societal Change in Late Prehistoric Eastern North America. Evolutionary Anthropology: Issues, News, and Reviews 22(3):96-102. 
Moore, Michael C.

2005 The Brentwood Library Site: A Mississippian Town on the Little Harpeth River, Williamson County, Tennessee. Research Series No. 15, Tennessee Division of Archaeology, Nashville.

Moore, Michael C., and Emanuel Breitburg

1998 Gordontown: Salvage Archaeology at a Mississippian Town in Davidson County, Tennessee. Research Series No. 11. Tennessee Division of Archaeology, Nashville.

Moore, Michael C., Emanuel Breitburg, Kevin E. Smith, and Mary Beth Trubitt 2006 One Hundred Years of Archaeology at Gordontown: a Fortified Mississippian Town in Middle Tennessee. Southeastern Archaeology 25:89-109.

Moore, Michael C., and Kevin E. Smith (editors)

2001 Archaeological Excavations at the Rutherford-Kizer Site: A Mississippian Mound Center in Sumner County, Tennessee. Research Series No. 13. Tennessee Department of Environment and Conservation Division of Archaeology, Nashville.

Moore, Michael C., and Kevin E. Smith

2009 Archaeological Expeditions of the Peabody Museum in Middle Tennessee, 18771884. (Revised 2012). Division of Archaeology Research Series No. 16. Tennessee Department of Environment and Conservation, Nashville. 
Morse. Dan F., and Phyllis A. Morse

1983 Archaeology of the Central Mississippi Valley. Academic Press, New York.

Regnier, Amanda L.

2014 Reconstructing Tascalusa's Chiefdom: Pottery Styles and the Social Composition of Late Mississippian Communities Along the Alabama River. University of Alabama Press, Tuscaloosa.

Reimer, Paula J., Edouard Bard, Alex Bayliss, J. Warren Beck, Paul G. Blackwell, Christopher Bronk Ramsey, Caitlin E. Buck, Hai Cheng, R. Lawrence Edwards, Michael Friedrich, Pieter M. Grootes, Thomas P. Guilderson, Haflidi Haflidason, Irka Hajdas, Christine Hatté, Timothy J. Heaton, Dirk L. Hoffmann, Alan G. Hogg, Konrad A. Hughen, K. Felix Kaiser, Bernd Kromer, Sturt W. Manning, Mu Niu, Ron W. Reimer, David A. Richards, E. Marian Scott, John R. Southon, Richard A. Staff, Christian S. M. Turney and Johannes van der Plicht

2013 IntCal13 and Marine13 Radiocarbon Age Calibration Curves 0-50,000 Years cal BP. Radiocarbon 55(4):1869-1887.

Richards, Colin, Andrew Meirion Jones, Ann MacSween, Alison Sheridan, Elaine Dunbar, Paula Reimer, Alex Bayliss, Seren Griffiths and Alasdair Whittle 
2016 Settlement Duration and Materiality: Formal Chronological Models for the Development of Barnhouse, a Grooved Ware Settlement in Orkney. Proceedings of the Prehistoric Society:1-33.

Stuiver, M., and R. S. Kra

1986 Editorial comment. Radiocarbon 28(2B):ii.

Stuiver, M., and H. A. Polach

1977 Reporting of 14C data. Radiocarbon 19(3):355-363.

Tasić, Nenad, Miroslav Marić, Dragana Filipović, Kristina Penezić, Elaine Dunbar, Paula Reimer, Alistair Barclay, Alex Bayliss, Bisserka Gaydarska and Alasdair Whittle 2016 Interwoven Strands for Refining the Chronology of the Neolithic Tell of VinčaBelo Brdo, Serbia. Radiocarbon:1-37.

Thompson, Victor D., and Anthony M. Krus

2018 Contemplating the History and Future of Radiocarbon Dating in the American Southeast. Southeastern Archaeology: in press.

Walling, Richard, Lawrence S. Alexander, and Evan Peacock

2000 The Jefferson Street Bridge Project: Archaeological Investigations at the East Nashville Mounds Site (40DV4) and the French Lick / Sulphur Dell Site (40DV5) 
in Nashville, Davidson County, Tennessee, Volume I: Text. Publication in Archaeology 1. Tennessee Department of Transportation, Nashville, TN.

Whittle, Alasdair, Alex Bayliss, Alistair Barclay, Bisserka Gaydasrka, Eszter Bánffy, Dušan Borić, Florin Draşovean, János Jakucs, Miroslav Marić, David Orton, Ivana Pantović, Wolfram Schier, Nenad Tasić and Marc Vander Linden

2016 A Vinča Potscape: Formal Chronological Models for the Use and Development of Vinča Ceramics in South-East Europe. Documenta Praehistorica XLIII:1-54.

Williams, Alan

2012 The Use of Summed Radiocarbon Probability Distributions in Archaeology: A Review of Methods. Journal of Archaeological Science 39:578-89.

Williams, Stephen

1983 Some Ruminations on the Current Strategy of Archaeology in the Southeast. Southeastern Archaeological Conference Bulletin 21:72-81.

1990 The Vacant Quarter and Other Late Events in the Lower Valley. In Towns and Temples along the Mississippi, edited by David H. Dye and Cheryl A. Cox, 170180. University of Alabama Press, Tuscaloosa.

2001 The Vacant Quarter Hypothesis and the Yazoo Delta. In Societies in Eclipse: Archaeology of the Eastern Woodlands, A.D. 1400-1700, edited by David S. Brose, C. Wesley Cowan, and Robert C. Mainfort, Jr., pp. 191-203. Smithsonian Institution Press, Washington, D.C. 


\section{Figure Captions}

Figure 1: General boundaries of the Vacant Quarter (based on Williams 1990).

Figure 2: Late Thruston phase sites used for modeling abandonment in the Middle Cumberland Region.

Figure 3: Posterior probability densities for the start of activity at late Thruston Phase sites in the MCR.

Figure 4: Posterior probability densities for the end of activity at late Thruston Phase sites in the MCR.

Figure 5: Posterior probabilities for estimated span of time between the end of activity at Brentwood Library and the end of activity at Rutherford-Kizer in the primary models.

Figure 6: Posterior probability densities for the timing of palisade construction at late Thruston Phase sites in the MCR.

Figure 7: Posterior probability densities for the estimated settlement spans and spans of the palisades at late Thruston Phase sites in the MCR. 
Figure 8: The solid posterior probabilities are derived from simulation models with the minimum number of simulated radiocarbon dates required to meet the simulation model parameters with posterior 95 percent probability confidence intervals spanning 50 years (or less) for the start and end of activity. The posterior probabilities shown in outline are derived from the primary Bayesian models and estimate the start and end of activity at the late Thruston Phase sites in the MCR. 
Figure 1

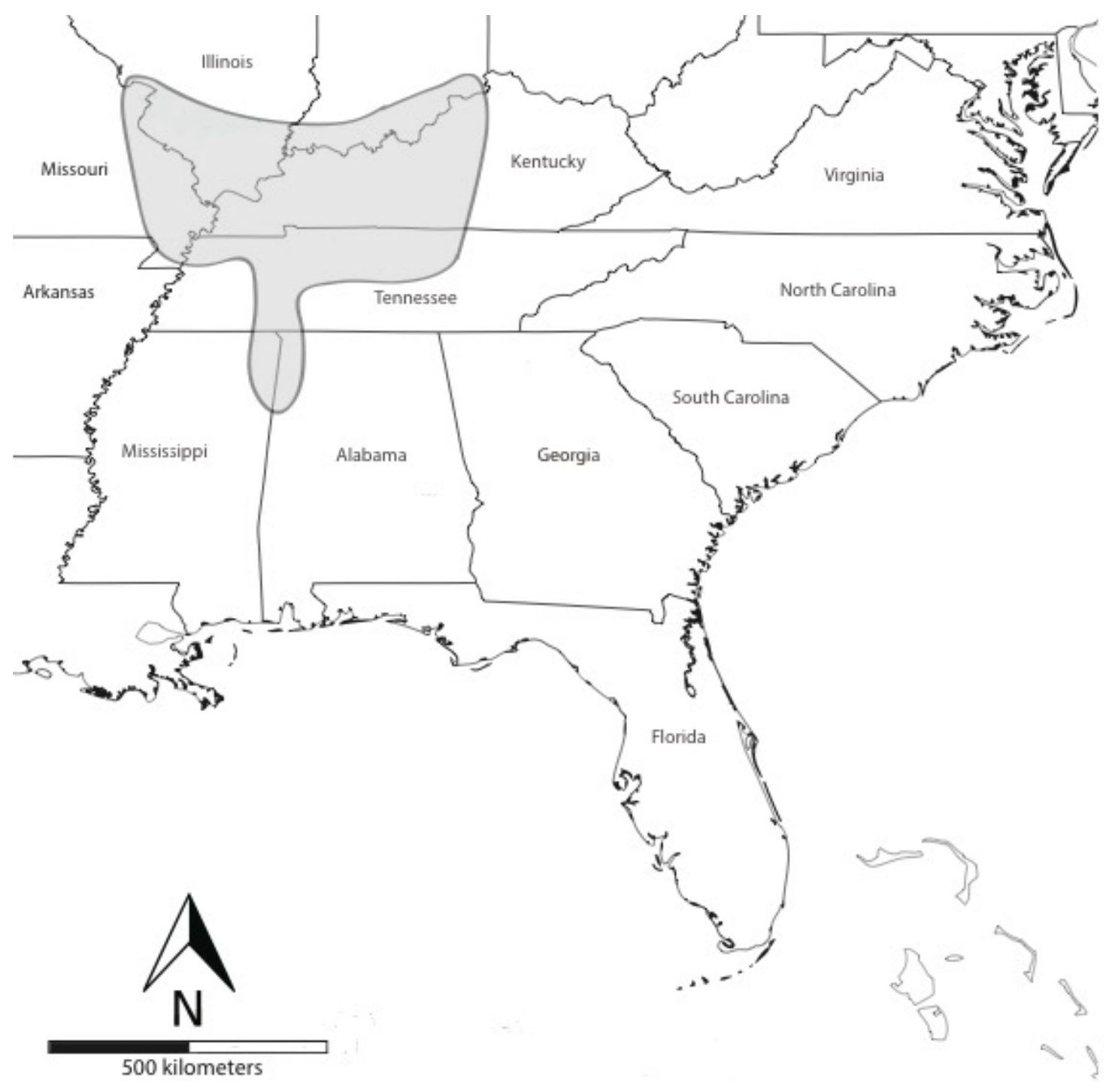


Figure 2

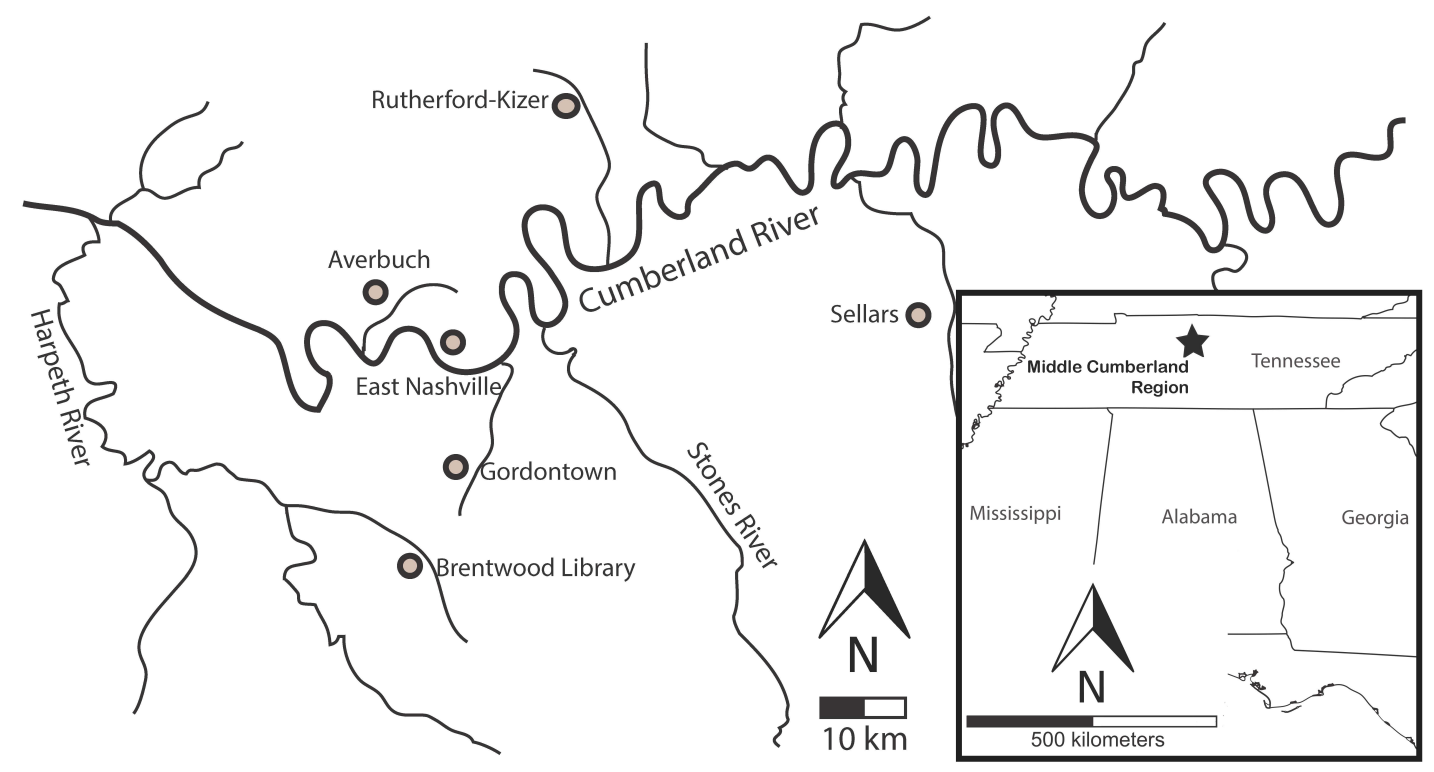




\section{Figure 3}

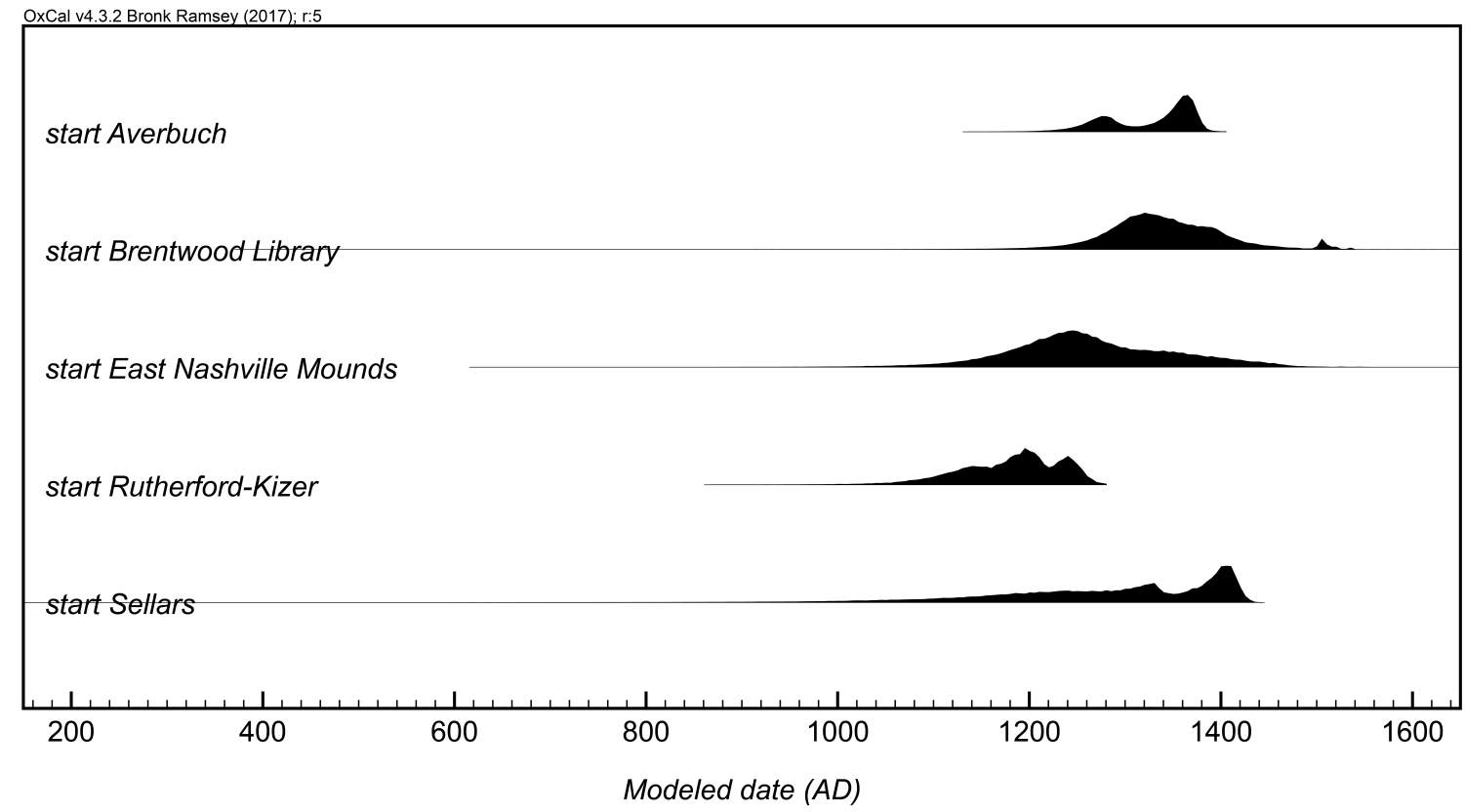

\section{Figure 4}

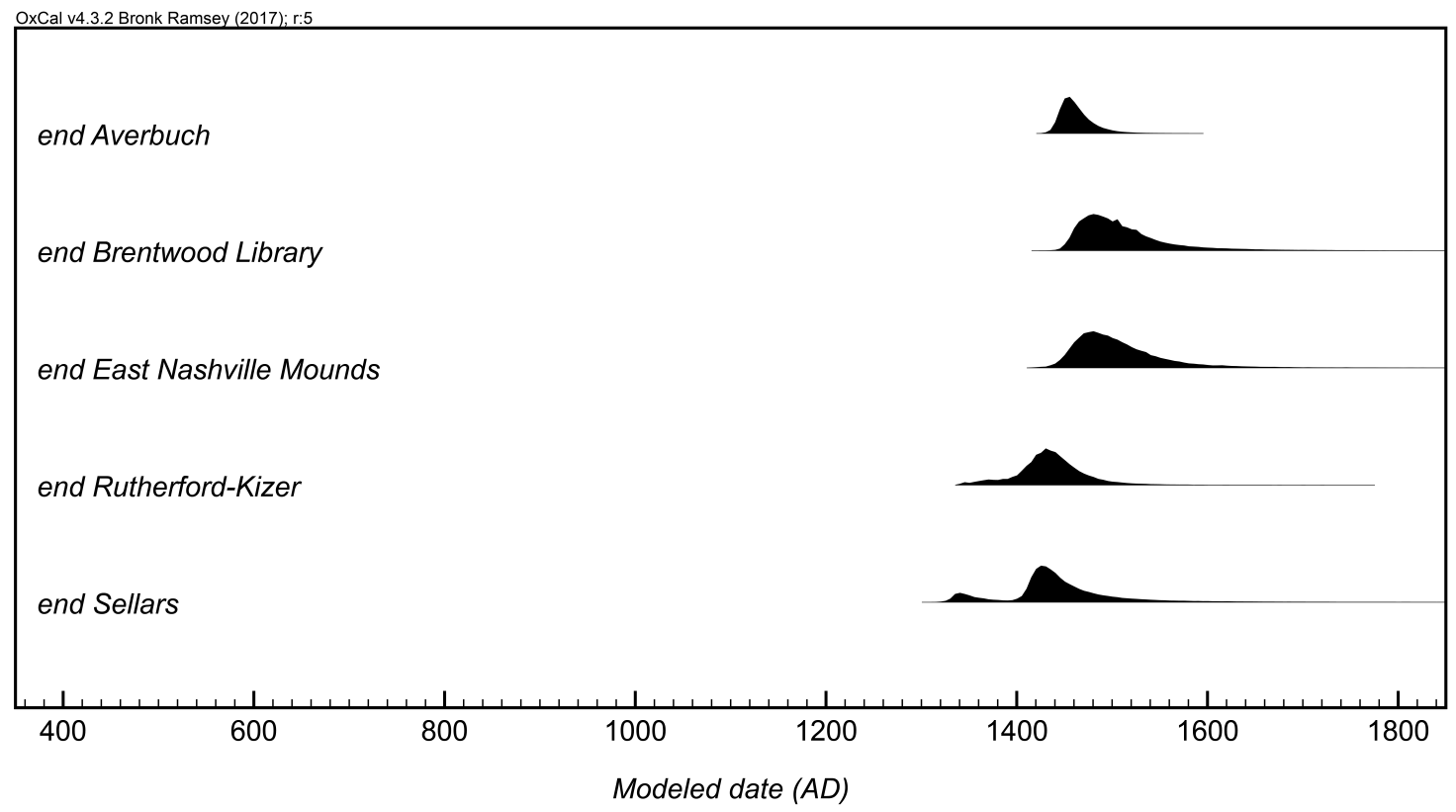


Figure 5

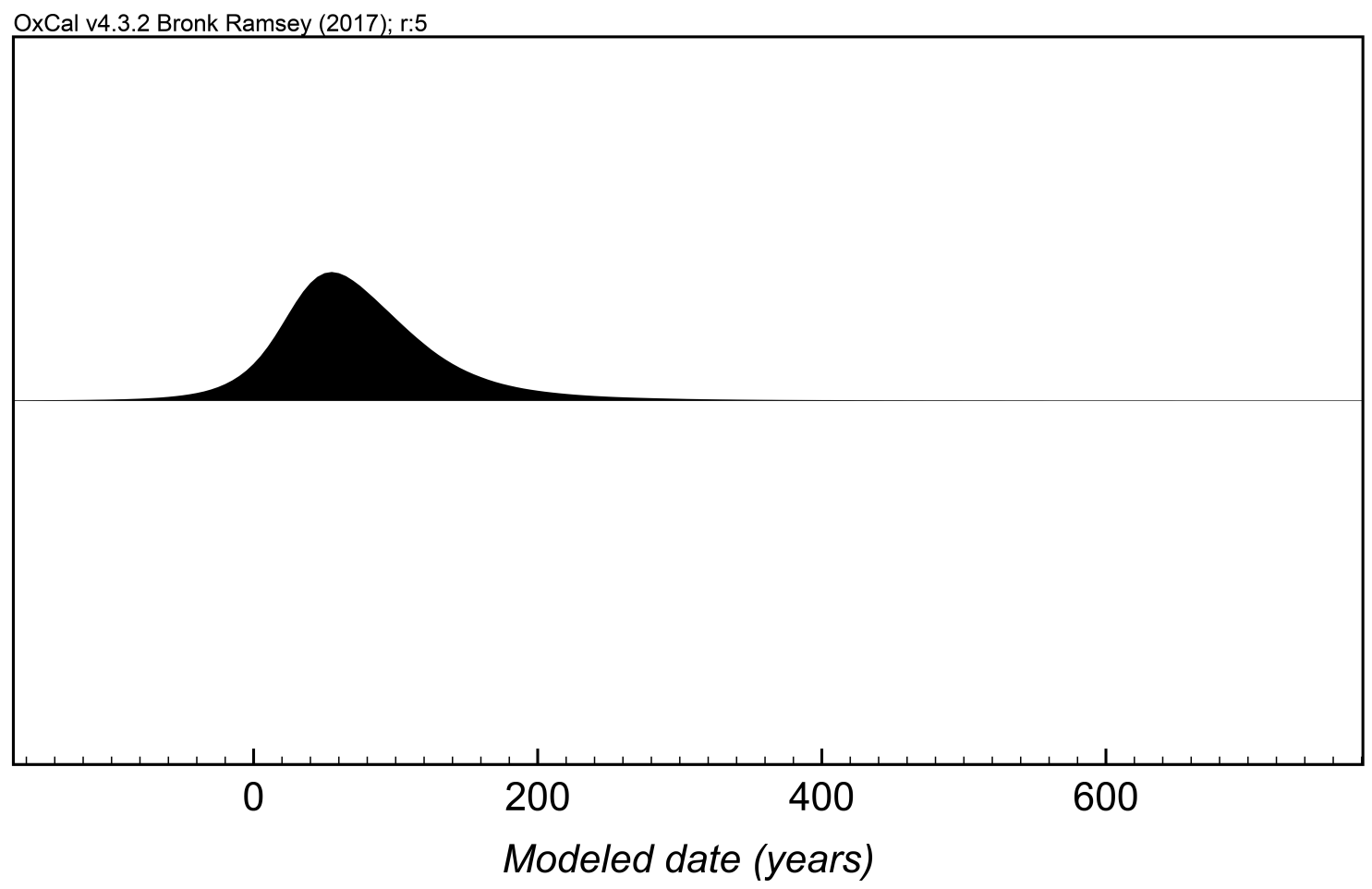




\section{Figure 6}

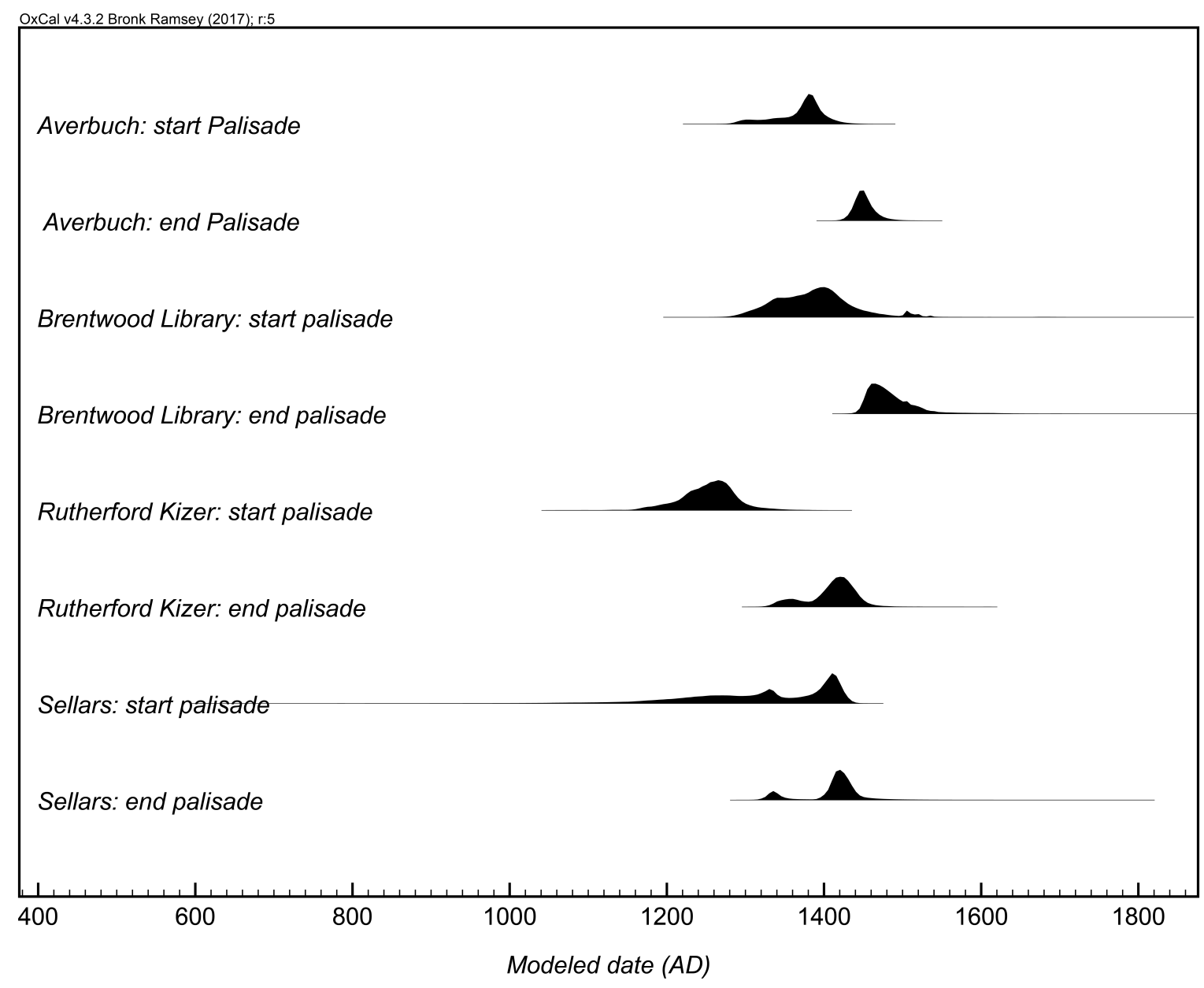




\section{Figure 7}

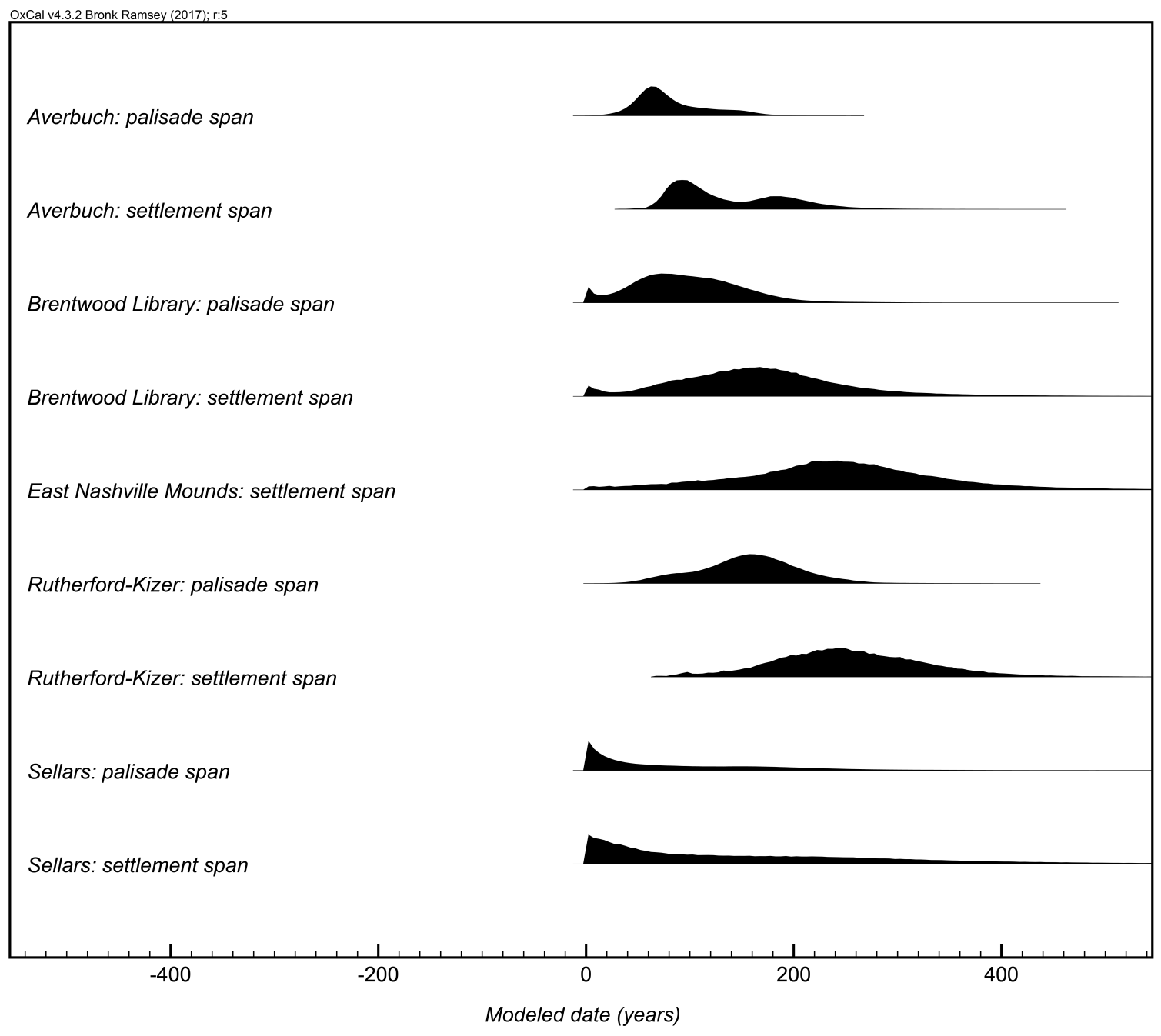




\section{Figure 8}

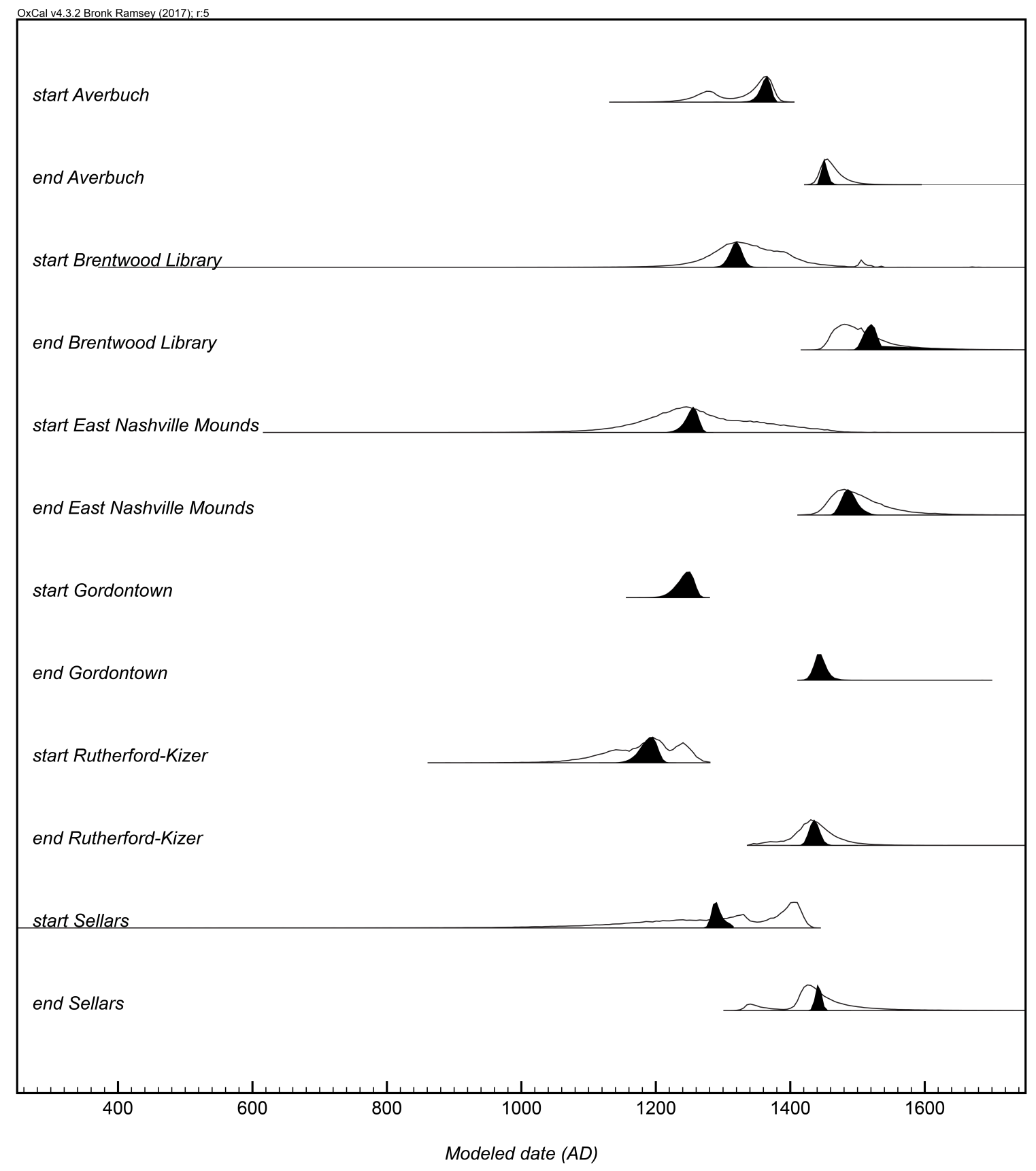


Table 1. Comparison of Bayesian Modeling Probability Ranges to Previous Estimates for late Thrustan Phase Site Chronologies in the MCR.

\begin{tabular}{|c|c|c|c|c|}
\hline Event dated & $\begin{array}{l}\text { Best approximate time } \\
\text { ranges provided in } \\
\text { previous studies }\end{array}$ & $\begin{array}{l}\text { Primary model }(95.4 \% \\
\text { probability) }\end{array}$ & $\begin{array}{l}\text { Primary model }(68.2 \% \\
\text { probability) }\end{array}$ & References \\
\hline $\begin{array}{l}\text { Start of Mississippian Activity at Averbuch } \\
(40 \mathrm{DV} 60)\end{array}$ & A.D. 1250 & cal A.D. 1235-1385 & cal A.D. $1260-1380$ & $\begin{array}{l}\text { Cobb et al. 2015; Klippel et } \\
\text { al. 1984; Moore et al. } 2006\end{array}$ \\
\hline $\begin{array}{l}\text { End of Mississippian Activity at Averbuch } \\
(40 \mathrm{DV} 60)\end{array}$ & A.D. 1450 & cal A.D. $1430-1500$ & cal A.D. $1440-1475$ & $\begin{array}{l}\text { Cobb et al. 2015; Klippel et } \\
\text { al. 1984; Moore et al. } 2006\end{array}$ \\
\hline $\begin{array}{l}\text { Start of Mississippian Activity at Brentwood } \\
\text { Library (40WM210) }\end{array}$ & A.D. 1298 & cal A.D. $1220-1515$ & cal A.D. $1285-1395$ & Moore 2005 \\
\hline $\begin{array}{l}\text { End of Mississippian Activity at Brentwood } \\
\text { Library (40WM210) }\end{array}$ & A.D. 1465 & cal A.D. $1445-1620$ & cal A.D. $1455-1525$ & Moore 2005 \\
\hline $\begin{array}{l}\text { Start of Mississippian Activity at East } \\
\text { Nashville Mounds (40DV4) }\end{array}$ & A.D. 1250 & cal A.D. 1105-1450 & cal A.D. $1175-1345$ & Walling et al. 2000 \\
\hline $\begin{array}{l}\text { End of Mississippian Activity at East } \\
\text { Nashville Mounds (40DV4) }\end{array}$ & A.D. 1450 & cal A.D. 1435-1605 & cal A.D. $1450-1525$ & Walling et al. 2000 \\
\hline $\begin{array}{l}\text { Start of Mississippian Activity at } \\
\text { Rutherford-Kizer (40SU15) }\end{array}$ & A.D. 1100 & cal A.D. $1075-1270$ & cal A.D. 1135-1255 & $\begin{array}{l}\text { Moore and Smith 2001; } \\
\text { Deter-Wolf and Moore } 2016\end{array}$ \\
\hline
\end{tabular}


End of Mississippian Activity at Rutherford- A.D. 1425

Kizer (40SU15)

Start of Mississippian Activity at Sellars

(40WI1)

End of Mississippian Activity at Sellars

(40WI1) cal A.D. $1350-1510$

A.D. 1000

A.D. 1400

cal A.D. $1040-1435$

cal A.D. 1325-1565 cal A.D. $1400-1465$
Moore and Smith 2001;

Deter-Wolf and Moore 2016

Butler 1981

Butler 1981 
Table 2. Probability Matrix that Event $\tau_{1}$ Occurred Before Event $\tau_{2}$ in the Primary Models.

\begin{tabular}{|l|l|l|l|l|l|}
\hline$\tau_{1}<\tau_{2}$ & end: & end: Sellars & end: & end: East & end: \\
& Rutherford- & & Averbuch & Nashville & Brentwood \\
\hline end: Rutherford-Kizer & & $53.2 \%$ & $79.5 \%$ & $92.3 \%$ & $93.4 \%$ \\
\hline end: Sellars & $46.8 \%$ & & $72.3 \%$ & $85.5 \%$ & $86.5 \%$ \\
\hline end: Averbuch & $20.5 \%$ & $27.7 \%$ & & $84.6 \%$ & $88.0 \%$ \\
\hline end: East Nashville & $7.7 \%$ & $14.5 \%$ & $15.4 \%$ & & $52.5 \%$ \\
Mounds & & & & & \\
\hline end: Brentwood Library & $6.6 \%$ & $13.5 \%$ & $12.0 \%$ & $47.5 \%$ & \\
\hline
\end{tabular}


Table 3. Summary of the minimum number of simulated radiocarbon dates required to meet the simulation experiment parameters with posterior $68 \%$ and $95 \%$ probability confidence intervals spanning 50-years (or less) for both the start and end of activity.

\begin{tabular}{|c|c|c|c|c|c|c|}
\hline Event dated & $\begin{array}{l}\text { Number of } \\
\text { existing } \\
\text { radiocarbon } \\
\text { dates }\end{array}$ & $\begin{array}{l}\text { Primary model with no } \\
\text { simulated dates }(95.4 \% \\
\text { probability) }\end{array}$ & $\begin{array}{l}\text { Minimum number of } \\
\text { additional dates needed } \\
\text { for } 50 \text {-year resolutions } \\
\text { (68.2\% probability }\end{array}$ & $\begin{array}{l}\text { Simulation model with } \\
\text { 50-year resolutions } \\
\text { (68.2\% probability) }\end{array}$ & $\begin{array}{l}\text { Minimum number of } \\
\text { additional dates needed } \\
\text { for } 50 \text {-year resolutions } \\
\text { (95.4\% probability) }\end{array}$ & $\begin{array}{l}\text { Simulation model with } \\
\text { 50-year resolutions } \\
\text { (95.4\% probability) }\end{array}$ \\
\hline \multicolumn{7}{|l|}{ Start of } \\
\hline \multicolumn{7}{|l|}{ Mississippian } \\
\hline Activity at & & cal A.D. $1240-1385$ & & cal A.D. $1345-1380$ & & cal A.D. $1335-1380$ \\
\hline $\begin{array}{l}\text { Averbuch } \\
\text { (40DV60) }\end{array}$ & & & & & & \\
\hline \multicolumn{7}{|l|}{ End of } \\
\hline \multicolumn{7}{|l|}{ Mississippian } \\
\hline Activity at & & cal A.D. $1430-1500$ & & cal A.D. $1445-1460$ & & cal A.D. $1440-1465$ \\
\hline \multicolumn{7}{|l|}{ (40DV60) } \\
\hline \multicolumn{7}{|l|}{ Start of } \\
\hline Mississippian & 8 & cal A.D. $1220-1515$ & 25 & cal A.D. $1295-1340$ & 150 & cal A.D. $1295-1340$ \\
\hline
\end{tabular}

Activity at 
Brentwood

Library

(40WM210)

End of

Mississippian

Activity at

Brentwood

Library

(40WM210)

Start of

Mississippian

Activity at East

cal A.D. 1105-1450

cal A.D. $1220-1270$

cal A.D. 1230-1270

Nashville Mounds

(40DV4)

End of

Mississippian

Activity at East

(40DV4) 
Start of

Mississippian

Activity at

n.a.

Gordontown

(40DV6)

End of

Mississippian

Activity at

Gordontown

(40DV6)

Start of

Mississippian

Activity at

cal A.D. $1075-1270$

cal A.D. $1180-1230$

cal A.D. 1160-1210

Rutherford-Kizer

(40SU15)

End of

Mississippian

cal A.D. 1350-1510

cal A.D. 1215-1265

cal A.D. 1210-1265

Activity at 
Rutherford-Kizer

(40SU15)

Start of

Mississippian

cal A.D. 1040-1435

cal A.D. $1285-1330$

cal A.D. $1275-1315$

Activity at Sellars

(40WI1)

End of

Mississippian

Activity at Sellars 


\section{Supplemental Material Captions}

Appendix A. Radiocarbon data.

Appendix B. Description of Bayesian models and results.

Appendix C. Description of alternative Bayesian models and results.

Appendix D. Description of simulation experiments and results.

Appendix E. Code for OxCal models. 


\begin{tabular}{|c|c|c|c|c|c|c|c|}
\hline \multicolumn{8}{|c|}{ Appendix A. Radiocarbon Data } \\
\hline $\begin{array}{c}\text { Laboratory } \\
\text { ID }\end{array}$ & Site & Context & Material & $\delta^{13} \mathrm{C}$ & Date B.P. & $\begin{array}{c}\text { Calibration } \\
(95 \% \\
\text { confidence) } \\
\end{array}$ & Reference \\
\hline Beta-335226 & $\begin{array}{l}\text { Averbuch } \\
(40 \mathrm{DV} 60)\end{array}$ & Cemetery 1 & $\begin{array}{c}\text { unidentified wood } \\
\text { charcoal }\end{array}$ & -26.9 & $520 \pm 30$ & $\begin{array}{c}\text { cal AD } \\
1320-1450\end{array}$ & Cobb et al. 2015; this paper \\
\hline Beta-331858 & $\begin{array}{l}\text { Averbuch } \\
\text { (40DV60) }\end{array}$ & Cemetery 1 & $\begin{array}{c}\text { unidentified wood } \\
\text { charcoal }\end{array}$ & -27.1 & $460 \pm 30$ & $\begin{array}{c}\text { cal AD } \\
1410-1470\end{array}$ & Cobb et al. 2015; this paper \\
\hline Beta-342426 & $\begin{array}{l}\text { Averbuch } \\
\text { (40DV60) }\end{array}$ & Palisade & $\begin{array}{c}\text { unidentified wood } \\
\text { charcoal }\end{array}$ & -24.5 & $560 \pm 30$ & $\begin{array}{c}\text { cal AD } \\
1300-1430 \\
\end{array}$ & Cobb et al. 2015; this paper \\
\hline GX-7754 & $\begin{array}{l}\text { Averbuch } \\
(40 D V 60)\end{array}$ & Palisade & $\begin{array}{c}\text { unidentified wood } \\
\text { charcoal }\end{array}$ & - & $565 \pm 120$ & $\begin{array}{c}\mathrm{cal} \text { AD } \\
1210-1640 \\
\end{array}$ & $\begin{array}{c}\text { Klippel and Bass 1984; Reed } \\
1984\end{array}$ \\
\hline Beta-346182 & $\begin{array}{l}\text { Averbuch } \\
(40 \mathrm{DV} 60)\end{array}$ & Palisade & $\begin{array}{c}\text { unidentified wood } \\
\text { charcoal }\end{array}$ & -26.5 & $670 \pm 30$ & $\begin{array}{c}\mathrm{cal} \text { AD } \\
1270-1400\end{array}$ & Cobb et al. 2015; this paper \\
\hline Beta-331859 & $\begin{array}{l}\text { Averbuch } \\
\text { (40DV60) }\end{array}$ & Palisade & $\begin{array}{l}\text { unidentified wood } \\
\text { charcoal }\end{array}$ & -23.5 & $420 \pm 30$ & $\begin{array}{c}\text { cal AD } \\
1420-1620\end{array}$ & Cobb et al. 2015; this paper \\
\hline UGa-2004 & $\begin{array}{l}\text { Averbuch } \\
(40 \mathrm{DV} 60)\end{array}$ & Structure 1 & $\begin{array}{l}\text { unidentified wood } \\
\text { charcoal }\end{array}$ & - & $525 \pm 55$ & $\begin{array}{c}\mathrm{cal} \text { AD } \\
1290-1460 \\
\end{array}$ & $\begin{array}{l}\text { Klippel and Bass 1984; Reed } \\
1984\end{array}$ \\
\hline UGa-2005 & $\begin{array}{l}\text { Averbuch } \\
(40 \mathrm{DV} 60)\end{array}$ & Structure 1 & $\begin{array}{c}\text { unidentified wood } \\
\text { charcoal }\end{array}$ & - & $695 \pm 50$ & $\begin{array}{c}\mathrm{cal} \text { AD } \\
1220-1400 \\
\end{array}$ & $\begin{array}{c}\text { Klippel and Bass 1984; Reed } \\
1984\end{array}$ \\
\hline GX-7752 & $\begin{array}{l}\text { Averbuch } \\
\text { (40DV60) }\end{array}$ & Structure 11 & $\begin{array}{l}\text { unidentified wood } \\
\text { charcoal }\end{array}$ & - & $660 \pm 125$ & $\begin{array}{c}\mathrm{cal} \text { AD } \\
1040-1470\end{array}$ & $\begin{array}{c}\text { Klippel and Bass 1984; Reed } \\
1984\end{array}$ \\
\hline Beta-342425 & $\begin{array}{l}\text { Averbuch } \\
\text { (40DV60) }\end{array}$ & Structure 15 & nut shell (Carya) & -24.1 & $480 \pm 30$ & $\begin{array}{c}\mathrm{cal} \text { AD } \\
1400-1460\end{array}$ & Cobb et al. 2015; this paper \\
\hline Beta-346184 & $\begin{array}{l}\text { Averbuch } \\
\text { (40DV60) }\end{array}$ & Structure 3 & nut shell $($ Carya $)$ & -25 & $460 \pm 30$ & $\begin{array}{c}\text { cal AD } \\
1410-1470\end{array}$ & Cobb et al. 2015; this paper \\
\hline GX-7750 & $\begin{array}{l}\text { Averbuch } \\
\text { (40DV60) }\end{array}$ & Structure 3 & $\begin{array}{l}\text { unidentified wood } \\
\text { charcoal }\end{array}$ & - & $610 \pm 120$ & $\begin{array}{c}\mathrm{cal} \mathrm{AD} \\
1150-1630\end{array}$ & $\begin{array}{c}\text { Klippel and Bass 1984; Reed } \\
1984\end{array}$ \\
\hline GX-7755 & $\begin{array}{l}\text { Averbuch } \\
(40 D V 60)\end{array}$ & Structure 3 & $\begin{array}{c}\text { unidentified wood } \\
\text { charcoal }\end{array}$ & - & $440 \pm 120$ & $\begin{array}{c}\text { cal AD } \\
1280-1950\end{array}$ & $\begin{array}{c}\text { Klippel and Bass 1984; Reed } \\
1984\end{array}$ \\
\hline Beta-342427 & $\begin{array}{l}\text { Averbuch } \\
\text { (40DV60) }\end{array}$ & Structure 4 & $\begin{array}{l}\text { unidentified wood } \\
\text { charcoal }\end{array}$ & -21.5 & $610 \pm 30$ & $\begin{array}{c}\mathrm{cal} \text { AD } \\
1290-1410\end{array}$ & Cobb et al. 2015; this paper \\
\hline GX-7753 & $\begin{array}{l}\text { Averbuch } \\
\text { (40DV60) }\end{array}$ & Structure 4 (Feature 16) & nut shell (Carya) & - & $805 \pm 130$ & $\begin{array}{c}\text { cal AD } \\
980-1410 \\
\end{array}$ & $\begin{array}{c}\text { Klippel and Bass 1984; Reed } \\
1984 \\
\end{array}$ \\
\hline Beta-335225 & $\begin{array}{l}\text { Averbuch } \\
\text { (40DV60) }\end{array}$ & Structure 5 & nut shell (Carya) & -26.0 & $670 \pm 30$ & $\begin{array}{c}\text { cal AD } \\
1270-1400 \\
\end{array}$ & Cobb et al. 2015; this paper \\
\hline GX-7751 & $\begin{array}{l}\text { Averbuch } \\
\text { (40DV60) }\end{array}$ & Structure 8 & $\begin{array}{l}\text { unidentified wood } \\
\text { charcoal }\end{array}$ & - & $660 \pm 125$ & $\begin{array}{c}\mathrm{cal} \text { AD } \\
1040-1470\end{array}$ & $\begin{array}{c}\text { Klippel and Bass 1984; Reed } \\
1984\end{array}$ \\
\hline Beta-186722 & $\begin{array}{c}\text { Brentwood } \\
\text { Library } \\
(40 \mathrm{WM} 210)\end{array}$ & Feature 10 (refuse-filled pit) & unidentified charred wood & - & $580 \pm 50$ & $\begin{array}{c}\text { cal AD } \\
1290-1430\end{array}$ & Moore 2005:Table 2 \\
\hline
\end{tabular}




\begin{tabular}{|c|c|c|c|c|c|c|c|}
\hline \multicolumn{8}{|c|}{ Appendix A. Radiocarbon Data } \\
\hline $\begin{array}{l}\text { Laboratory } \\
\text { ID }\end{array}$ & Site & Context & Material & $\delta^{13} \mathrm{C}$ & Date B.P. & $\begin{array}{c}\text { Calibration } \\
(95 \% \\
\text { confidence) } \\
\end{array}$ & Reference \\
\hline Beta-186725 & $\begin{array}{c}\text { Brentwood } \\
\text { Library } \\
(40 \mathrm{WM} 210) \\
\end{array}$ & Feature 60 (refuse-filled pit) & unidentified charred wood & - & $570 \pm 60$ & $\begin{array}{c}\text { cal AD } \\
1290-1440\end{array}$ & Moore 2005:Table 2 \\
\hline Beta-186724 & $\begin{array}{l}\text { Brentwood } \\
\text { Library } \\
(40 \mathrm{WM} 210)\end{array}$ & Palisade (Feature 279: palisade post) & unidentified charred wood & - & $630 \pm 60$ & $\begin{array}{c}\text { cal AD } \\
1270-1420\end{array}$ & Moore 2005:Table 2 \\
\hline Beta-364007 & $\begin{array}{l}\text { Brentwood } \\
\text { Library } \\
(40 \mathrm{WM} 210)\end{array}$ & $\begin{array}{l}\text { Palisade (Feature 402: interior palisade bastion } \\
\text { post) }\end{array}$ & unidentified charred wood & -24.8 & $370 \pm 30$ & $\begin{array}{c}\text { cal AD } \\
1440-1640\end{array}$ & Moore 2005; this paper \\
\hline Beta-364008 & $\begin{array}{l}\text { Brentwood } \\
\text { Library } \\
(40 \mathrm{WM} 210)\end{array}$ & $\begin{array}{l}\text { Palisade (Feature 411: interior palisade bastion } \\
\text { post) }\end{array}$ & unidentified charred wood & -25.4 & $530 \pm 30$ & $\begin{array}{c}\mathrm{cal} \mathrm{AD} \\
1310-1440\end{array}$ & Moore 2005; this paper \\
\hline Beta-186723 & $\begin{array}{c}\text { Brentwood } \\
\text { Library } \\
(40 \mathrm{WM} 210) \\
\end{array}$ & Structure 2, charred post on floor & unidentified charred wood & - & $480 \pm 50$ & $\begin{array}{c}\text { cal AD } \\
1310-1620\end{array}$ & Moore 2005:Table 2 \\
\hline Beta-186727 & $\begin{array}{l}\text { Brentwood } \\
\text { Library } \\
(40 \mathrm{WM} 210) \\
\end{array}$ & Structure 3 post (Feature 530) & unidentified charred wood & - & $570 \pm 60$ & $\begin{array}{c}\text { cal AD } \\
1290-1440\end{array}$ & Moore 2005:Table 2 \\
\hline Beta-186726 & $\begin{array}{c}\text { Brentwood } \\
\text { Library } \\
(40 \mathrm{WM} 210)\end{array}$ & Structure 4 post (Feature 620) & unidentified charred wood & - & $610 \pm 50$ & $\begin{array}{c}\text { cal AD } \\
1280-1420\end{array}$ & Moore 2005:Table 2 \\
\hline Beta-61242 & $\begin{array}{c}\text { East } \\
\text { Nashville } \\
\text { Mounds } \\
\text { (40DV4) } \\
\end{array}$ & Large subrectangular feature (Feature 11) & unidentified charred wood & - & $750 \pm 70$ & $\begin{array}{l}\text { cal AD } \\
1050-1400\end{array}$ & Walling 2000:Table 51 \\
\hline TX-7855 & $\begin{array}{c}\text { East } \\
\text { Nashville } \\
\text { Mounds } \\
\text { (40DV4) } \\
\end{array}$ & Large subrectangular feature (Feature 11) & unidentified charred wood & - & $670 \pm 60$ & $\begin{array}{c}\text { cal AD } \\
1250-1420\end{array}$ & Walling 2000:Table 51 \\
\hline Beta-61243 & $\begin{array}{c}\text { East } \\
\text { Nashville } \\
\text { Mounds } \\
\text { (40DV4) }\end{array}$ & Well-defined pit, possible hearth (Feature 18) & unidentified charred wood & - & $660 \pm 60$ & $\begin{array}{c}\text { cal AD } \\
1260-1420\end{array}$ & Walling 2000:Table 51 \\
\hline TX-7860 & $\begin{array}{c}\text { East } \\
\text { Nashville } \\
\text { Mounds } \\
\text { (40DV4) }\end{array}$ & $\begin{array}{l}115 \mathrm{~N} \text { 101E Zone } 2 \text {, Level } 2 \text {. Non-feature context } \\
\text { possibly associated with the general midden }\end{array}$ & $\begin{array}{l}\text { residue or soot from a } \\
\text { Mississippi Plain jar } \\
\text { fragment }\end{array}$ & - & $600 \pm 40$ & $\begin{array}{c}\text { cal AD } \\
1290-1420\end{array}$ & Walling 2000:Table 51 \\
\hline
\end{tabular}




\begin{tabular}{|c|c|c|c|c|c|c|c|}
\hline \multicolumn{8}{|c|}{ Appendix A. Radiocarbon Data } \\
\hline $\begin{array}{l}\text { Laboratory } \\
\text { ID }\end{array}$ & Site & Context & Material & $\delta^{13} \mathrm{C}$ & Date B.P. & $\begin{array}{c}\text { Calibration } \\
(95 \% \\
\text { confidence) }\end{array}$ & Reference \\
\hline Beta-61246 & $\begin{array}{c}\text { East } \\
\text { Nashville } \\
\text { Mounds } \\
\text { (40DV4) } \\
\end{array}$ & Posthole (Posthole 15) & unidentified charred wood & - & $530 \pm 60$ & $\begin{array}{c}\text { cal AD } \\
1290-1460\end{array}$ & Walling 2000:Table 51 \\
\hline TX-7859 & $\begin{array}{l}\text { East } \\
\text { Nashville } \\
\text { Mounds } \\
\text { (40DV4) } \\
\end{array}$ & $\begin{array}{l}\text { Charred mass of indeterminate material recovered } \\
\text { from a partial jar presumed to be associated with } \\
\text { from a burial (Burial } 4 \mathrm{a}, 4 \mathrm{~b}, 9) \text {. }\end{array}$ & unidentified charred mass & - & $440 \pm 50$ & $\begin{array}{c}\text { cal AD } \\
1400-1640\end{array}$ & Walling 2000:Table 51 \\
\hline Beta-61250 & $\begin{array}{l}\text { East } \\
\text { Nashville } \\
\text { Mounds } \\
\text { (40DV4) }\end{array}$ & Subrectangular pit (Feature 57) & unidentified charred wood & - & $640 \pm 70$ & $\begin{array}{c}\text { cal AD } \\
1260-1430\end{array}$ & Walling 2000:Table 51 \\
\hline TX-7866 & $\begin{array}{l}\text { East } \\
\text { Nashville } \\
\text { Mounds } \\
\text { (40DV4) } \\
\end{array}$ & Subrectangular pit (Feature 57) & $\begin{array}{l}\text { unidentified wood } \\
\text { charcoal }\end{array}$ & - & $910 \pm 140$ & $\begin{array}{l}\text { cal AD } \\
770-1390\end{array}$ & Walling 2000:Table 51 \\
\hline TX-7856 & $\begin{array}{l}\text { East } \\
\text { Nashville } \\
\text { Mounds } \\
\text { (40DV4) } \\
\end{array}$ & Possible house floor segment (Feature 36) & unidentified charred wood & - & $890 \pm 100$ & $\begin{array}{l}\text { cal AD } \\
960-1290\end{array}$ & Walling 2000:Table 51 \\
\hline TX-7857 & $\begin{array}{l}\text { East } \\
\text { Nashville } \\
\text { Mounds } \\
\text { (40DV4) }\end{array}$ & Shallow pit (Feature 37) & unidentified charred wood & - & $580 \pm 50$ & $\begin{array}{c}\text { cal AD } \\
1290-1430\end{array}$ & Walling 2000:Table 51 \\
\hline TX-7858 & $\begin{array}{l}\text { East } \\
\text { Nashville } \\
\text { Mounds } \\
\text { (40DV4) }\end{array}$ & Subrectangular pit (Feature 58) & unidentified charred wood & - & $380 \pm 50$ & $\begin{array}{c}\text { cal AD } \\
1440-1640\end{array}$ & Walling 2000:Table 51 \\
\hline Beta-61245 & $\begin{array}{l}\text { East } \\
\text { Nashville } \\
\text { Mounds } \\
\text { (40DV4) }\end{array}$ & Subrectangular pit (Feature 58) & unidentified charred wood & - & $530 \pm 50$ & $\begin{array}{c}\text { cal AD } \\
1300-1450\end{array}$ & Walling 2000:Table 51 \\
\hline Beta-61244 & $\begin{array}{c}\text { East } \\
\text { Nashville } \\
\text { Mounds } \\
\text { (40DV4) }\end{array}$ & Large pit (Feature 24). & unidentified charred wood & - & $550 \pm 50$ & $\begin{array}{c}\text { cal AD } \\
1290-1450\end{array}$ & Walling 2000:Table 51 \\
\hline TX-5551 & Gordontown & Structure 1 (southeast quadrant) & unidentified wood & - & $640 \pm 70$ & cal AD & Moore and Breitburg 1998, \\
\hline
\end{tabular}




\begin{tabular}{|c|c|c|c|c|c|c|c|}
\hline \multicolumn{8}{|c|}{ Appendix A. Radiocarbon Data } \\
\hline $\begin{array}{l}\text { Laboratory } \\
\text { ID }\end{array}$ & Site & Context & Material & $\delta^{13} \mathrm{C}$ & Date B.P. & $\begin{array}{l}\text { Calibration } \\
(95 \% \\
\text { confidence) }\end{array}$ & Reference \\
\hline & (40DV6) & & charcoal & & & $1260-1430$ & Moore et al. 2006 \\
\hline $\mathrm{TX}-5550$ & $\begin{array}{l}\text { Gordontown } \\
\text { (40DV6) }\end{array}$ & Structure 3 (floor) & $\begin{array}{c}\text { unidentified wood } \\
\text { charcoal }\end{array}$ & - & $530 \pm 60$ & $\begin{array}{c}\mathrm{cal} \text { AD } \\
1290-1460\end{array}$ & $\begin{array}{l}\text { Moore and Breitburg 1998; } \\
\text { Moore et al. } 2006\end{array}$ \\
\hline Beta-70873 & $\begin{array}{l}\text { Rutherford- } \\
\text { Kizer } \\
\text { (40SU15) }\end{array}$ & Feature 101 (large refuse filled pit, Strip Block B) & unidentified charred wood & - & $580 \pm 50$ & $\begin{array}{c}\text { cal AD } \\
1290-1430\end{array}$ & Moore and Smith 2001:Table 1 \\
\hline Beta-70872 & $\begin{array}{l}\text { Rutherford- } \\
\text { Kizer } \\
\text { (40SU15) }\end{array}$ & Feature 101 (large refuse filled pit, Strip Block B) & unidentified charred wood & - & $550 \pm 50$ & $\begin{array}{c}\text { cal AD } \\
1290-1450\end{array}$ & Moore and Smith 2001:Table 1 \\
\hline Beta-70876 & $\begin{array}{l}\text { Rutherford- } \\
\text { Kizer } \\
\text { (40SU15) }\end{array}$ & Feature 15 (small refuse filled pit, Strip Block B) & unidentified charred wood & - & $970 \pm 50$ & $\begin{array}{c}\text { cal AD } \\
980-1190\end{array}$ & Moore and Smith 2001:Table 1 \\
\hline Beta-70874 & $\begin{array}{l}\text { Rutherford- } \\
\text { Kizer } \\
\text { (40SU15) }\end{array}$ & Feature 20 (large refuse filled pit, Strip Block B) & unidentified charred wood & - & $630 \pm 60$ & $\begin{array}{c}\text { cal AD } \\
1270-1420\end{array}$ & Moore and Smith 2001:Table 1 \\
\hline Beta-70875 & $\begin{array}{l}\text { Rutherford- } \\
\text { Kizer } \\
\text { (40SU15) }\end{array}$ & Feature 20 (large refuse filled pit, Strip Block B) & unidentified charred wood & - & $580 \pm 50$ & $\begin{array}{c}\text { cal AD } \\
1290-1430\end{array}$ & Moore and Smith 2001:Table 1 \\
\hline Beta-70877 & $\begin{array}{l}\text { Rutherford- } \\
\text { Kizer } \\
\text { (40SU15) } \\
\end{array}$ & Feature 36 (large refuse filled pit, Strip Block B) & unidentified charred wood & - & $630 \pm 50$ & $\begin{array}{c}\text { cal AD } \\
1280-1410\end{array}$ & Moore and Smith 2001:Table 1 \\
\hline Beta-90627 & $\begin{array}{l}\text { Rutherford- } \\
\text { Kizer } \\
\text { (40SU15) }\end{array}$ & Feature 738 (large hearth, lot 85) & unidentified charred wood & - & $1320 \pm 60$ & $\begin{array}{l}\text { cal AD } \\
610-870\end{array}$ & Moore and Smith 2001:Table 1 \\
\hline Beta-90625 & $\begin{array}{l}\text { Rutherford- } \\
\text { Kizer } \\
\text { (40SU15) }\end{array}$ & $\begin{array}{l}\text { Palisade (Feature 528: interior palisade bastion } \\
\text { post) }\end{array}$ & unidentified charred wood & - & $780 \pm 60$ & $\begin{array}{c}\mathrm{cal} \mathrm{AD} \\
1050-1390\end{array}$ & Moore and Smith 2001:Table 1 \\
\hline Beta-90626 & $\begin{array}{l}\text { Rutherford- } \\
\text { Kizer } \\
\text { (40SU15) }\end{array}$ & Palisade (Feature 708: interior palisade post) & unidentified charred wood & - & $570 \pm 60$ & $\begin{array}{c}\text { cal AD } \\
1290-1440\end{array}$ & Moore and Smith 2001:Table 1 \\
\hline Beta-90024 & $\begin{array}{l}\text { Rutherford- } \\
\text { Kizer } \\
\text { (40SU15) }\end{array}$ & $\begin{array}{l}\text { Palisade (Feature 733: exterior palisade bastion } \\
\text { post) }\end{array}$ & unidentified charred wood & - & $590 \pm 60$ & $\begin{array}{c}\text { cal AD } \\
1280-1430\end{array}$ & Moore and Smith 2001:Table 1 \\
\hline Beta-90025 & $\begin{array}{l}\text { Rutherford- } \\
\text { Kizer } \\
\text { (40SU15) }\end{array}$ & Palisade (Feature 832: exterior palisade post) & unidentified charred wood & - & $540 \pm 60$ & $\begin{array}{c}\text { cal AD } \\
1290-1450\end{array}$ & Moore and Smith 2001:Table 1 \\
\hline
\end{tabular}




\begin{tabular}{|c|c|c|c|c|c|c|c|}
\hline \multicolumn{8}{|c|}{ Appendix A. Radiocarbon Data } \\
\hline $\begin{array}{l}\text { Laboratory } \\
\quad \text { ID }\end{array}$ & Site & Context & Material & $\delta^{13} \mathrm{C}$ & Date B.P. & $\begin{array}{c}\text { Calibration } \\
(95 \% \\
\text { confidence) }\end{array}$ & Reference \\
\hline Beta-90023 & $\begin{array}{l}\text { Rutherford- } \\
\text { Kizer } \\
\text { (40SU15) }\end{array}$ & Palisade (Feature 867: exterior palisade post) & unidentified charred wood & - & $500 \pm 50$ & $\begin{array}{c}\text { cal AD } \\
1300-1480\end{array}$ & Moore and Smith 2001:Table 1 \\
\hline Beta-70878 & $\begin{array}{l}\text { Rutherford- } \\
\text { Kizer } \\
\text { (40SU15) }\end{array}$ & Structure 1 (Feature 34, posthole, Strip Block B) & unidentified charred wood & - & $570 \pm 60$ & $\begin{array}{c}\text { cal AD } \\
1290-1440\end{array}$ & Moore and Smith 2001:Table 1 \\
\hline Beta-70879 & $\begin{array}{l}\text { Rutherford- } \\
\text { Kizer } \\
\text { (40SU15) }\end{array}$ & Structure 1 (Feature 88: posthole, Strip Block B) & unidentified charred wood & - & $540 \pm 50$ & $\begin{array}{c}\text { cal AD } \\
1290-1450\end{array}$ & Moore and Smith 2001:Table 1 \\
\hline Beta-70880 & $\begin{array}{l}\text { Rutherford- } \\
\text { Kizer } \\
\text { (40SU15) } \\
\end{array}$ & Structure 1 (Feature 96: postmold, Strip Block B) & unidentified charred wood & - & $640 \pm 50$ & $\begin{array}{c}\text { cal AD } \\
1270-1410\end{array}$ & Moore and Smith 2001:Table 1 \\
\hline UGa-945 & $\begin{array}{l}\text { Sellars } \\
(40 \text { WI1) }\end{array}$ & Feature 4, large refuse filled pit & unidentified charred wood & - & $705 \pm 65$ & $\begin{array}{c}\mathrm{cal} \text { AD } \\
1200-1410\end{array}$ & Butler 1981:Table 1 \\
\hline UGa-4552 & $\begin{array}{c}\text { Sellars } \\
(40 \text { WI1 })\end{array}$ & $\begin{array}{c}\text { Feature 67, hearth (Trench 3) at the base of a } \\
\text { possible mound }\end{array}$ & unidentified charred wood & - & $730 \pm 80$ & $\begin{array}{c}\mathrm{cal} \text { AD } \\
1050-1410\end{array}$ & $\begin{array}{c}\text { Beahm 2013:Table 4.8; Butler } \\
\text { 1981; Smith 2002 }\end{array}$ \\
\hline UGa-4553 & $\begin{array}{c}\text { Sellars } \\
(40 \text { WI1) }\end{array}$ & Feature 7 & unidentified charred wood & - & $965 \pm 55$ & $\begin{array}{c}\text { cal AD } \\
980-1210\end{array}$ & $\begin{array}{c}\text { Beahm 2013:Table 4.8; Butler } \\
\text { 1981; Smith } 2002\end{array}$ \\
\hline UGa-946 & $\begin{array}{c}\text { Sellars } \\
(40 \text { WI1 })\end{array}$ & $\begin{array}{l}\text { Palisade (Feature 22: post trench of main village } \\
\text { palisade) }\end{array}$ & unidentified charred wood & - & $800 \pm 65$ & $\begin{array}{c}\mathrm{cal} \text { AD } \\
1040-1300\end{array}$ & Butler 1981:Table 1 \\
\hline UGa-948 & $\begin{array}{c}\text { Sellars } \\
(40 \text { WI1 })\end{array}$ & Palisade (Feature 39: early village palisade) & unidentified charred wood & - & $\begin{array}{c}1545 \pm \\
110\end{array}$ & $\begin{array}{c}\text { cal AD } \\
250-670\end{array}$ & Butler 1981:Table 1 \\
\hline UGa-947 & $\begin{array}{c}\text { Sellars } \\
(40 \text { WI1 })\end{array}$ & $\begin{array}{l}\text { Palisade (Feature 6, refuse filled pits associated } \\
\text { with early palisade) }\end{array}$ & unidentified charred wood & - & $975 \pm 235$ & $\begin{array}{c}\text { cal AD } \\
610-1420\end{array}$ & Butler 1981:Table 1 \\
\hline $\mathrm{UGa}-4551$ & $\begin{array}{c}\text { Sellars } \\
(40 \text { WI1) }\end{array}$ & Palisade postmold (Posthole 48) & unidentified charred wood & - & $\begin{array}{c}1160 \pm \\
100\end{array}$ & $\begin{array}{c}\text { cal AD } \\
660-1040\end{array}$ & $\begin{array}{c}\text { Beahm 2013:Table 4.8; Butler } \\
\text { 1981; Smith 2002 }\end{array}$ \\
\hline Beta-364010 & $\begin{array}{c}\text { Sellars } \\
(40 \text { WI1) }\end{array}$ & Palisade post (Posthole 36) & charred maize & -9.9 & $510 \pm 30$ & $\begin{array}{c}\mathrm{cal} \mathrm{AD} \\
1320-1450\end{array}$ & Butler 1981 ; this paper \\
\hline Beta-364009 & $\begin{array}{c}\text { Sellars } \\
(40 \mathrm{WI} 1) \\
\end{array}$ & Pit feature (Feature 33) & charred maize & -8.9 & $540 \pm 30$ & $\begin{array}{c}\text { cal AD } \\
1310-1440 \\
\end{array}$ & Butler 1981; this paper \\
\hline UGa-944 & $\begin{array}{c}\text { Sellars } \\
(40 \text { WI1) }\end{array}$ & Structure 1 (Feature 2: wall trench of Structure 1) & unidentified charred wood & - & $900 \pm 110$ & $\begin{array}{c}\text { cal AD } \\
890-1290\end{array}$ & Butler 1981:Table 1 \\
\hline
\end{tabular}




\section{Appendix B. Description of Bayesian models and results}

Averbuch (40DV60)

This model is the primary model for Averbuch reported in Cobb et al. (2015) where it was run in OxCal 4.2. The algorithm used for this model can be directly derived from the model structure shown and described in Cobb et al. (2015) and Appendix E. When run in OxCal 4.3, the model shows good overall agreement $\left(\mathrm{A}_{\text {model }}=98.7\right)$ between the radiocarbon dates and the model assumptions. The model estimates that the earliest activity on the site began in cal AD 1235-1385 (95\% probability; Figure 3; start Averbuch), and probably in cal AD 1260-1380 (68\% probability). The model estimates that palisade construction began in cal AD 1290-1420 (95\% probability; Figure 6; Averbuch: start palisade), and probably in cal AD 1350-1410 (68\% probability). Palisade modifications and repair are estimated to have continued for the next 25-165 years (95\% probability; Figure 7; Averbuch: palisade span), and probably for 40-105 years (68\% probability). Palisade modifications and repair are estimated to have ended in cal AD 1425-1485 (95\% probability; Figure 6; Averbuch: end palisade), and probably in cal AD 1435-1465 (68\% probability). Activity on the site is estimated to have ended in cal AD 1430-1500 (95\% probability; Figure 4; end Averbuch), probably in cal AD 1440-1475 (68\% probability), spanning 60-240 years (95\% probability; Figure 7; Averbuch: settlement span), probably for 70-205 years (68\% probability). 


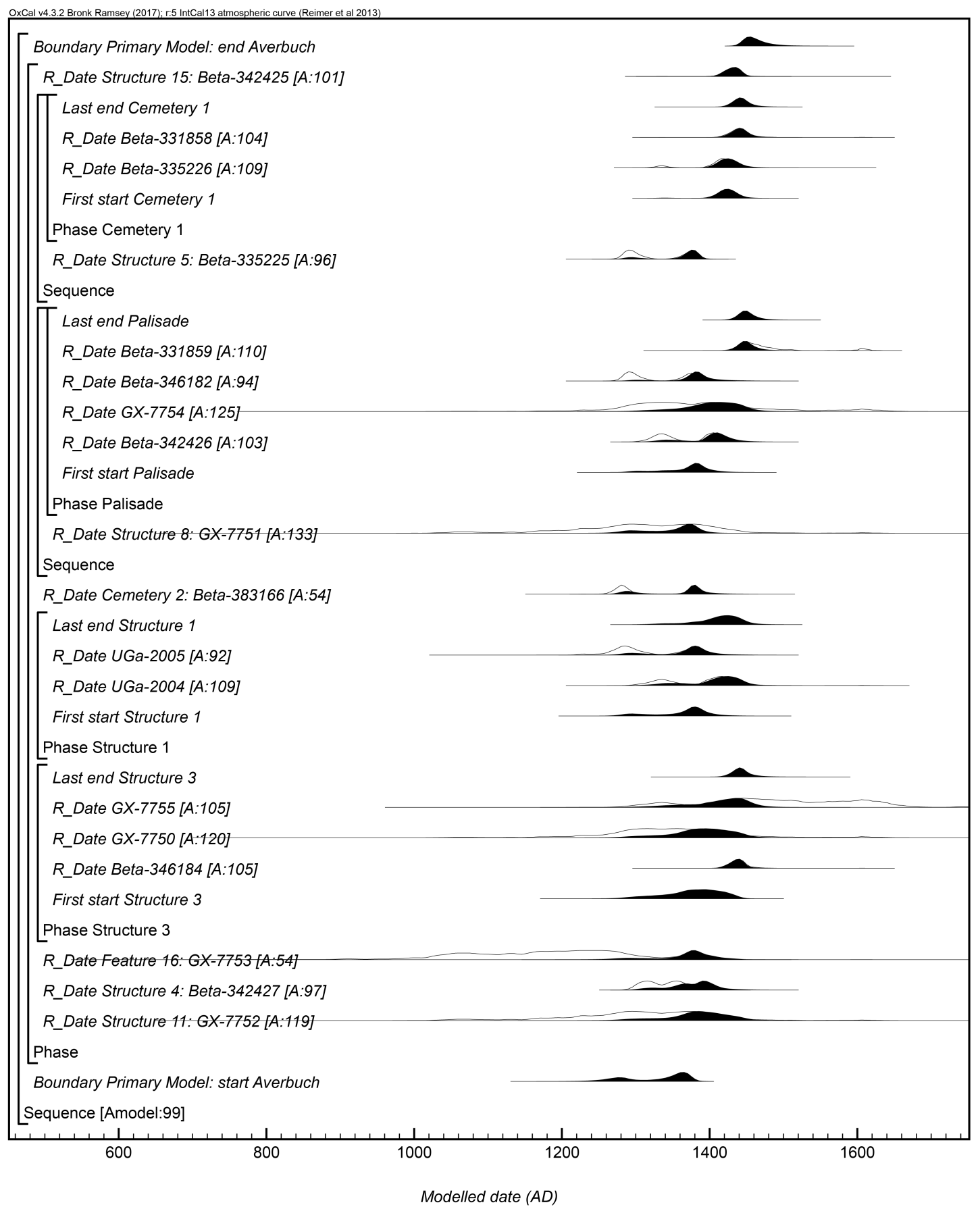

Figure B.1. Results and structure of the primary chronological model for Averbuch.

The brackets and keywords define the model structure. The outlined distribution is the result of radiocarbon calibration and the solid distributions are the chronological model results. 
Eight radiocarbon results from Brentwood Library have been modeled (Appendix A). The dated contexts are described in Appendix A and there are no stratigraphic relationships between the dated samples.

The algorithm used for this model can be directly derived from the model structure shown in Appendix E. The model shows good overall agreement $\left(A_{\text {model }}=104.7\right)$ between the radiocarbon dates and the model assumptions. The model estimates that the earliest activity on the site began in cal AD 1220-1515 (95\% probability; Figure 3; start Brentwood Library), and probably in cal AD 1285-1395 (68\% probability). The model estimates that palisade construction began in cal AD 1290-1515(95\% probability; Figure 6; Brentwood Library: start palisade), and probably in cal AD 1330-1425 (68\% probability). Palisade modifications and repair are estimated to have continued for the next 1-190 years (95\% probability; Figure 7; Brentwood Library: palisade span), and probably for 40-145 years (68\% probability). Palisade modifications and repair are estimated to have ended in cal AD $1435-1550(95 \%$ probability; Figure 6; Brentwood Library: end palisade), and probably in cal AD $1450-1500$ (68\% probability). Activity on the site is estimated to have ended in cal AD 1445-1620 (95\% probability; Figure 4; end Brentwood Library), probably in cal AD 1455-1525 (68\% probability), spanning 1-325 years (95\% probability; Figure 7; Brentwood Library: settlement span), probably for $80-230$ years (68\% probability). 


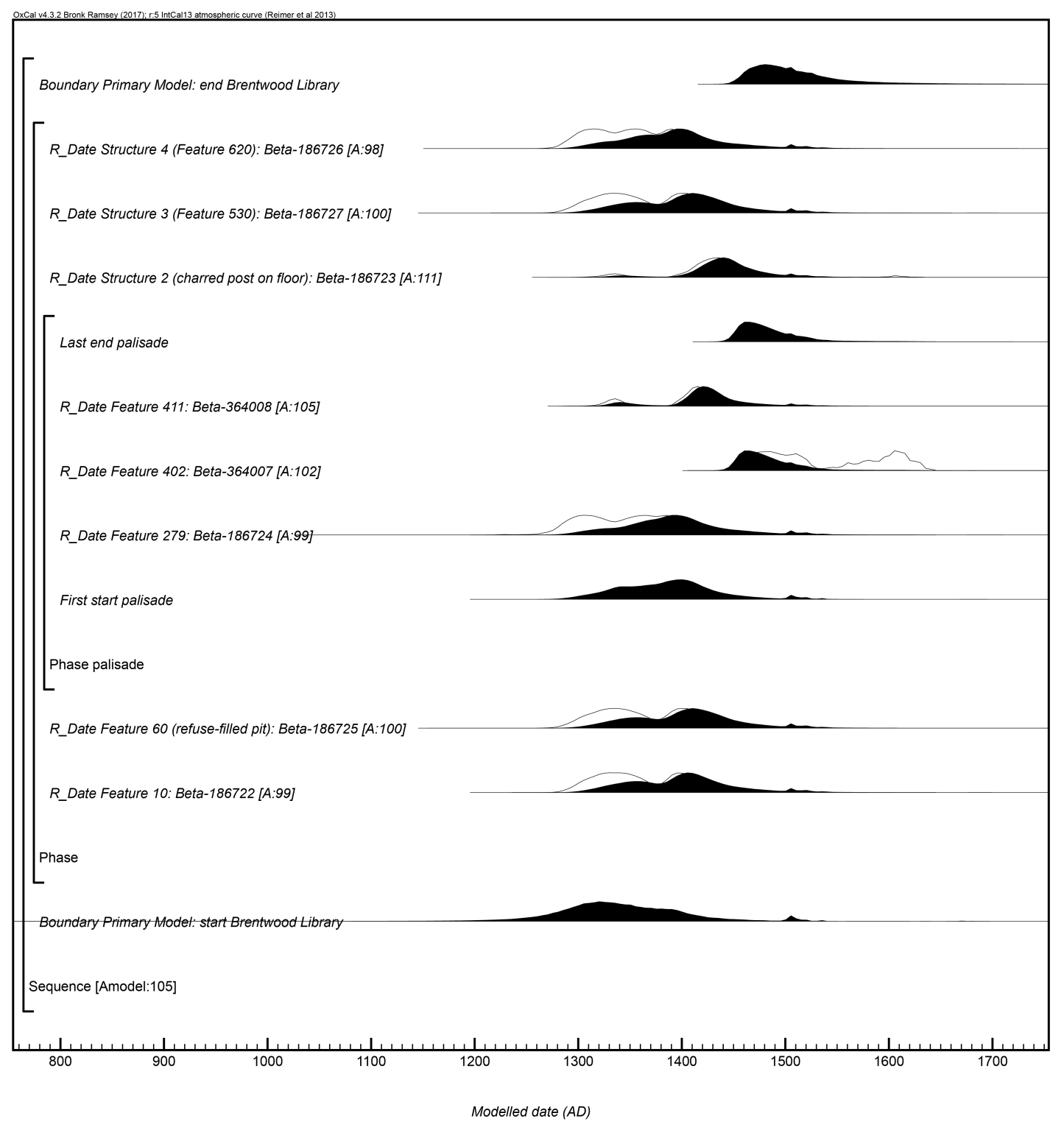

Figure B.2. Results and structure of the primary chronological model for Brentwood Library. The brackets and keywords define the model structure. The format is as described in Figure B.1. 
East Nashville Mounds (40DV4)

Thirteen radiocarbon results from East Nashville Mounds have been modeled (Appendix A). The dated contexts are described in Appendix A. The only stratigraphic relationships between the dated samples is that one sample (TX-7859) comes from unidentified charcoal found in a discrete charred mass spanning several mortuary contexts (Burials 4a,4b, and 9) that superimposes a posthole (Posthole 15) dated with an unidentified wood charcoal sample (Beta-61246) (Walling 2000).

The algorithm used for this model can be directly derived from the model structure shown in Appendix E. The model shows good overall agreement $\left(\mathrm{A}_{\text {model }}=96.8\right)$ between the radiocarbon dates and the model assumptions. The model estimates that the earliest activity on the site began in cal AD 1105-1450 (95\% probability; Figure 3; start East Nashville Mounds), and probably in cal AD 1175-1345 (68\% probability). Activity on the site is estimated to have ended in cal AD 1435-1605 (95\% probability; Figure 4; end East Nashville Mounds), probably in cal AD 14501525 (68\% probability), spanning $1-435$ years (95\% probability; Figure 7; East Nashville Mounds: settlement span), probably for 150-340 years (68\% probability). 


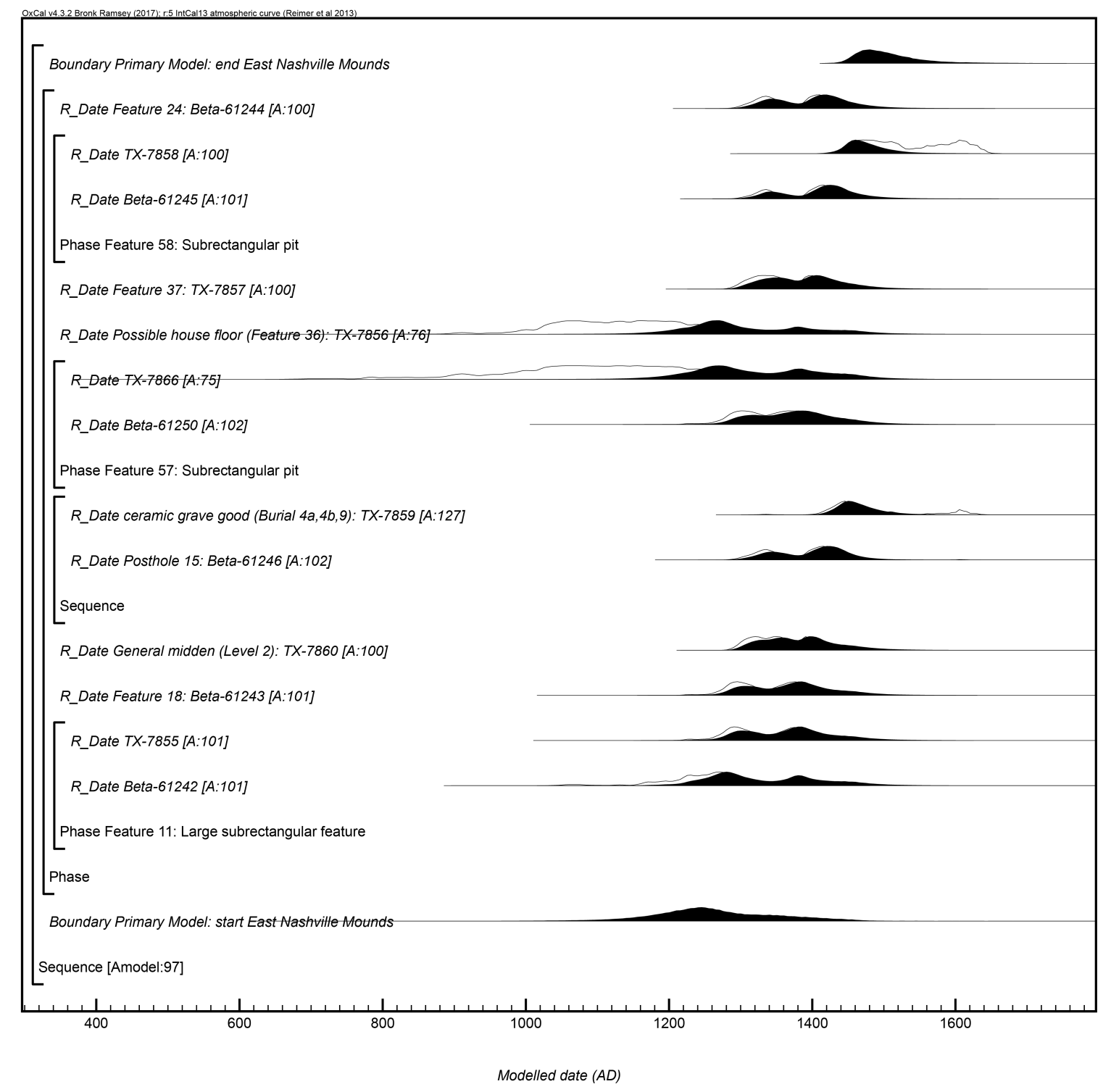

Figure B.3. Results and structure of the primary chronological model for East

Nashville Mounds. The brackets and keywords define the model structure. The format is as described in Figure B.1.

\section{Gordontown (40DV4)}

Three radiocarbon results from Gordontown are available (Appendix A) and only two radiocarbon dates (TX-5551, TX-5550) have been obtained from this site. One radiocarbon sample (TX-5551) is from unidentified wood charcoal found within the 
southeast quadrant of Structure 1 (Moore et al. 2006; Moore and Breitburg 1998). Another radiocarbon sample (TX-5550) is from unidentified wood charcoal found within a floor layer of Structure 3 (Moore et al. 2006; Moore and Breitburg 1998). The 95\% calibrations for the two dates ranges are cal A.D. 1260-1430 (TX-5551) and cal A.D. 1290-1460 (TX-5551) (Appendix A). These calibrations are in the same time range as the Bayesian modeling results for the other MCR settlements (Figures 3-4). These results were not modeled because the Gordontown radiocarbon dataset alone is not robust enough to construct a meaningful chronological model.

\section{Rutherford-Kizer (40SU15)}

Fifteen radiocarbon results from Rutherford-Kizer have been modeled (Appendix A). The dated contexts are described in Appendix A. The only stratigraphic relationships between the dated samples is that two pits (Feature 36, Feature 20) dated with samples of unidentified charcoal (Beta-70877, Beta-70874, Beta-70875) superimpose a structure (Structure 1) that is dated with samples of unidentified charcoal (Beta70878, Beta-70879, Beta-70880) from postholes (Feature 34, Feature 88, Feature 96) associated with this structure (Moore and Smith 2001). Additionally, one date (Beta90627) from unidentified wood charcoal has been excluded from modeling because it is a clear outlier that is much older than the other dates.

The algorithm used for this model can be directly derived from the model structure shown in Appendix E. The model shows good overall agreement $\left(\mathrm{A}_{\text {model }}=69.7\right)$ between the radiocarbon dates and the model assumptions. The model estimates that the earliest activity on the site began in cal AD 1075-1270 (95\% probability; Figure 
3; start Rutherford-Kizer), and probably in cal AD 1135-1255 (68\% probability). The model estimates that palisade construction began in cal AD 1170-1320 $(95 \%$ probability; Figure 6; Rutherford-Kizer: start palisade), and probably in cal $A D$ 1220-1290 (68\% probability). Palisade modifications and repair are estimated to have continued for the next 55-250 years (95\% probability; Figure 7; Rutherford-Kizer: palisade span), and probably for $110-210$ years ( $68 \%$ probability). Palisade modifications and repair are estimated to have ended in cal AD 1335-1460 (95\% probability; Figure 6; Rutherford-Kizer: end palisade), and probably in cal AD 13901445 (68\% probability). Activity on the site is estimated to have ended in cal AD 1350-1510 (95\% probability; Figure 4; end Rutherford-Kizer), probably in cal AD 1400-1465 (68\% probability), spanning 90-405 years (95\% probability; Figure 7; Rutherford-Kizer: settlement span), probably for $175-325$ years (68\% probability). 


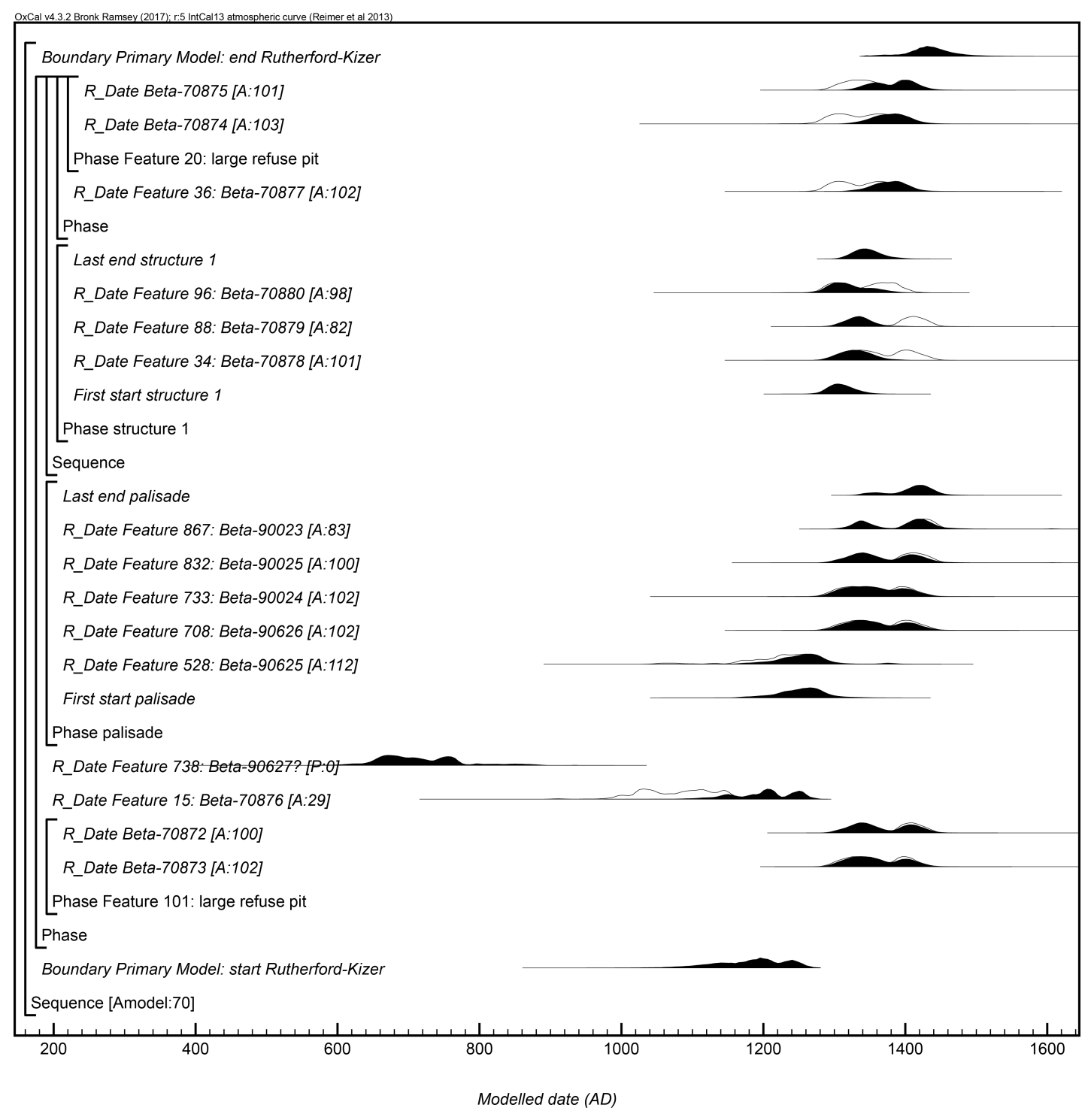

Figure B.4. Results and structure of the primary chronological model for Rutherford-

Kizer. The brackets and keywords define the model structure. The format is as described in Figure B.1.

Sellars (40WI1)

Ten radiocarbon results from Sellars have been modeled (Appendix A). The dated contexts are described in Appendix A and there are no stratigraphic relationships between the dated samples. Three dates (UGa-4553, UGa-948, UGa-4551) from 
unidentified wood charcoal have been excluded from modeling because they are clear outliers that are much older than the other dates.

The algorithm used for this model can be directly derived from the model structure shown in Appendix E. The model shows good overall agreement $\left(\mathrm{A}_{\text {model }}=101.5\right)$ between the radiocarbon dates and the model assumptions. The model estimates that the earliest activity on the site began in cal AD 1040-1435 (95\% probability; Figure 3; start Sellars), and probably in cal AD 1205-1425 (68\% probability). The model estimates that palisade construction began in cal AD 1145-1440 (95\% probability; Figure 6; Sellars: start palisade), and probably in cal AD 1245-1430 (68\% probability). Palisade modifications and repair are estimated to have continued for the next $1-270$ years (95\% probability; Figure 7; Sellars: palisade span), and probably for $1-160$ years (68\% probability). Palisade modifications and repair are estimated to have ended in cal AD 1315-1480 (95\% probability; Figure 6; Sellars: end palisade), and probably in cal AD 1400-1440 (68\% probability). Activity on the site is estimated to have ended in cal AD 1325-1565 (95\% probability; Figure 4; end Sellars), probably in cal AD 1335-1480 (68\% probability), spanning 1-465 years (95\% probability; Figure 7; Sellars: settlement span), probably for 1-225 years (68\% probability). 


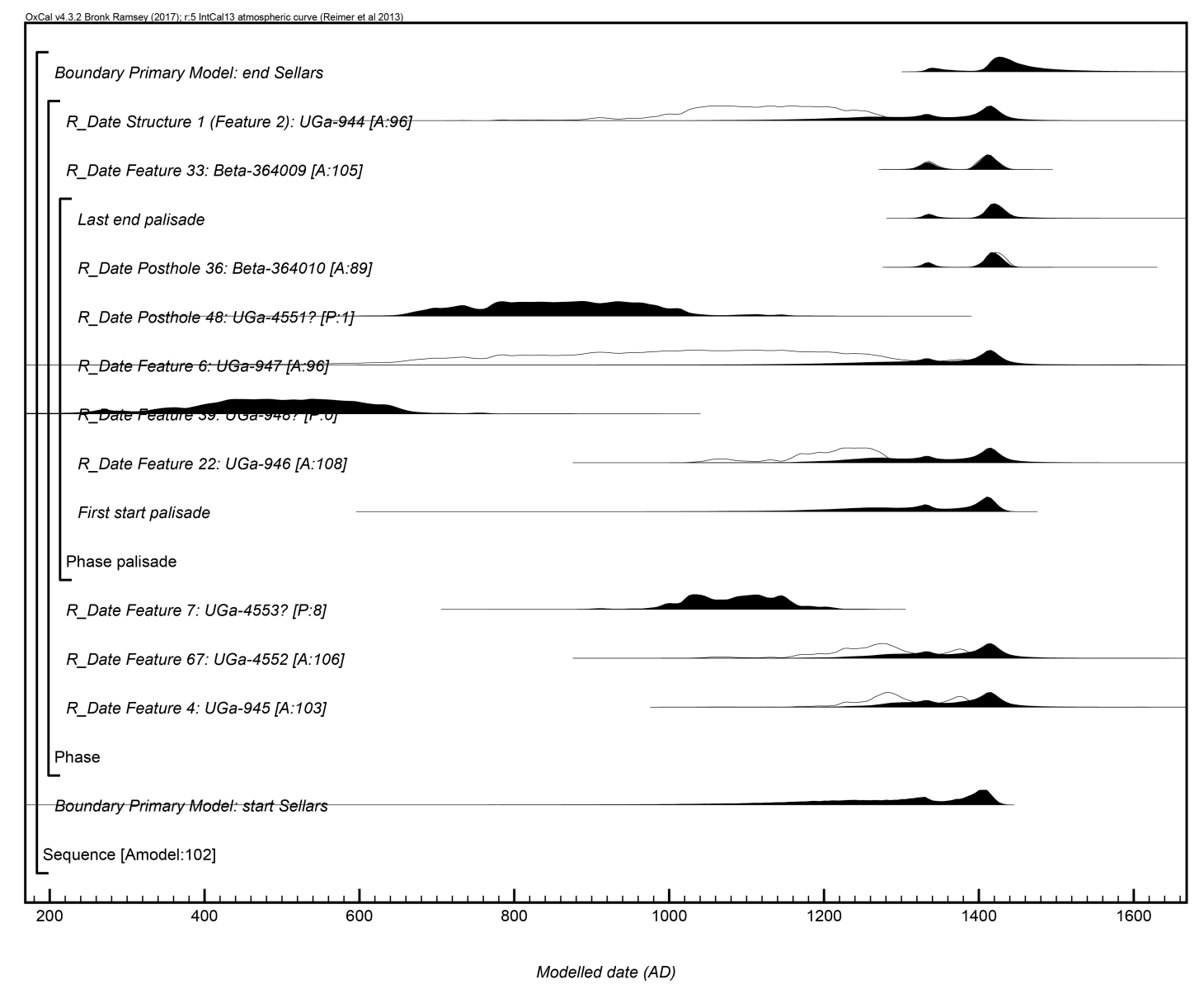

Figure B.5. Results and structure of the primary chronological model for Sellars. The brackets and keywords define the model structure. The format is as described in Figure B.1. 


\section{Appendix C. Description of alternative Bayesian models and results}

Averbuch (40DV60) (alternative)

An alternative Bayesian model was created for Averbuch by slightly modifying the primary model described in Cobb et al. (2015) and Appendix B. Specifically, charcoal outlier modeling was not used, otherwise the model is identical to the primary model described in Appendix B.

The algorithm used for this alternative model can be directly derived from the model structure shown in Appendix E. The model shows good overall agreement $\left(A_{\text {model }}=103.7\right)$ between the radiocarbon dates and the alternative model assumptions. The alternative model estimates that the earliest activity on the site began in cal $A D$ 1235-1380 (95\% probability), and probably in cal AD 1255-1375 (68\% probability). The alternative model estimates that palisade construction began in cal AD 12851395 (95\% probability), and probably in cal AD 1330-1395 (68\% probability). Palisade modifications and repair are estimated to have continued for the next 40-165 years (95\% probability), and probably for $45-110$ years ( $68 \%$ probability). Palisade modifications and repair are estimated to have ended in cal AD 1430-1495 (95\% probability), and probably in cal AD 1440-1465 (68\% probability). Activity on the site is estimated to have ended in cal AD 1430-1495 (95\% probability), probably in cal AD 1440-1465 (68\% probability), spanning 60-240 years (95\% probability), probably for $70-210$ years (68\% probability). 


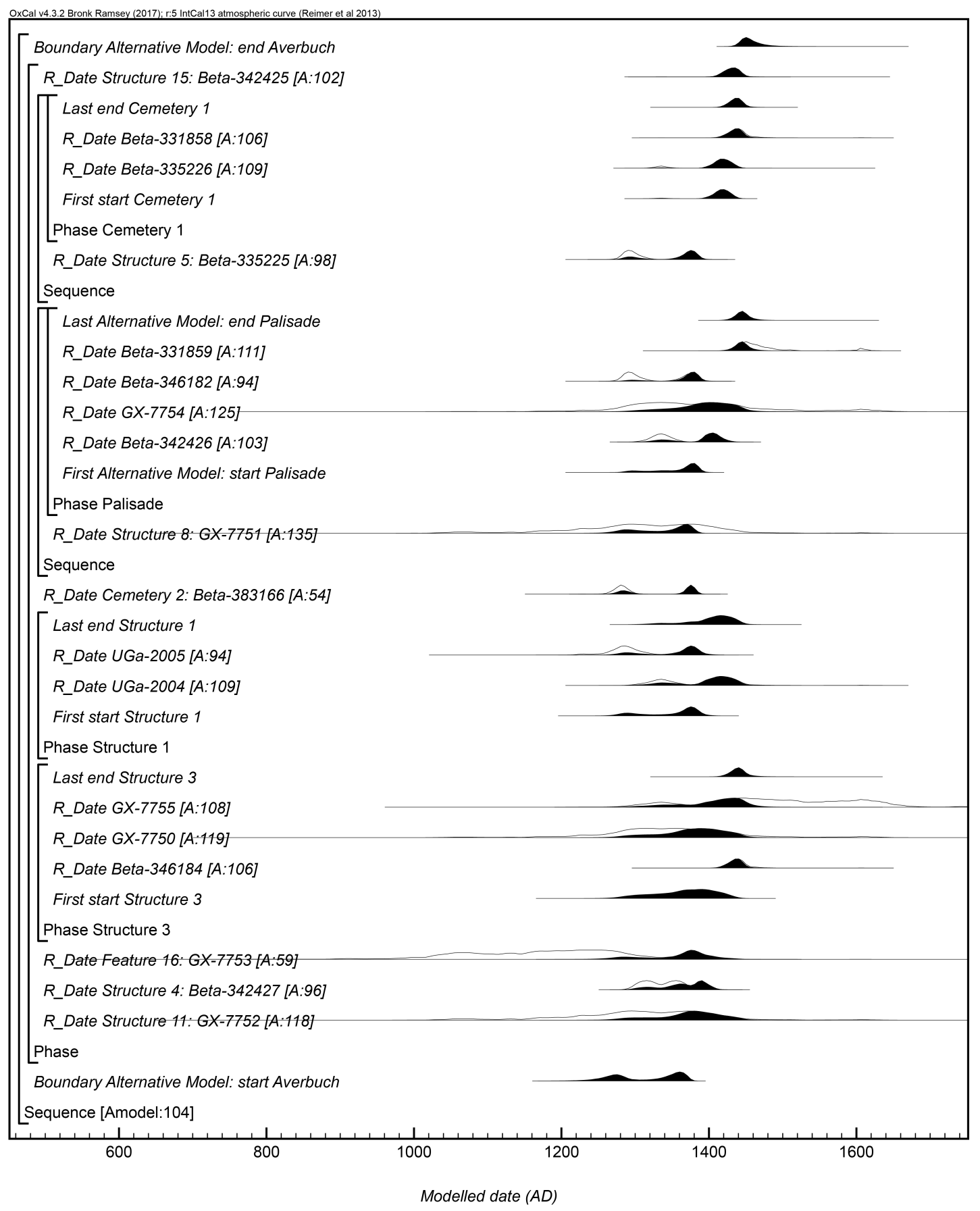

Figure C.1. Results and structure of the alternative chronological model for Averbuch.

The brackets and keywords define the model structure. The format is as described in

Figure B.1. 
An alternative Bayesian model was created for Brentwood Library by slightly modifying the primary model described in Appendix B. Specifically, charcoal outlier modeling was not used, otherwise the model is identical to the primary model described in Appendix B.

The algorithm used for this alternative model can be directly derived from the model structure shown in Appendix E. The model shows good overall agreement $\left(\mathrm{A}_{\text {model }}=103.6\right)$ between the radiocarbon dates and the alternative model assumptions. The alternative model estimates that the earliest activity on the site began in cal $A D$ 1235-1405 (95\% probability), and probably in cal AD 1275-1370 (68\% probability). The alternative model estimates that palisade construction began in cal AD 12951420 (95\% probability), and probably in cal AD 1330-1410 (68\% probability). Palisade modifications and repair are estimated to have continued for the next 30-190 years ( $95 \%$ probability), and probably for $50-140$ years ( $68 \%$ probability). Palisade modifications and repair are estimated to have ended in cal AD 1435-1515 (95\% probability), and probably in cal AD 1445-1480 (68\% probability). Activity on the site is estimated to have ended in cal AD 1440-1580 (95\% probability), probably in cal AD 1450-1505 (68\% probability), spanning 50-310 years (95\% probability), probably for 95-225 years (68\% probability). 


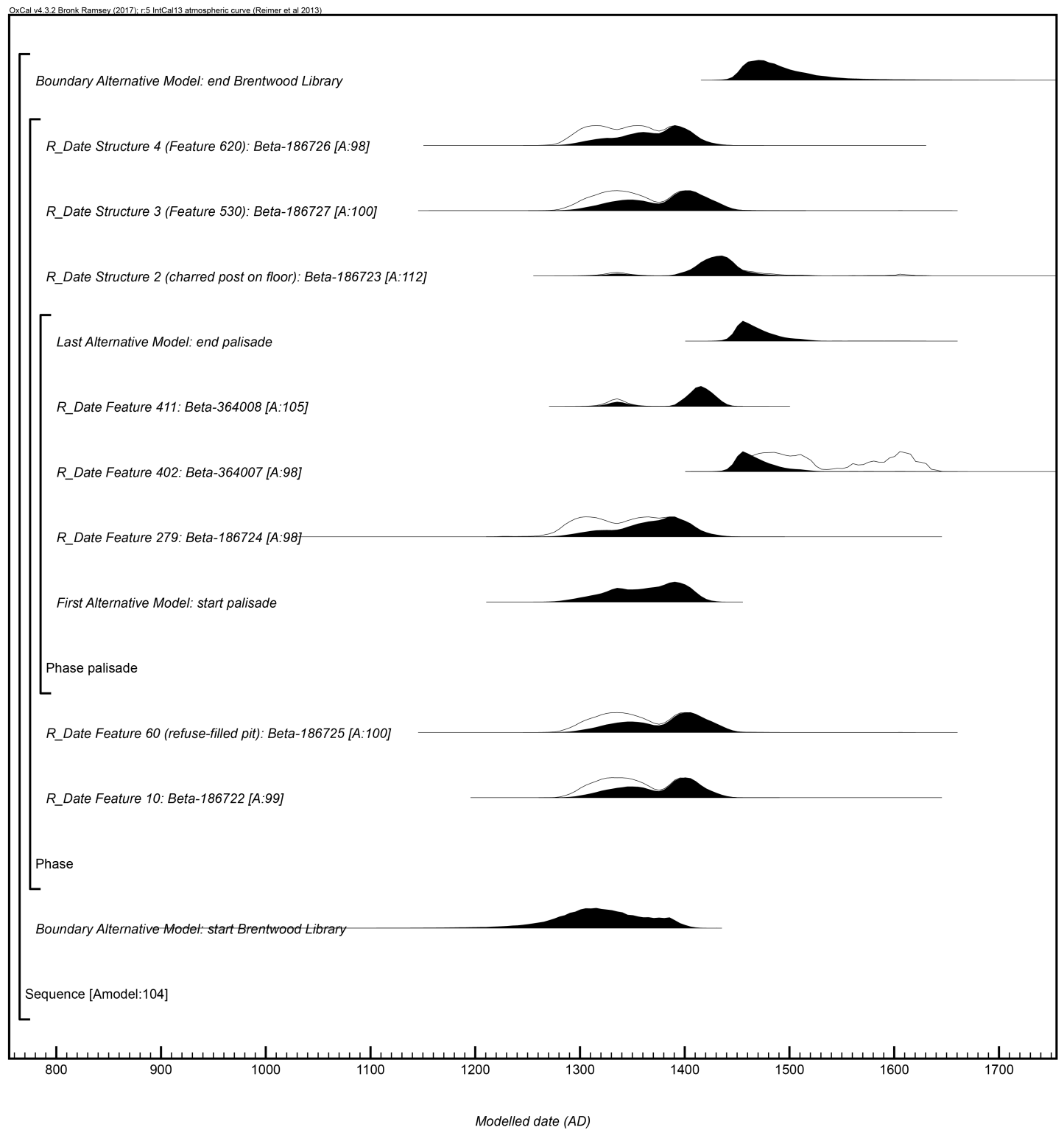

Figure C.2. Results and structure of the alternative chronological model for Brentwood Library. The brackets and keywords define the model structure. The format is as described in Figure B.1.

East Nashville Mounds (40DV4) (alternative)

An alternative Bayesian model was created for East Nashville Mounds by slightly modifying the primary model described in Appendix B. Specifically, charcoal outlier modeling was not used, otherwise the model is identical to the primary model 
described in Appendix B.

The algorithm used for this alternative model can be directly derived from the model structure shown in Appendix E. The model shows good overall agreement $\left(A_{\text {model }}=91.4\right)$ between the radiocarbon dates and the alternative model assumptions. The alternative model estimates that the earliest activity on the site began in cal $A D$ 1105-1390 (95\% probability), and probably in cal AD 1170-1275 (68\% probability). Activity on the site is estimated to have ended in cal AD 1420-1565 (95\% probability), probably in cal AD 1445-1505 (68\% probability), spanning 25-435 years (95\% probability), probably for $185-330$ years (68\% probability). 


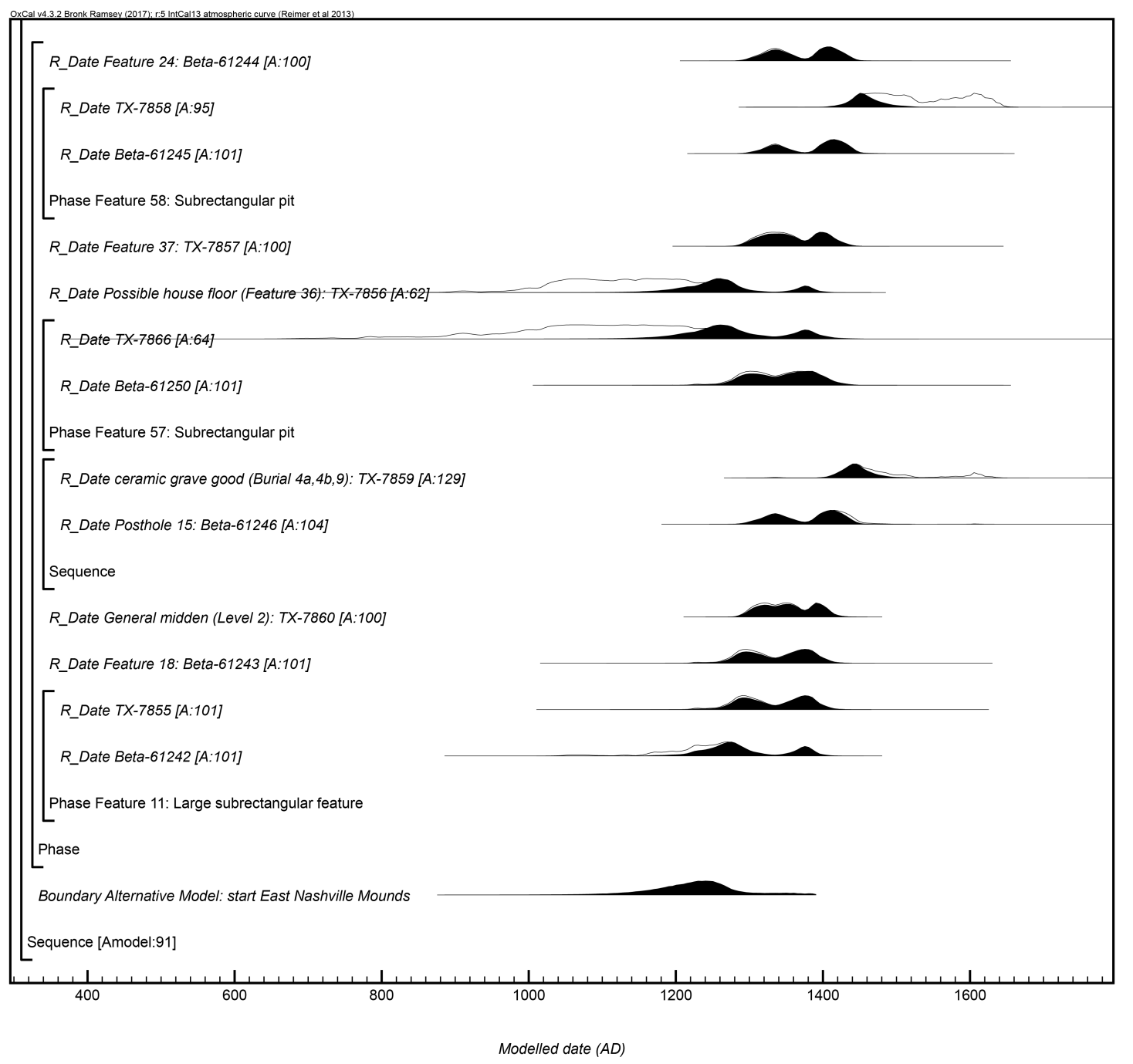

Figure C.3. Results and structure of the alternative chronological model for East Nashville Mounds. The brackets and keywords define the model structure. The format is as described in Figure B.1.

\section{Rutherford-Kizer (40SU15) (alternative)}

An alternative Bayesian model was created for Rutherford-Kizer by slightly modifying the primary model described in Appendix B. Specifically, charcoal outlier modeling was not used, otherwise the model is identical to the primary model described in Appendix B. 
The algorithm used for this alternative model can be directly derived from the model structure shown in Appendix E. The model shows good overall agreement $\left(\mathrm{A}_{\text {model }}=69.2\right)$ between the radiocarbon dates and the alternative model assumptions. The alternative model estimates that the earliest activity on the site began in cal $A D$ 1075-1265 (95\% probability), and probably in cal AD 1135-1255 (68\% probability). The alternative model estimates that palisade construction began in cal AD 11651305 (95\% probability), and probably in cal AD 1220-1285 (68\% probability). Palisade modifications and repair are estimated to have continued for the next 55-245 years (95\% probability), and probably for $115-210$ years (68\% probability). Palisade modifications and repair are estimated to have ended in cal AD 1345-1495 (95\% probability), and probably in cal AD 1400-1460 (68\% probability). Activity on the site is estimated to have ended in cal AD 1345-1495 (95\% probability), probably in cal AD 1400-1460 (68\% probability), spanning 85-310 years (95\% probability), probably for $175-315$ years (68\% probability). 


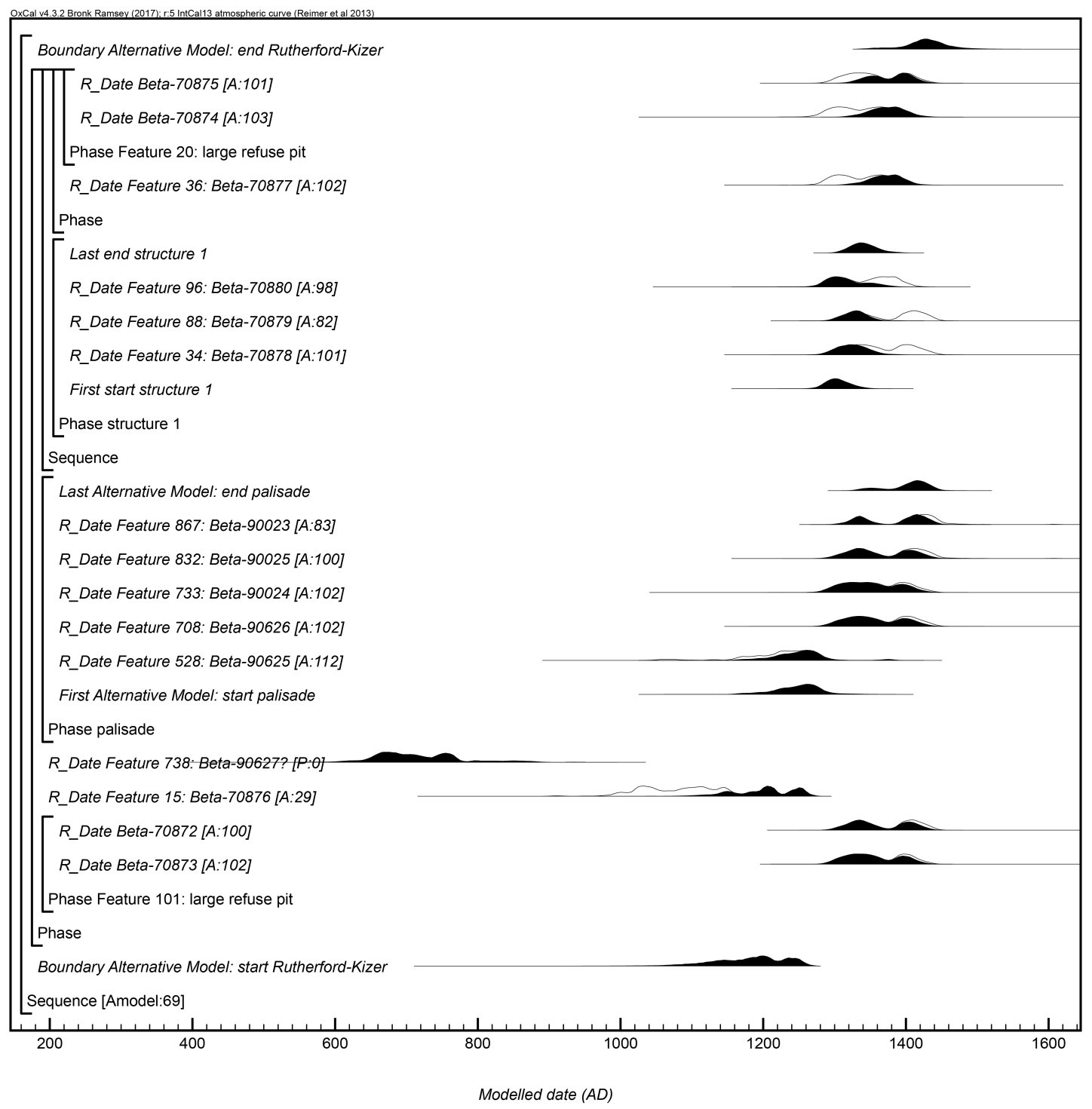

Figure C.4. Results and structure of the alternative chronological model for

Rutherford-Kizer. The brackets and keywords define the model structure. The format is as described in Figure B.1.

Sellars (40WI1) (alternative)

An alternative Bayesian model was created for Sellars by slightly modifying the primary model described in Appendix B. Specifically, charcoal outlier modeling was not used, otherwise the model is identical to the primary model described in Appendix 
B.

The algorithm used for this alternative model can be directly derived from the model structure shown in Appendix E. The model shows good overall agreement $\left(\mathrm{A}_{\text {model }}=92\right)$ between the radiocarbon dates and the alternative model assumptions. The alternative model estimates that the earliest activity on the site began in cal AD $915-1290(95 \%$ probability), and probably in cal AD 1095-1255 (68\% probability). The alternative model estimates that palisade construction began in cal AD $1045-1310(95 \%$ probability), and probably in cal AD 1170-1275 (68\% probability). Palisade modifications and repair are estimated to have continued for the next 35-375 years (95\% probability), and probably for $85-265$ years (68\% probability). Palisade modifications and repair are estimated to have ended in cal AD 1315-1445 (95\% probability), and probably in cal AD 1325-1435 (68\% probability). Activity on the site is estimated to have ended in cal AD 1320-1585 (95\% probability), probably in cal AD 1335-1495 (68\% probability), spanning 45-620 years (95\% probability), probably for $165-410$ years (68\% probability). 


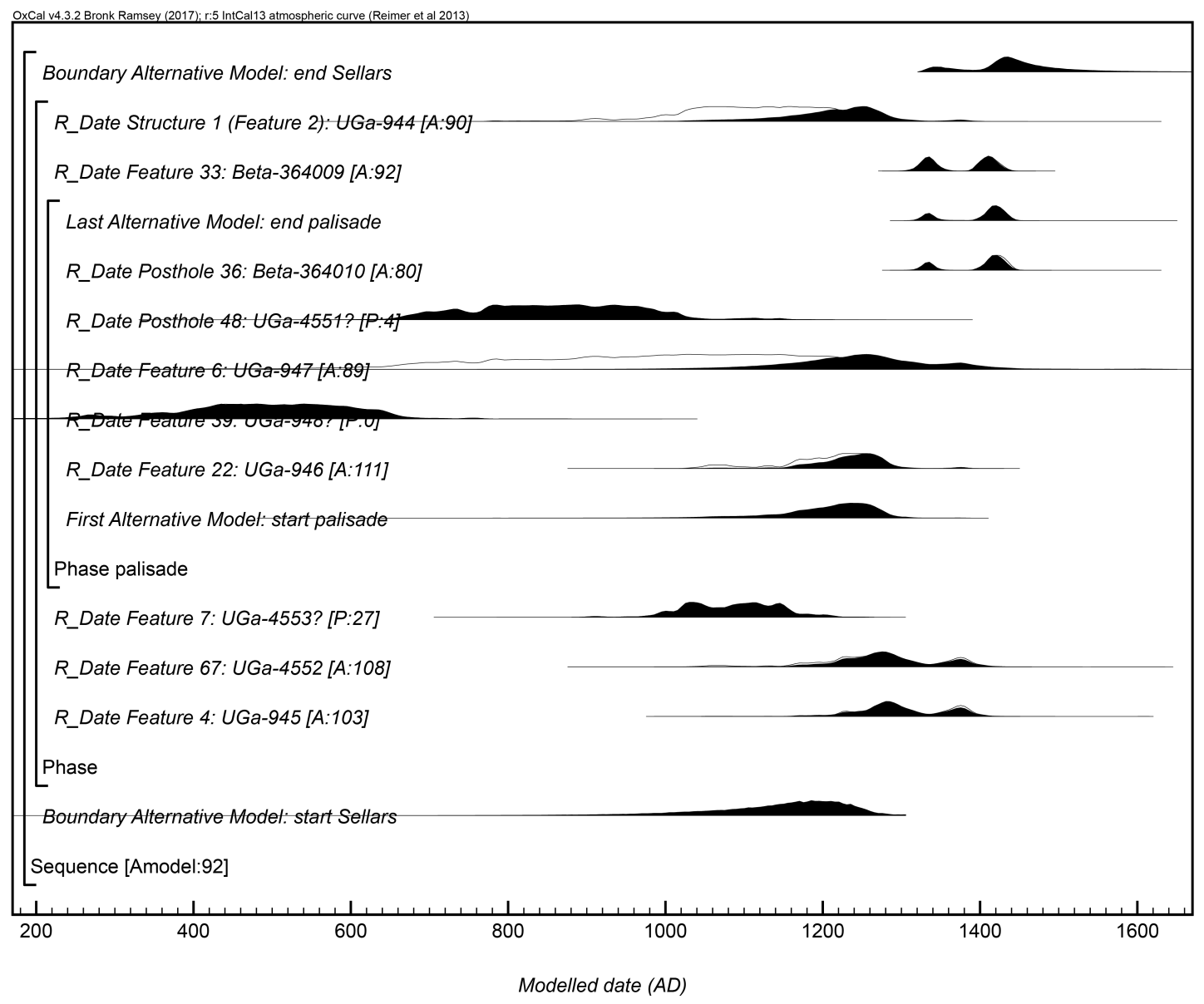

Figure C.5. Results and structure of the alternative chronological model for Sellars.

The brackets and keywords define the model structure. The format is as described in Figure B.1. 


\section{Appendix D. Description of simulation experiments and results}

Simulations were run to determine the minimum number of new dates needed to more precisely identify the occupation boundaries of Averbuch (40DV60), Brentwood Library (40WM210), East Nashville Mounds (40DV4), Gordontown (40DV4), Rutherford-Kizer (40SU15), and Sellars (40WI1).

In the chronological model simulations, calendar years for the site occupation are “known" (for example, see Bayliss et al. [2007], Bayliss [2009], and Griffiths [2014]). For this simulation experiment, the calendar years for the site occupations in the simulation models are the median value for posterior probabilities for the starting and ending boundaries, respectively, of the primary models described in Appendix B. Simulation models were created by adding simulated radiocarbon dates with OxCal's R_Simulate function. The simulated radiocarbon dates were given an error of 35 years and the true calendar dates of the simulated radiocarbon dates were evenly distributed in each model between the known calendar years for the site occupation. The minimum number of simulated radiocarbon dates needed to achieve the known calendar dates in the starting and ending boundaries posterior probabilities within confidence intervals spanning 50 years (or less) at $68 \%$ and $95 \%$ probability are reported in Table 3. New simulated radiocarbon dates were added in groups of five until the desired precision was obtained.

It should be noted, that no primary Bayesian chronological model had been created for Gordontown because only two radiocarbon dates are available from the site. As a result, the known calendar years for the site occupation for models created for 
Gordontown in the simulation experiment are AD 1250 and AD 1450.

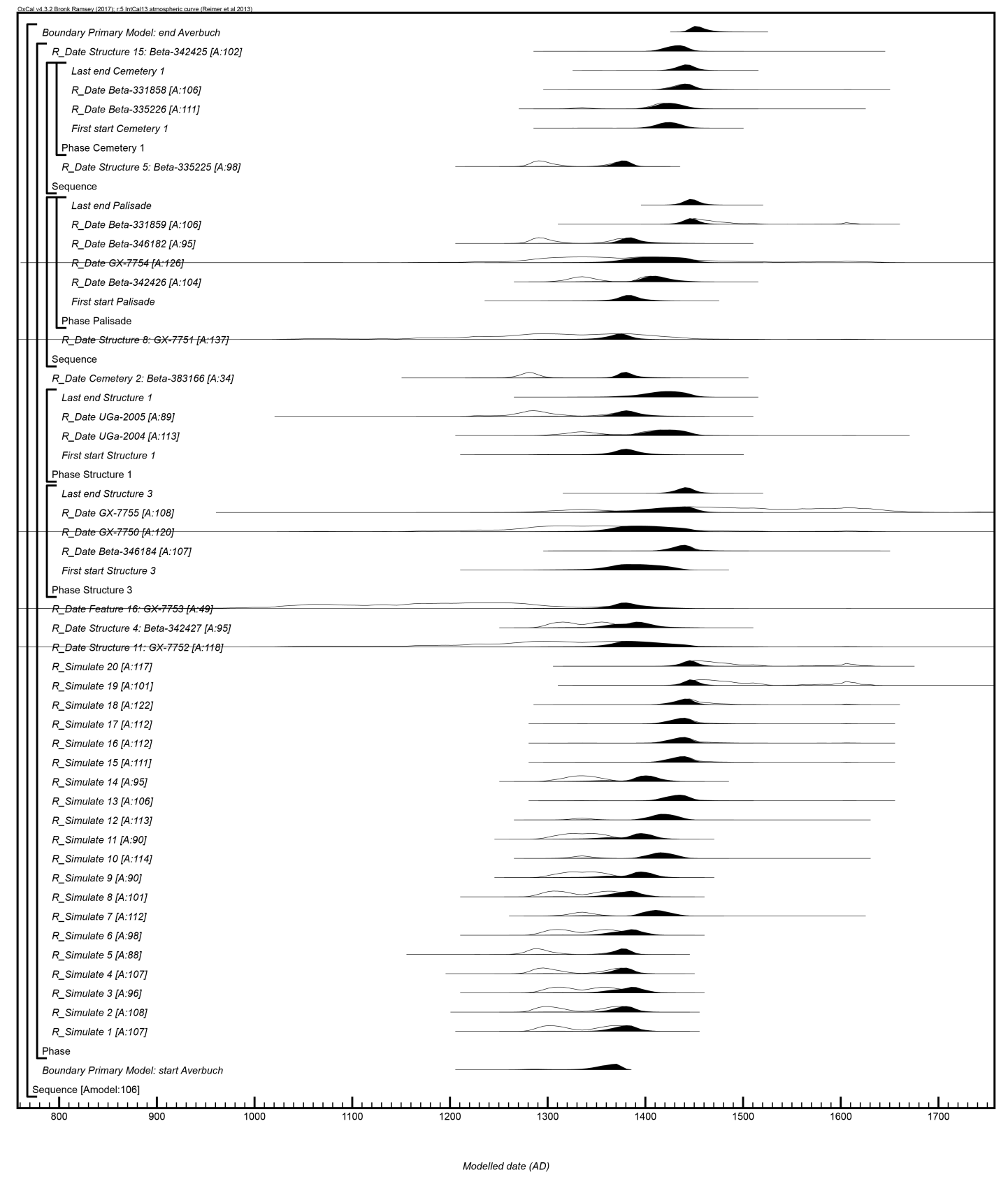

Figure D.1. Results and structure of the primary chronological model for Averbuch with the minimum number of simulated radiocarbon dates needed to achieve the desired precision at $68 \%$ probability for the posterior probabilities of the starting and ending boundaries for site activity. The brackets and keywords define the model structure. The format is as described in Figure B.1. 


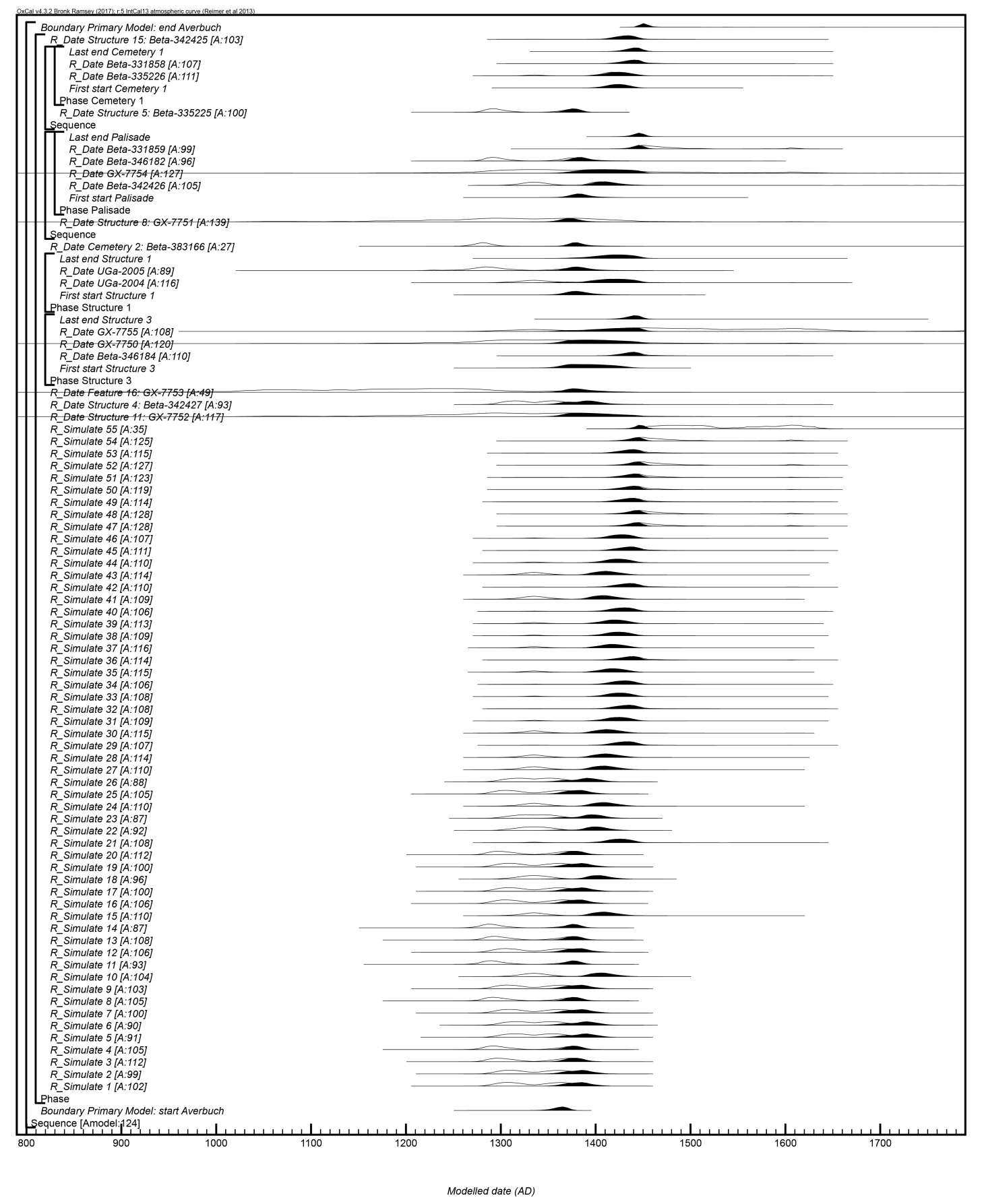

Figure D.2. Results and structure of the primary chronological model for Averbuch with the minimum number of simulated radiocarbon dates needed to achieve the desired precision at $95 \%$ probability for the posterior probabilities of the starting and ending boundaries for site activity. The brackets and keywords define the model structure. The format is as described in Figure B.1. 


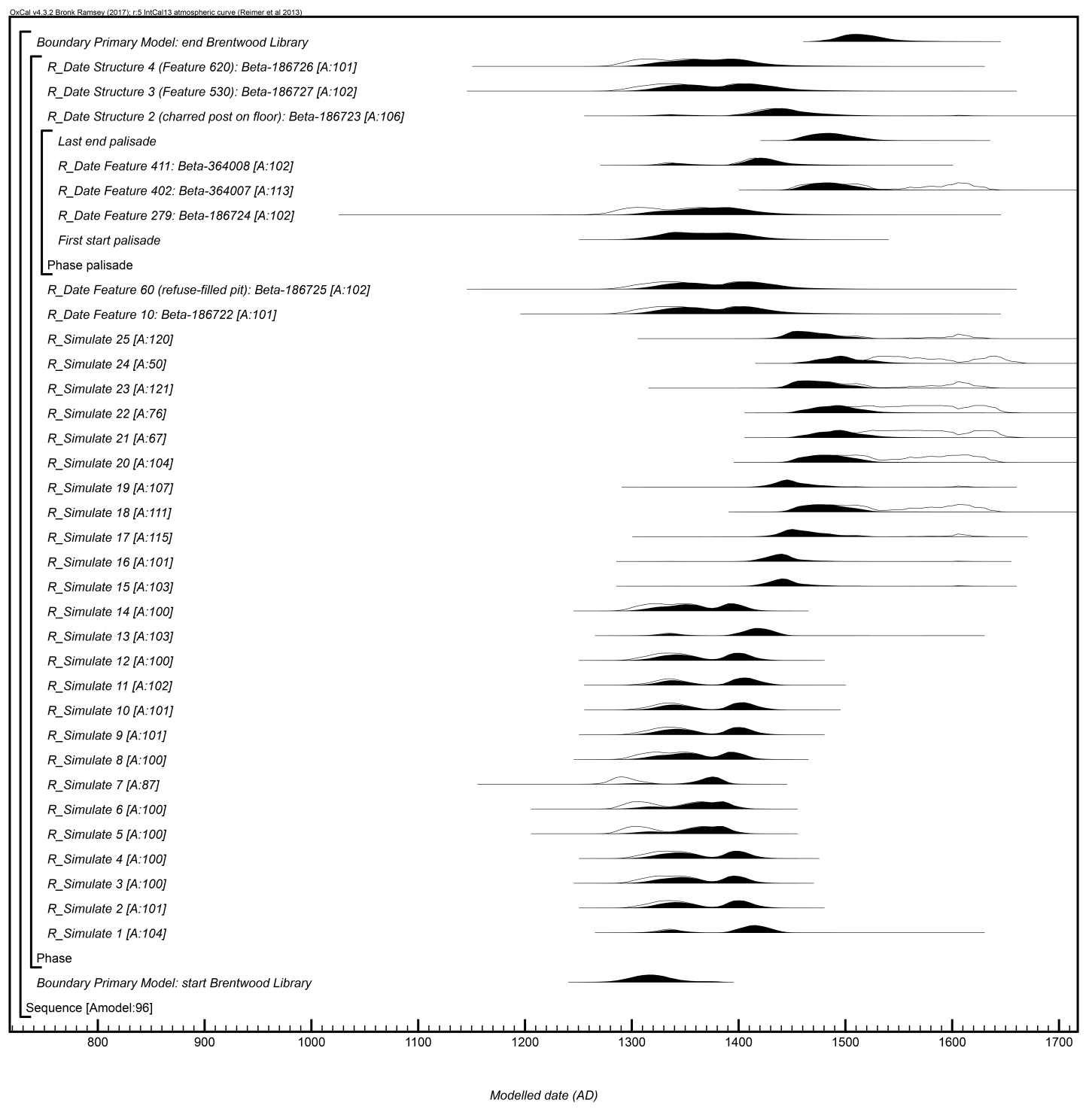

Figure D.3. Results and structure of the primary chronological model for Brentwood Library with the minimum number of simulated radiocarbon dates needed to achieve the desired precision at $68 \%$ probability for the posterior probabilities of the starting and ending boundaries for site activity. The brackets and keywords define the model structure. The format is as described in Figure B.1. 


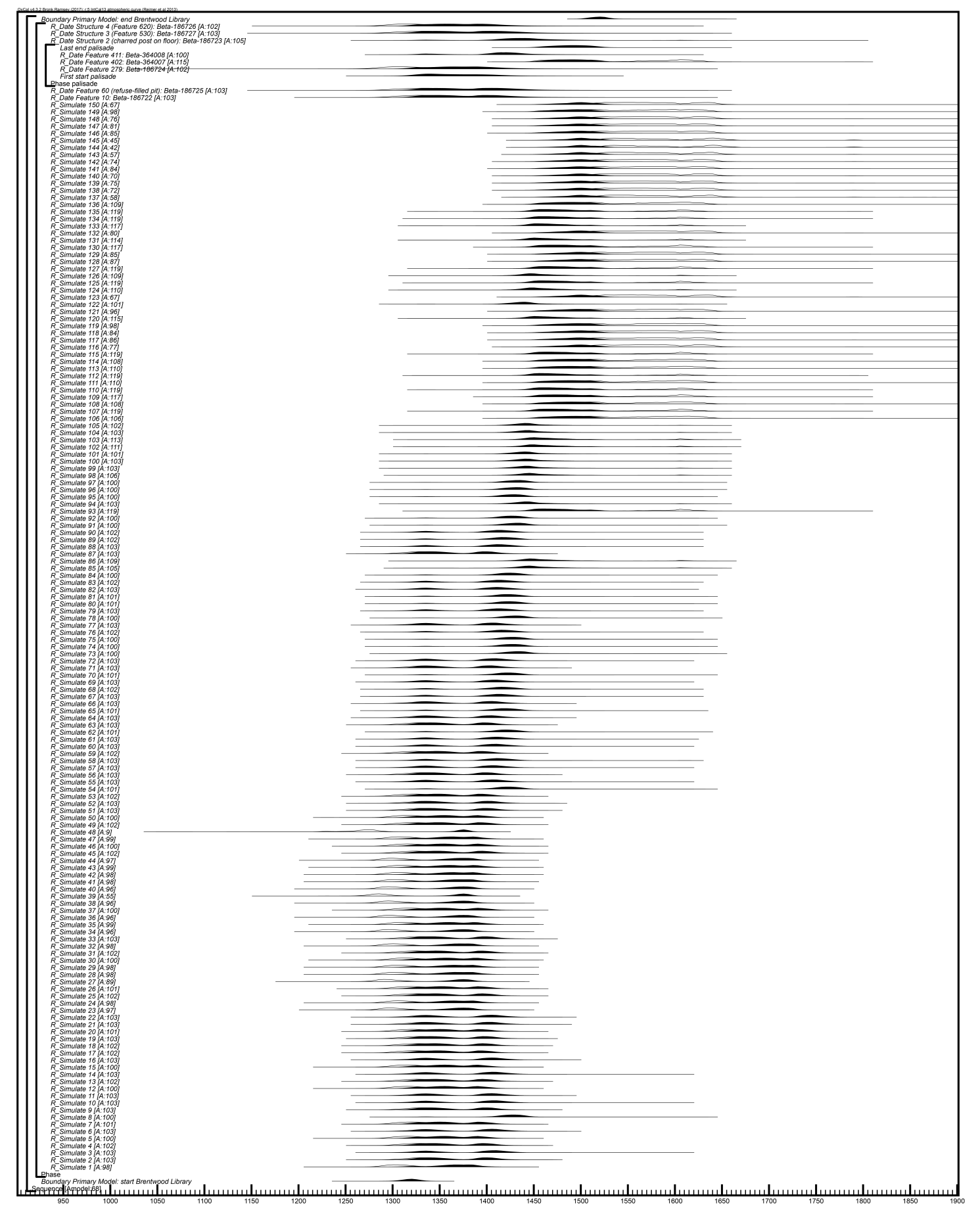

Figure D.4. Results and structure of the primary chronological model for Brentwood Library with the minimum number of simulated radiocarbon dates needed to achieve the desired precision at $95 \%$ probability for the posterior probabilities of the starting and ending boundaries for site activity. The brackets and keywords define the model structure. The format is as described in Figure B.1. 


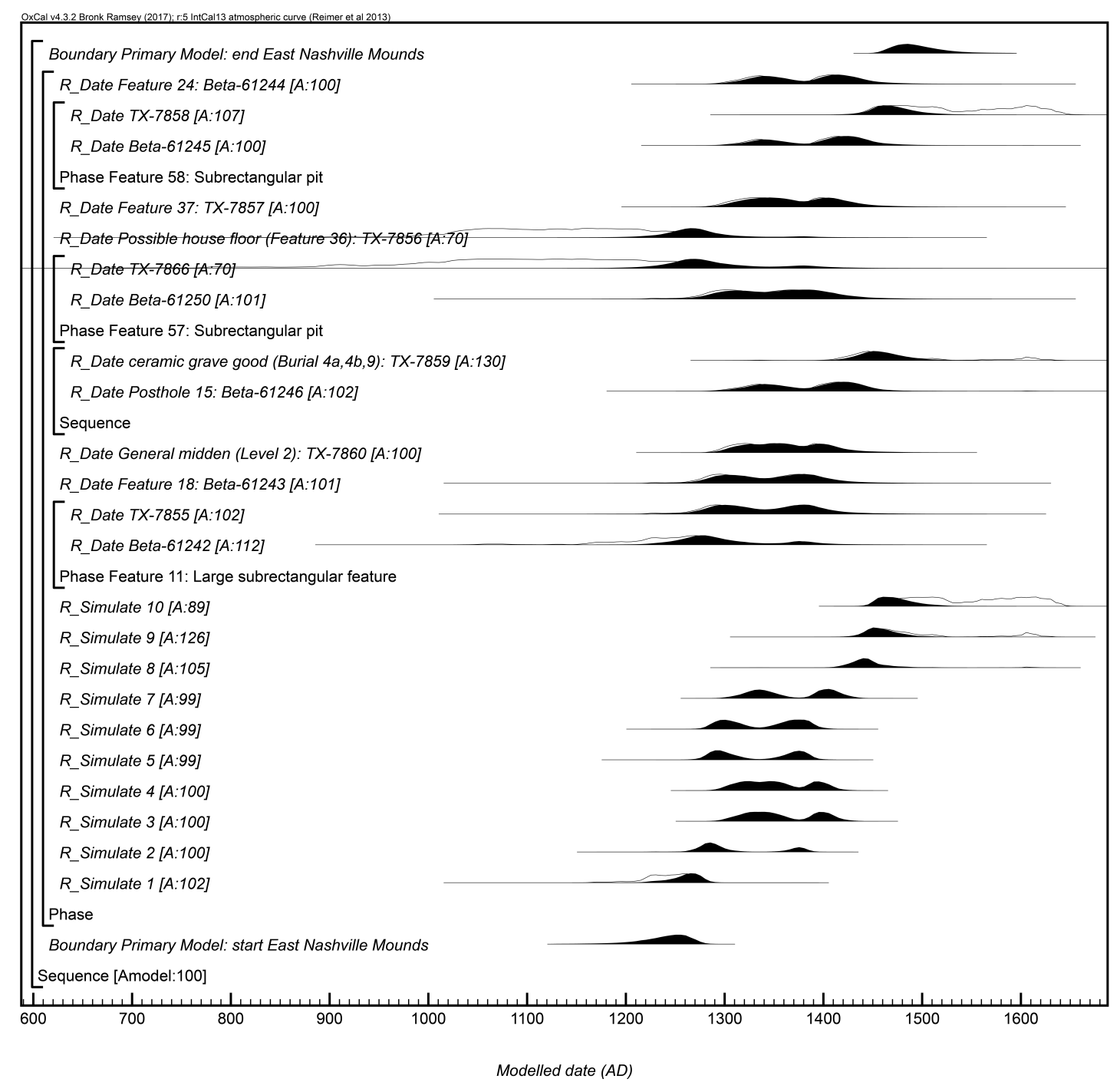

Figure D.5. Results and structure of the primary chronological model for East

Nashville Mounds with the minimum number of simulated radiocarbon dates needed to achieve the desired precision at $68 \%$ probability for the posterior probabilities of the starting and ending boundaries for site activity. The brackets and keywords define the model structure. The format is as described in Figure B.1. 


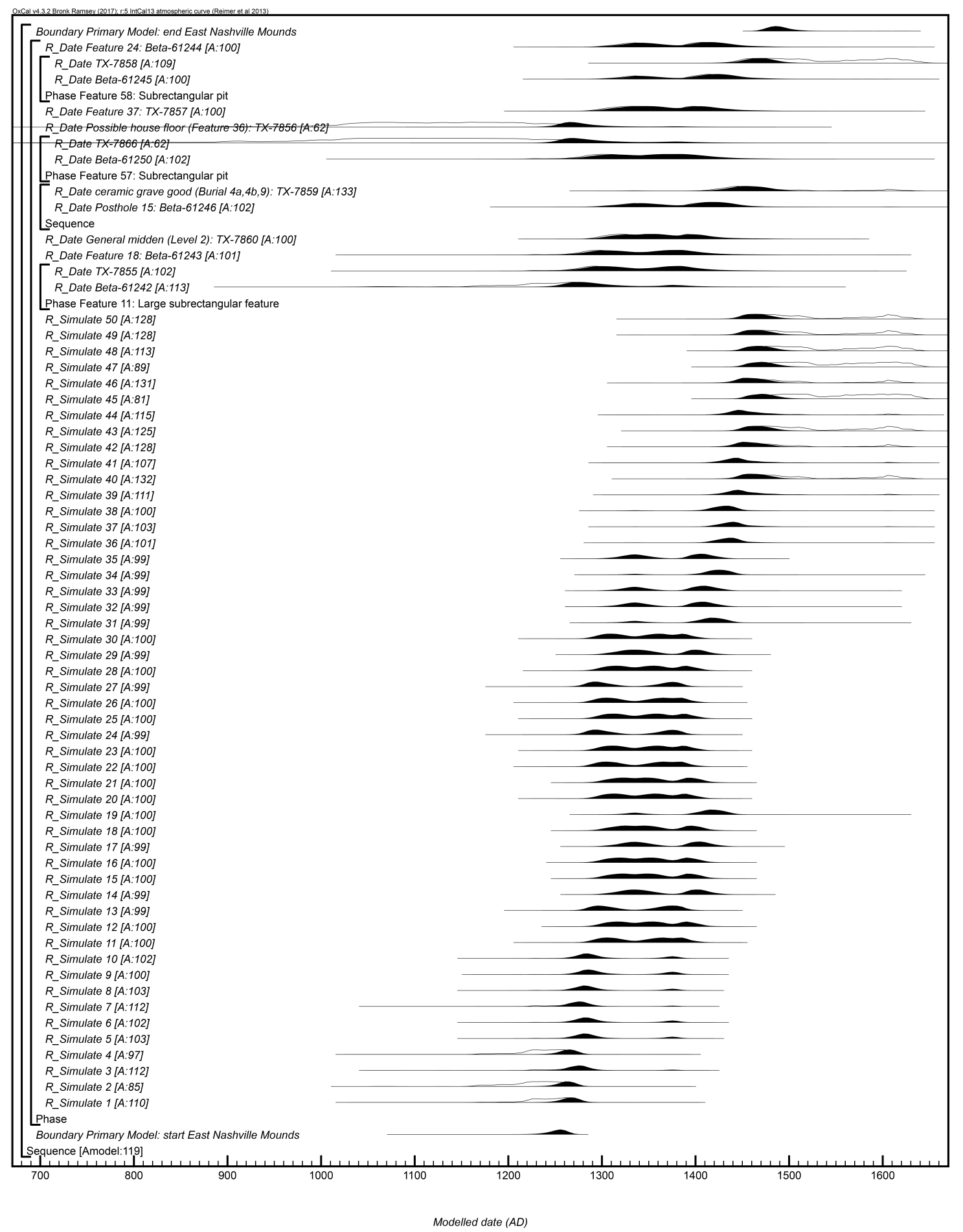

Figure D.6. Results and structure of the primary chronological model for East

Nashville Mounds with the minimum number of simulated radiocarbon dates needed to achieve the desired precision at $95 \%$ probability for the posterior probabilities of the starting and ending boundaries for site activity. The brackets and keywords define the model structure. The format is as described in Figure B.1. 


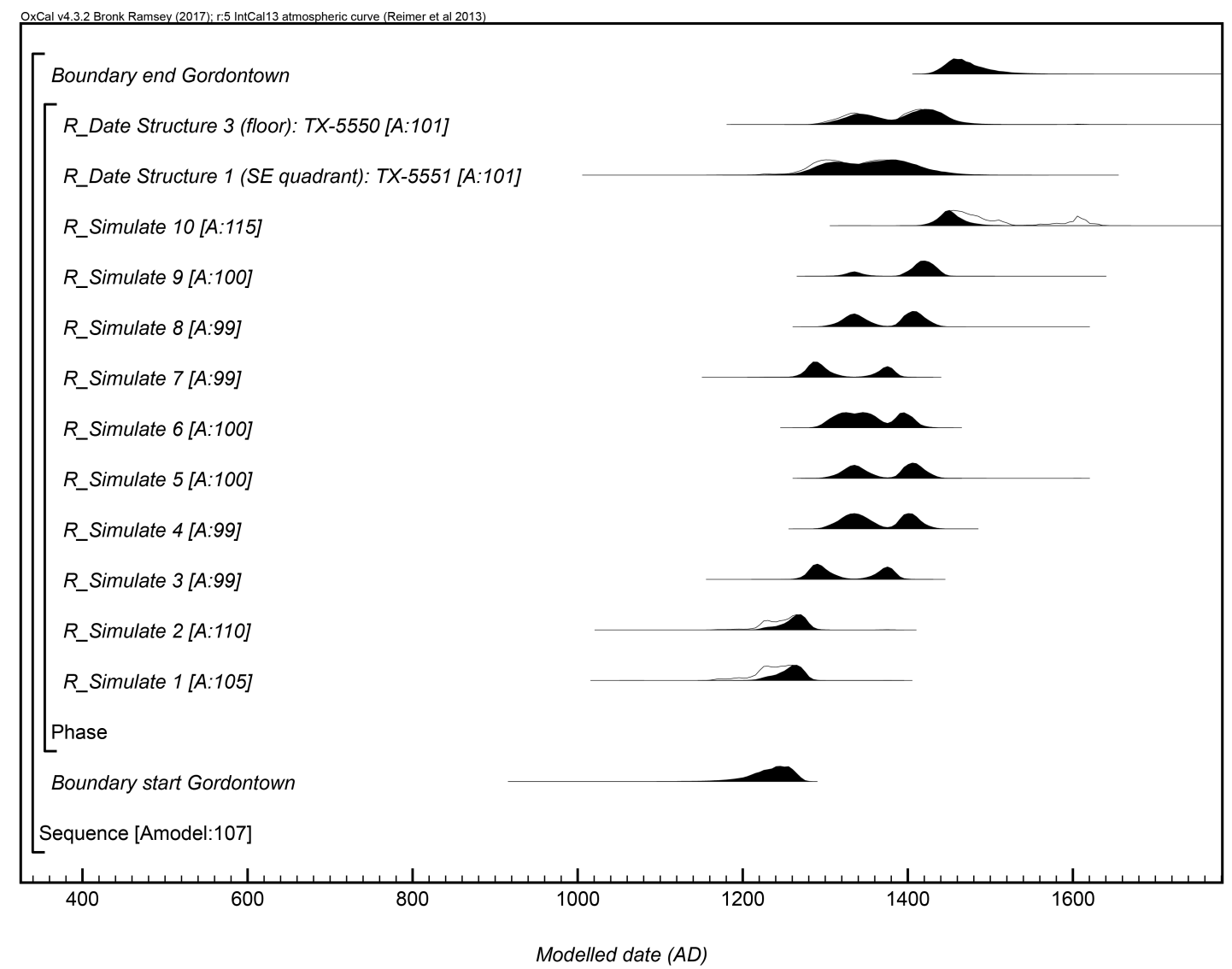

Figure D.7. Results and structure of the chronological model for Gordontown with the minimum number of simulated radiocarbon dates needed to achieve the desired precision at $68 \%$ probability for the posterior probabilities of the starting and ending boundaries for site activity. The brackets and keywords define the model structure. The format is as described in Figure B.1. 


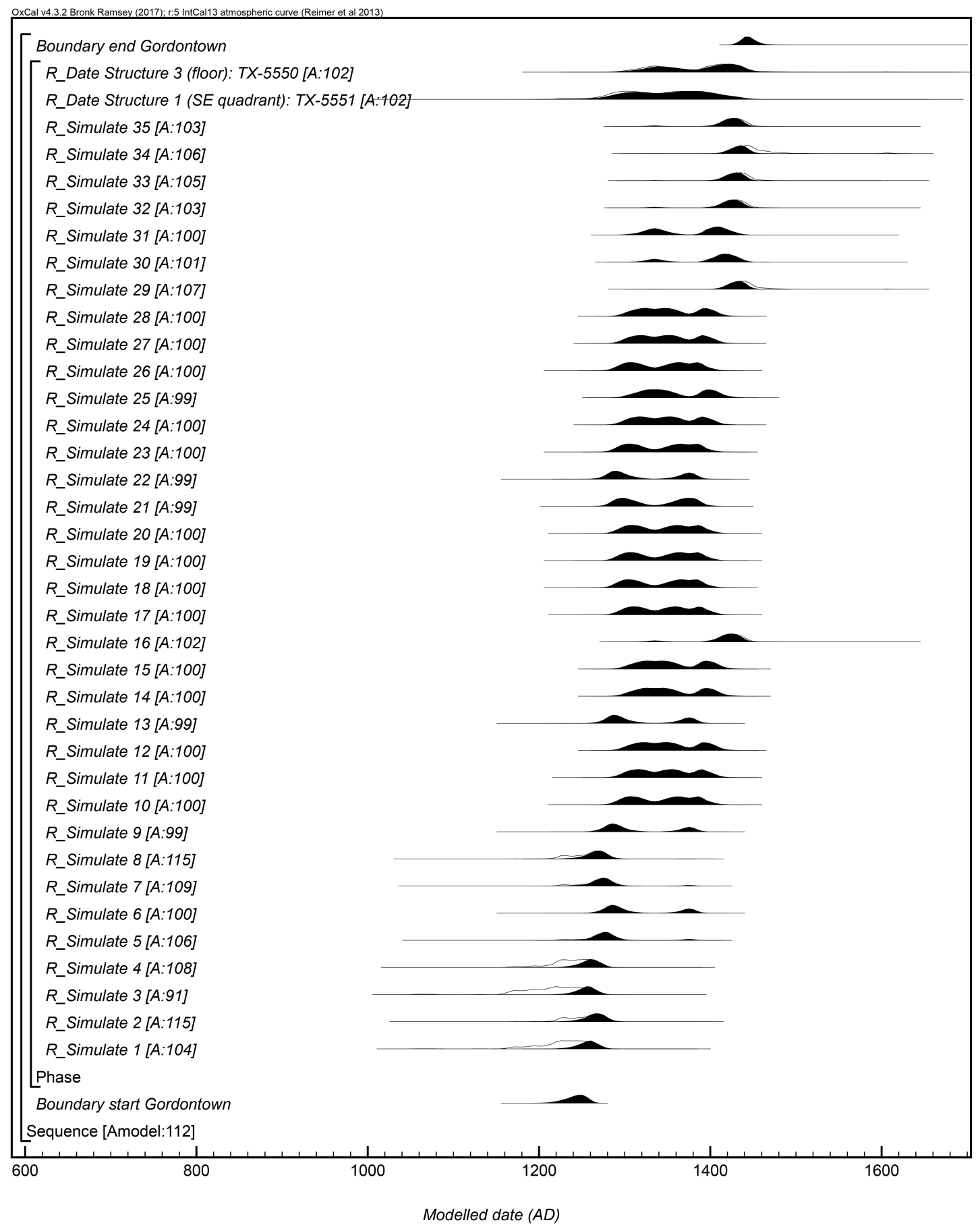

Figure D.8. Results and structure of the chronological model for Gordontown with the minimum number of simulated radiocarbon dates needed to achieve the desired precision at $95 \%$ probability for the posterior probabilities of the starting and ending boundaries for site activity. The brackets and keywords define the model structure.

The format is as described in Figure B.1. 


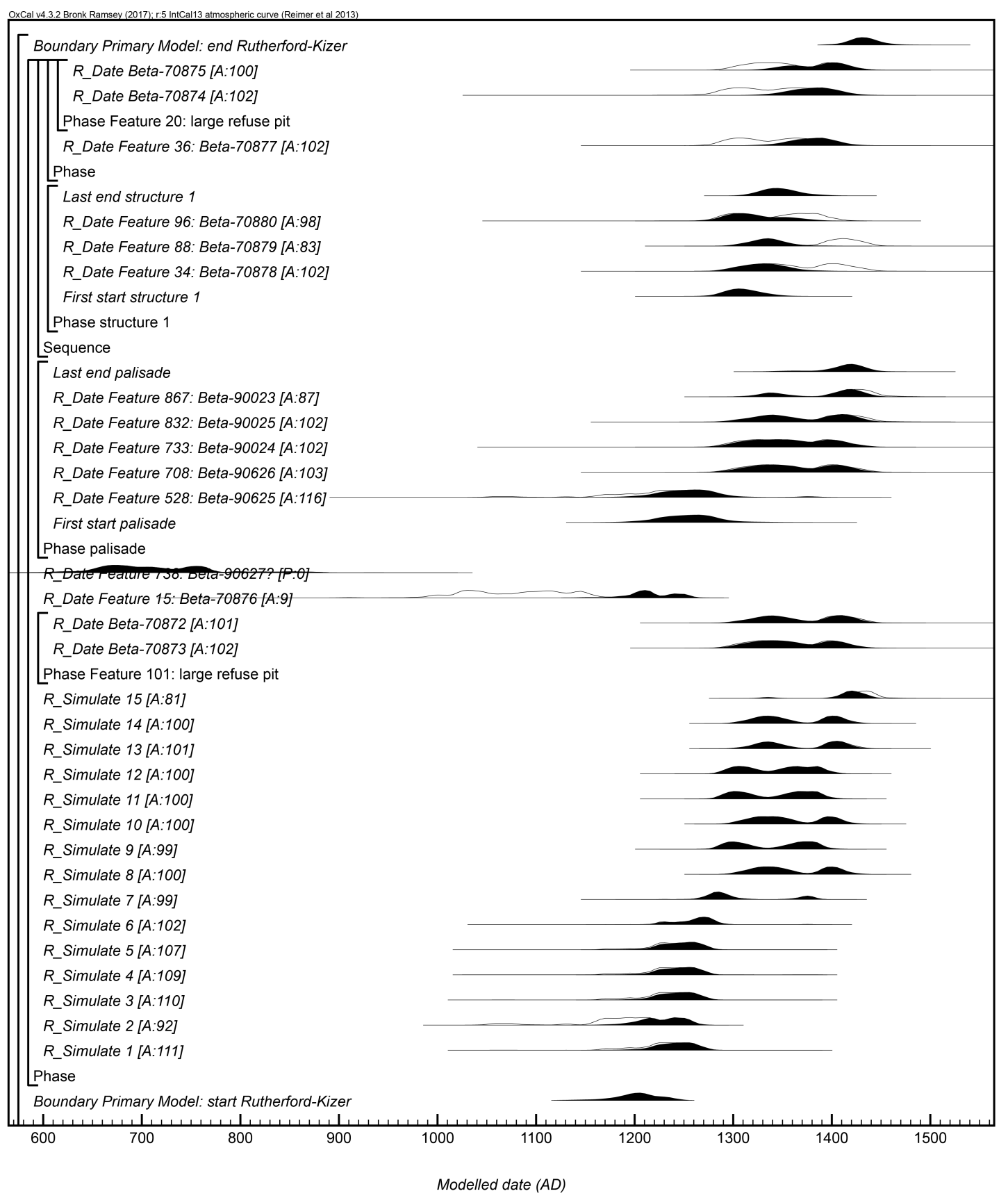

Figure D.9. Results and structure of the primary chronological model for RutherfordKizer with the minimum number of simulated radiocarbon dates needed to achieve the desired precision at $68 \%$ probability for the posterior probabilities of the starting and ending boundaries for site activity. The brackets and keywords define the model structure. The format is as described in Figure B.1. 


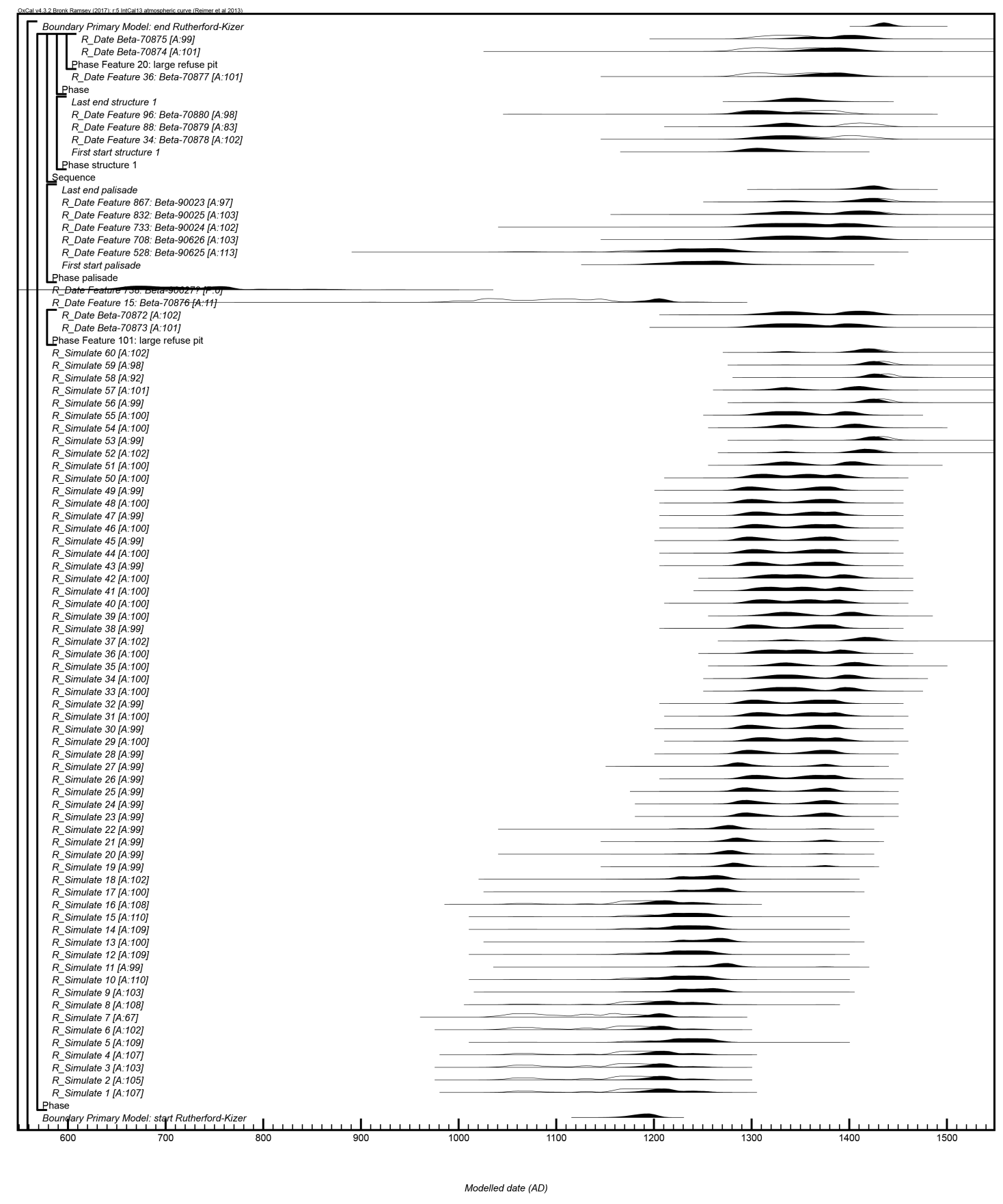

Figure D.10. Results and structure of the primary chronological model for Rutherford-

Kizer with the minimum number of simulated radiocarbon dates needed to achieve the desired precision at $95 \%$ probability for the posterior probabilities of the starting and ending boundaries for site activity. The brackets and keywords define the model structure. The format is as described in Figure B.1. 


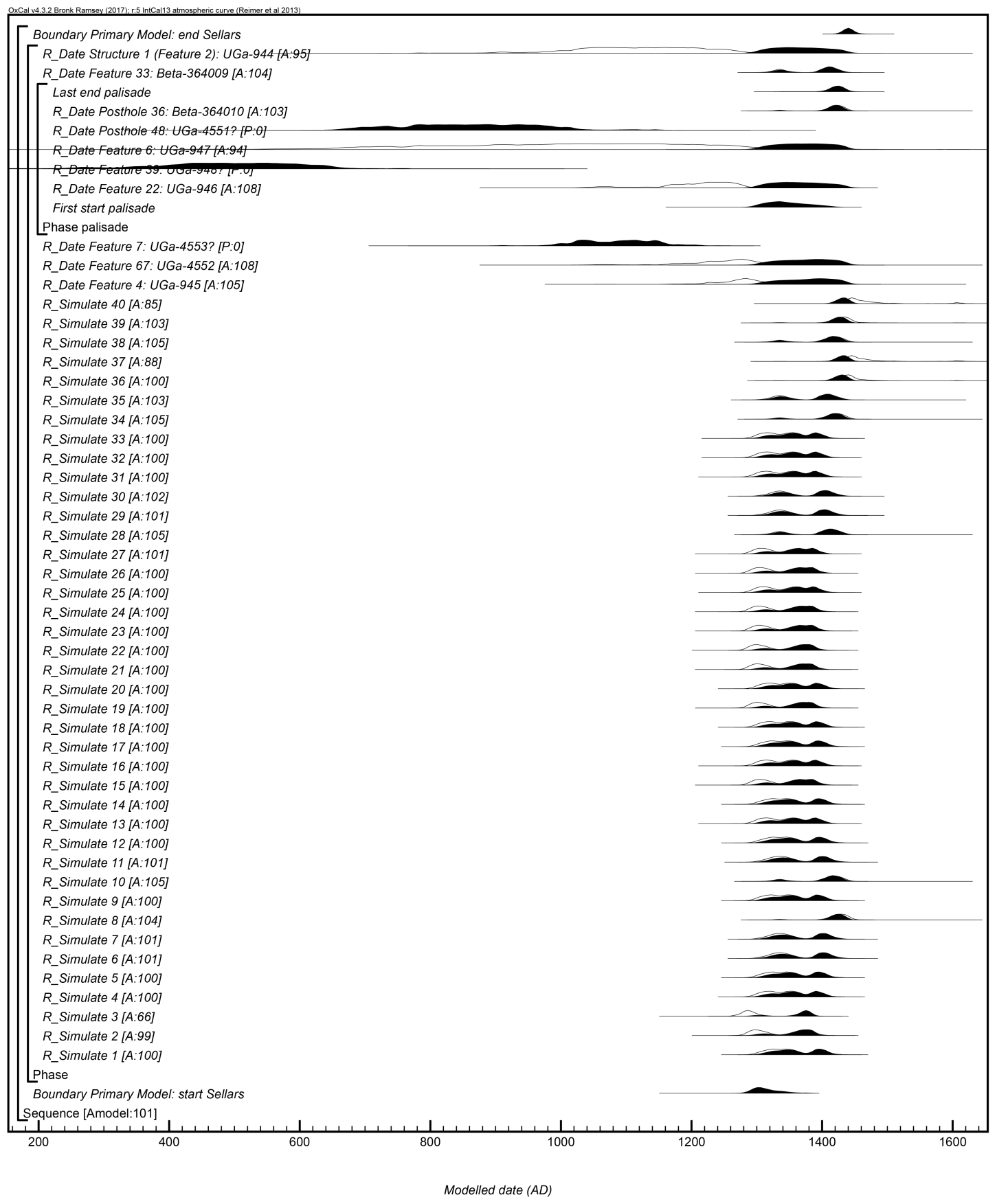

Figure D.11. Results and structure of the primary chronological model for Sellars with the minimum number of simulated radiocarbon dates needed to achieve the desired precision at $68 \%$ probability for the posterior probabilities of the starting and ending boundaries for site activity. The brackets and keywords define the model structure. The format is as described in Figure B.1. 


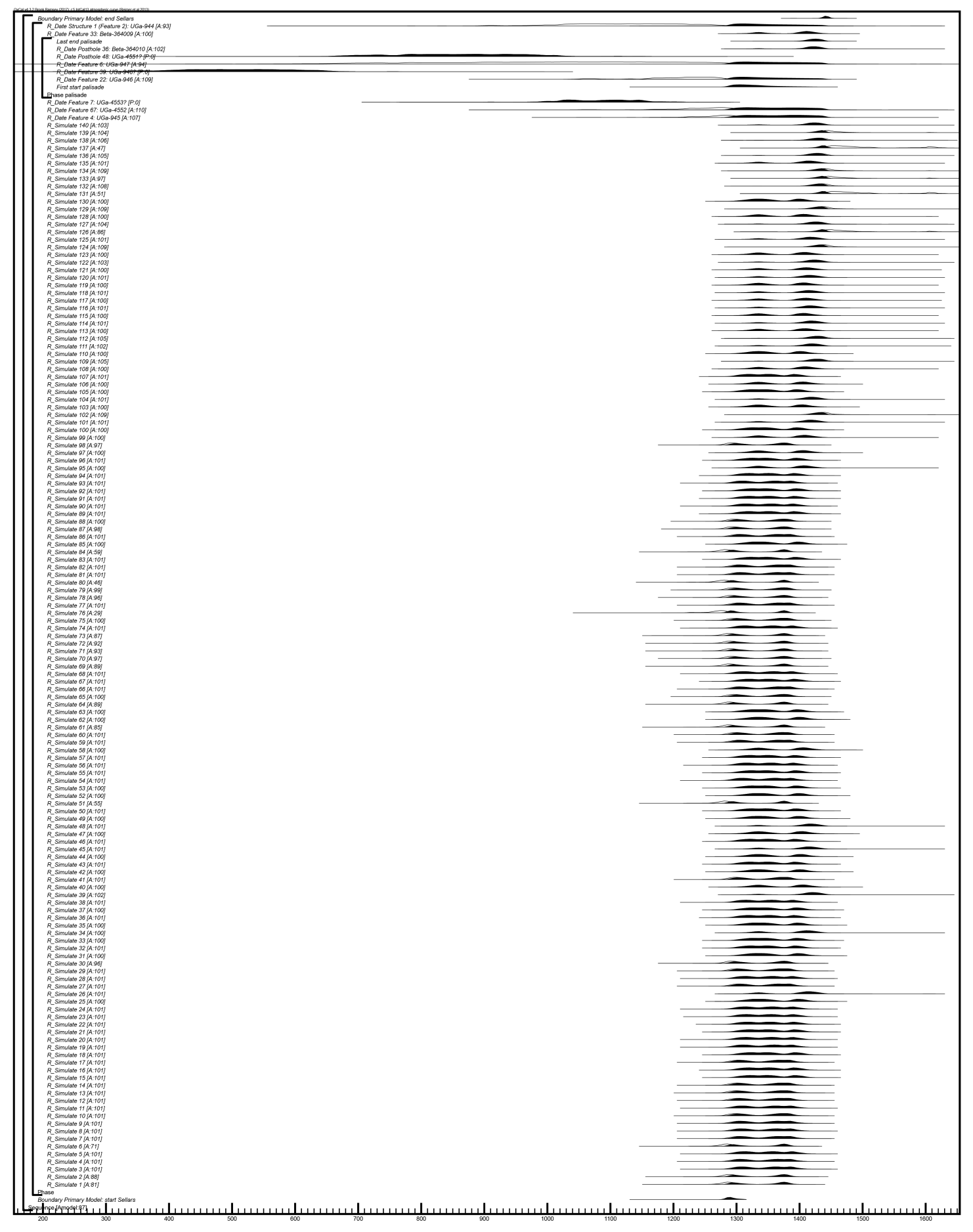

Figure D.12. Results and structure of the primary chronological model for Sellars with the minimum number of simulated radiocarbon dates needed to achieve the desired precision at $95 \%$ probability for the posterior probabilities of the starting and ending boundaries for site activity. The brackets and keywords define the model structure. The format is as described in Figure B.1. 


\section{Appendix E. Code for OxCal models}

Averbuch (40DV60) (primary model)

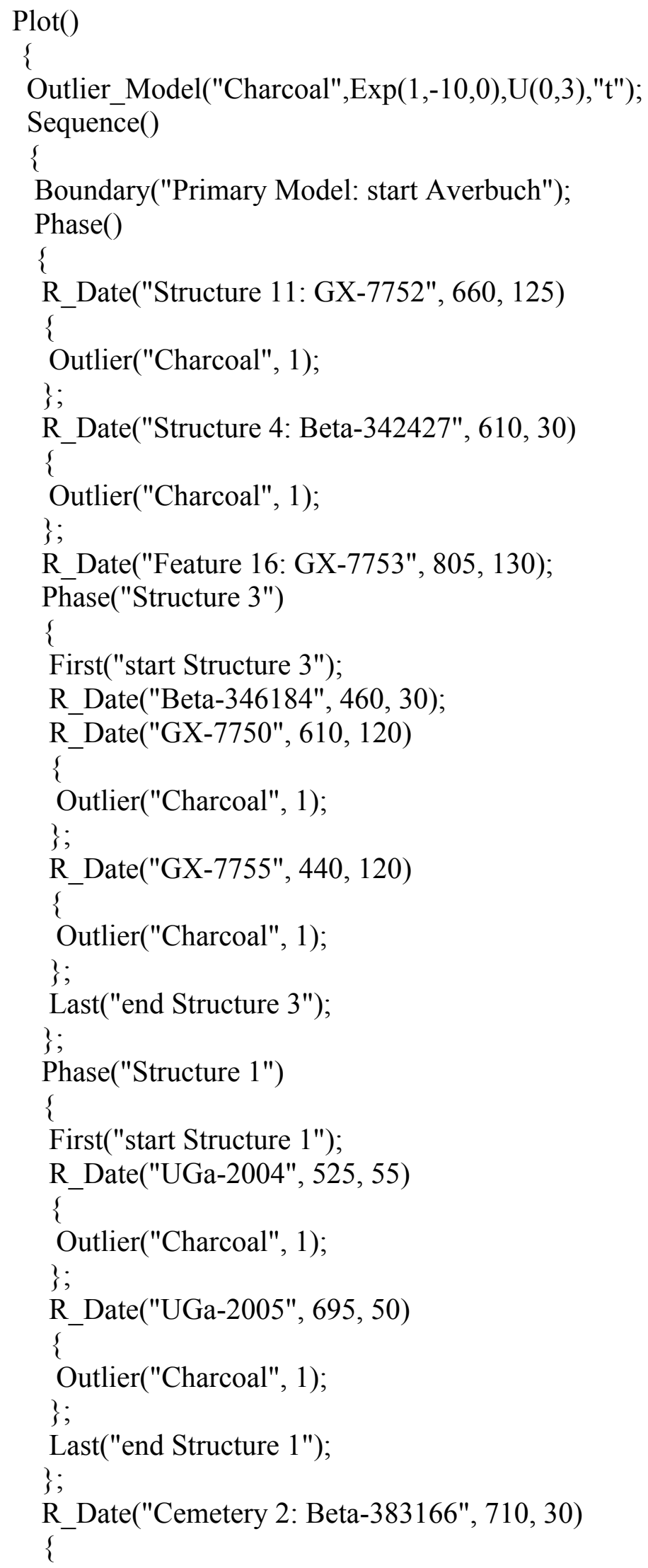




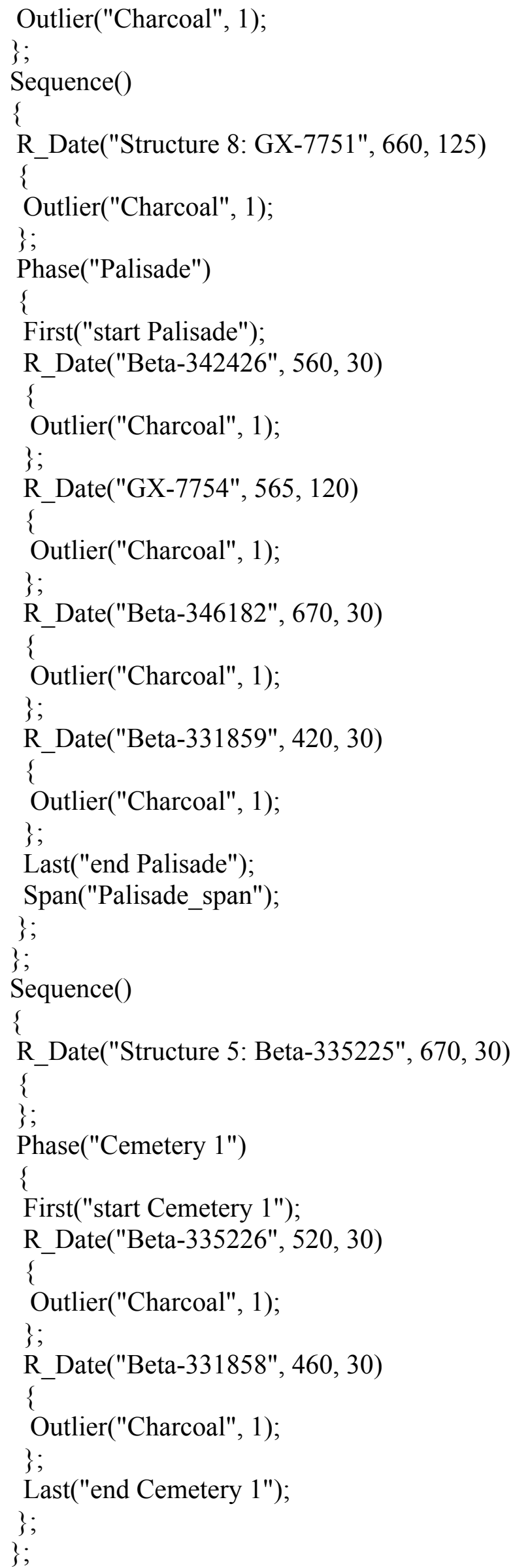


R_Date("Structure 15: Beta-342425", 480, 30);

;

Boundary("Primary Model: end Averbuch");

Span("Primary Model: span Averbuch");

;

\} 


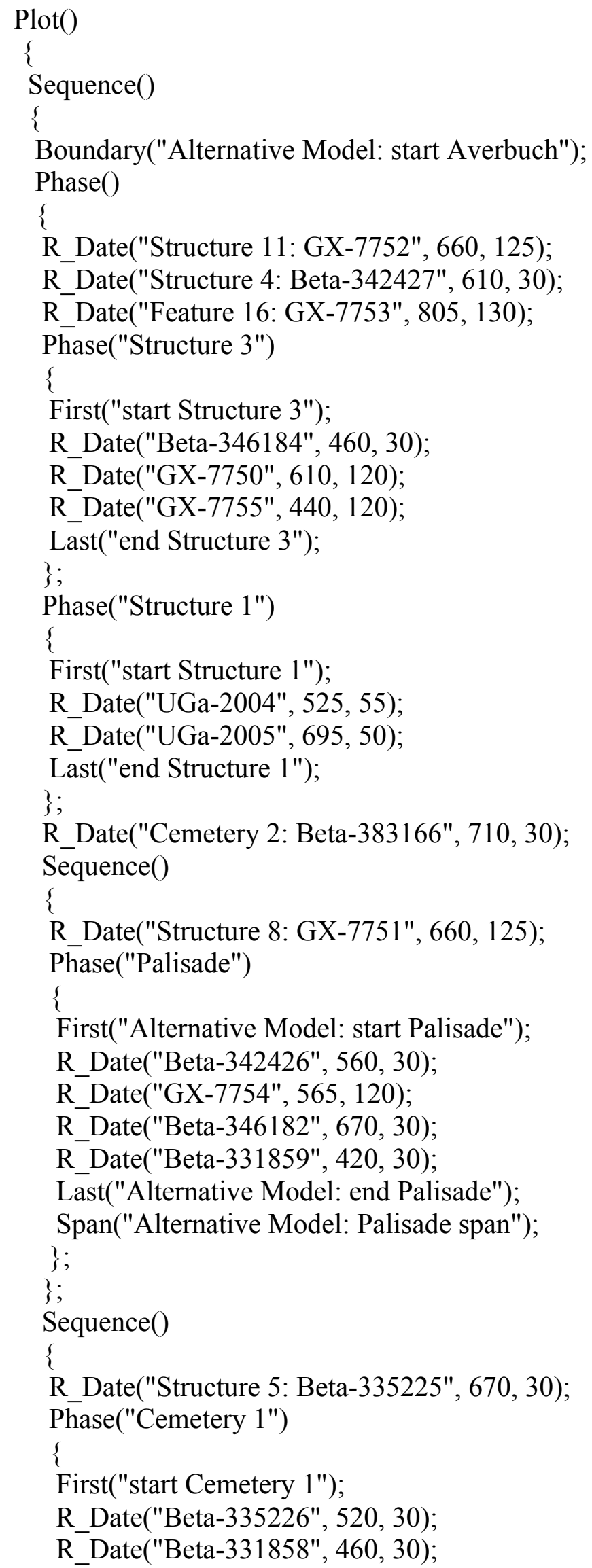


Last("end Cemetery 1");

\}

; ;

R_Date("Structure 15: Beta-342425", 480, 30);

;

Boundary("Alternative Model: end Averbuch");

Span("Alternative Model: span Averbuch");

\} ;

\} 
Averbuch (40DV60) (primary model with minimum number of simulated dates needed to achieve the desired result in the simulation experiment at $68 \%$ probability)

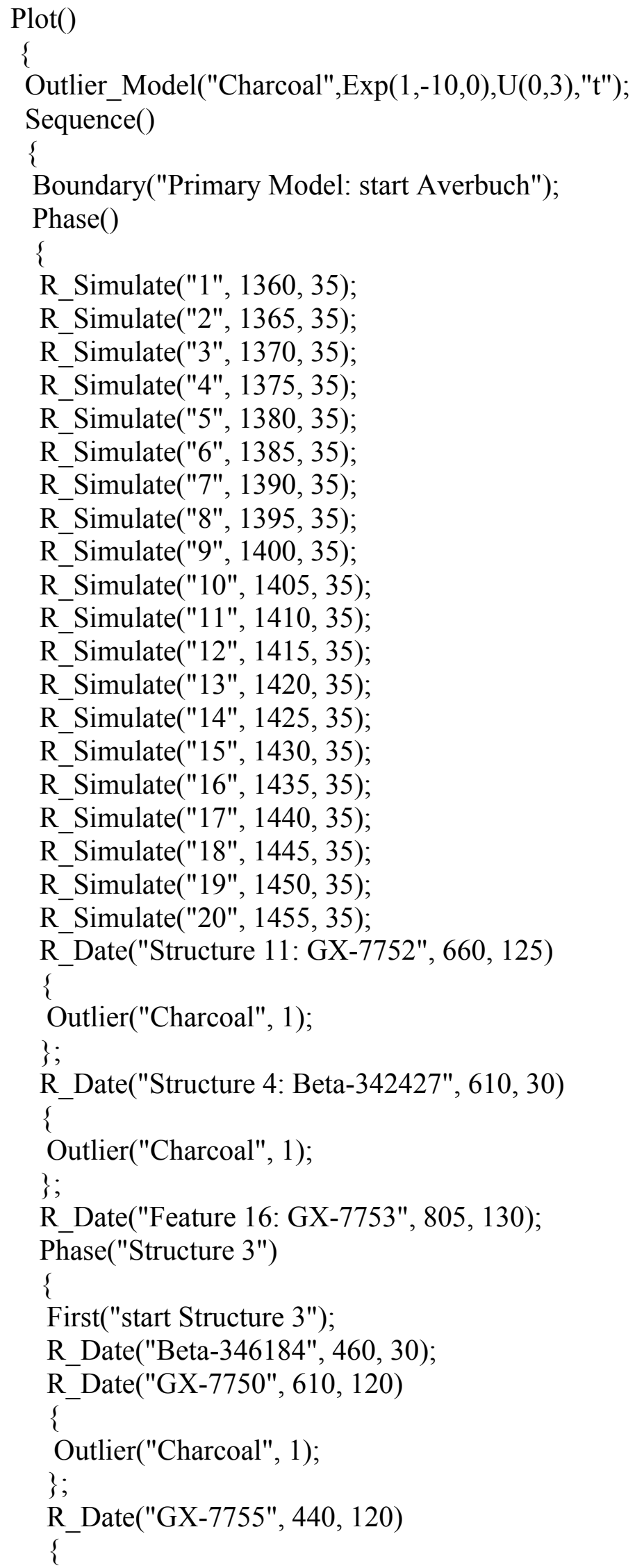




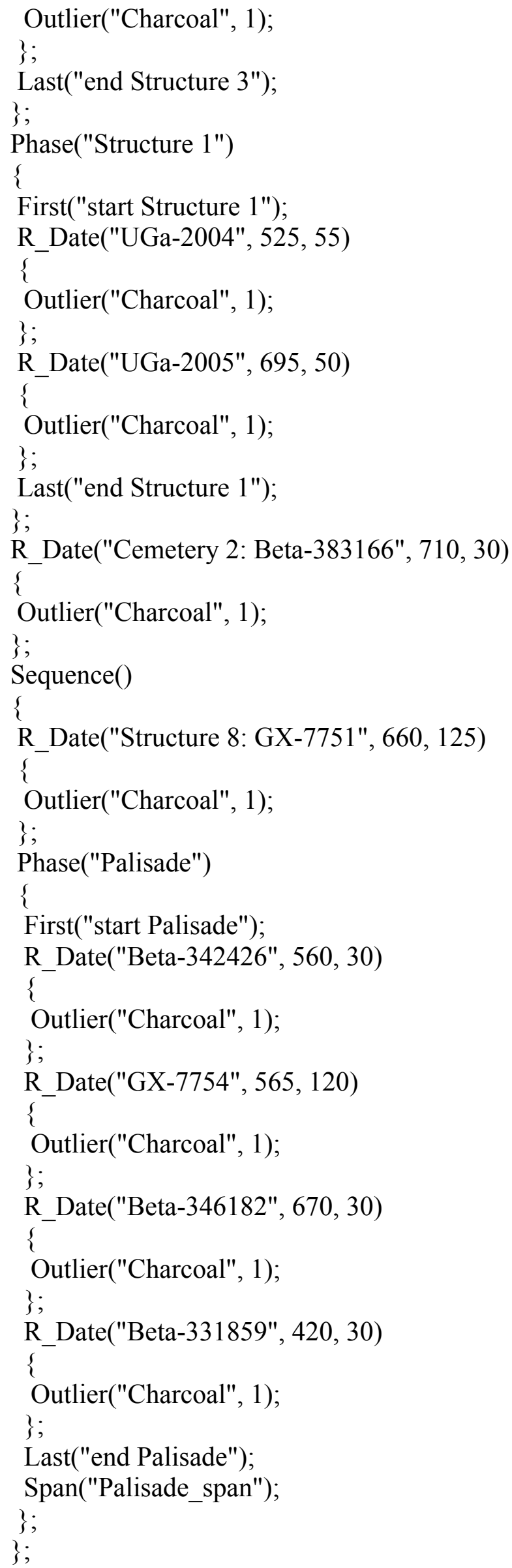




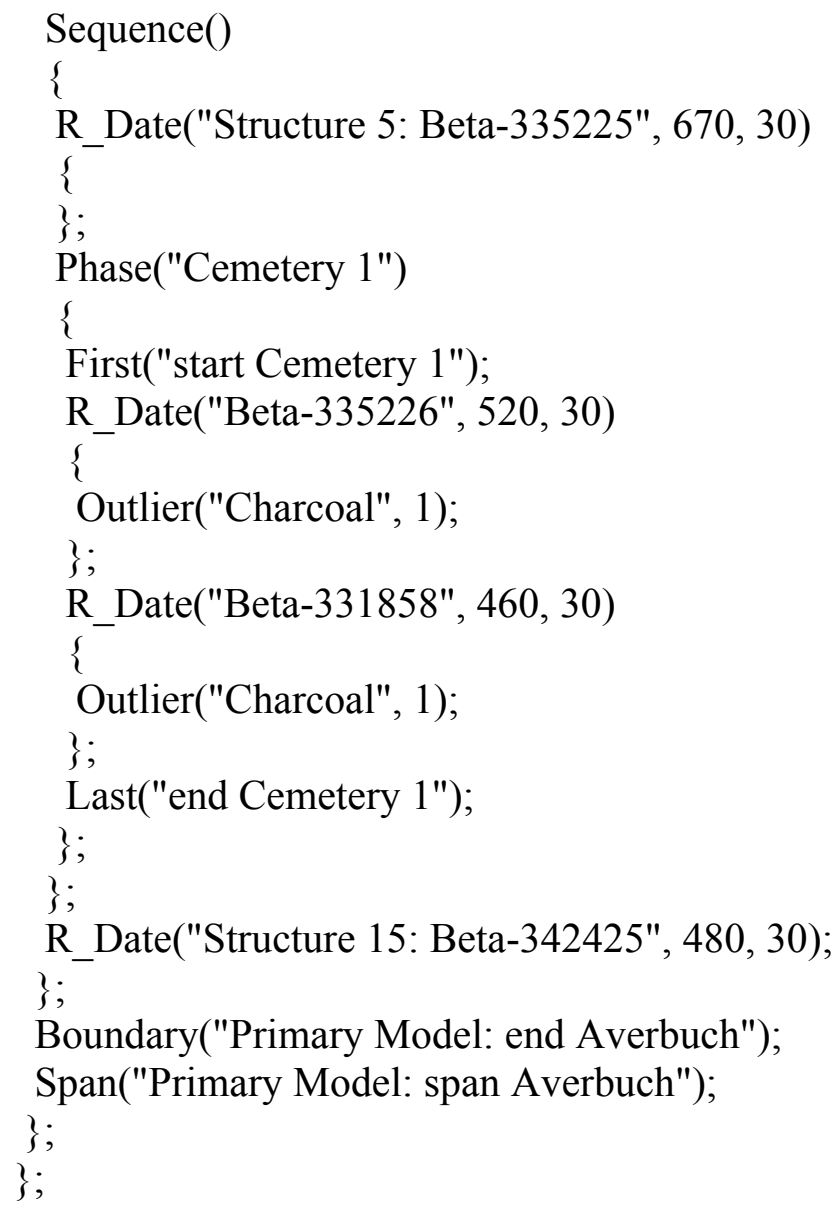


Averbuch (40DV60) (primary model with minimum number of simulated dates needed to achieve the desired result in the simulation experiment at 95\% probability)

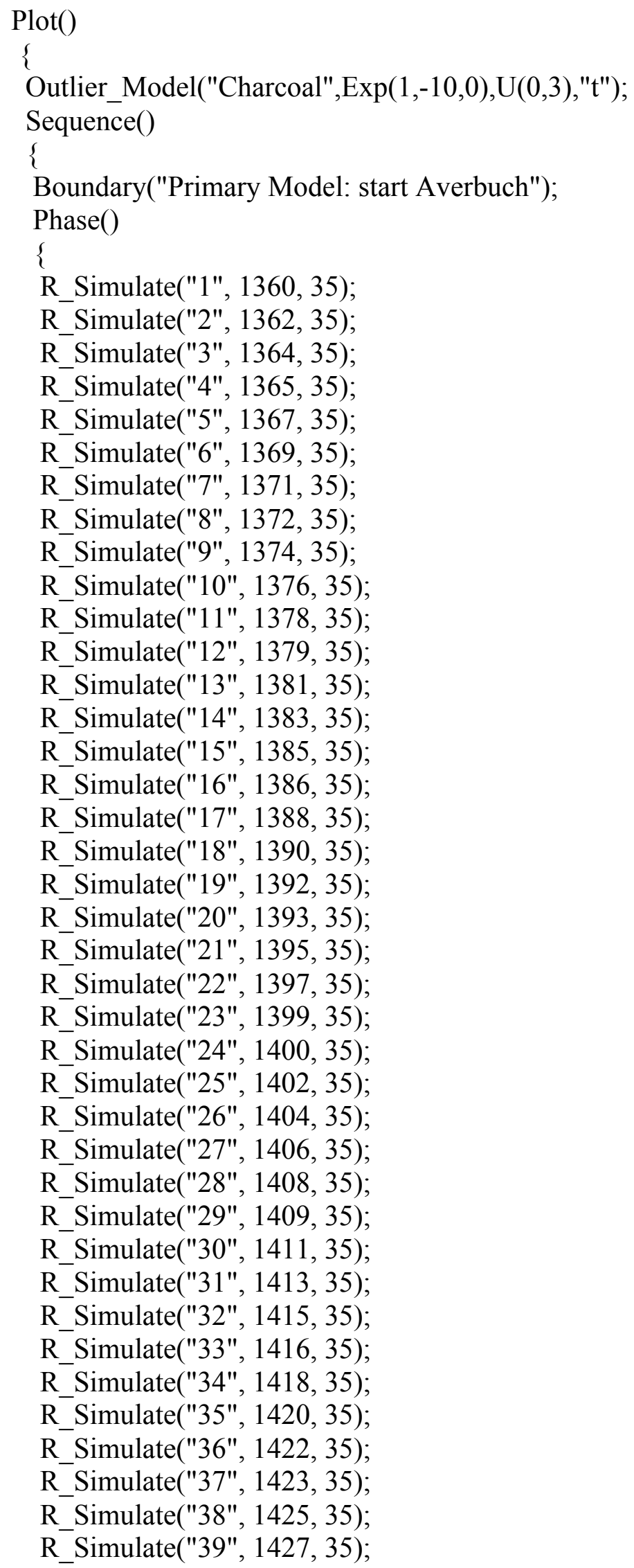


R_Simulate("40", 1429, 35);

R_Simulate("41", 1430, 35);

R_Simulate("42", 1432, 35);

R_Simulate("43", 1434, 35);

R_Simulate("44", 1436, 35);

R_Simulate("45", 1437, 35);

R_Simulate("46", 1439, 35);

R_Simulate("47", 1441, 35);

R_Simulate("48", 1443, 35);

R_Simulate("49", 1444, 35);

R_Simulate("50", 1446, 35);

R_Simulate("51", 1448, 35);

R_Simulate("52", 1450, 35);

R_Simulate("53", 1451, 35);

R_Simulate("54", 1453, 35);

R_Simulate("55", 1455, 35);

R_Date("Structure 11: GX-7752", 660, 125)

\{

Outlier("Charcoal", 1);

\};

R_Date("Structure 4: Beta-342427", 610, 30)

\{

Outlier("Charcoal", 1);

; ;

R_Date("Feature 16: GX-7753", 805, 130);

Phase("Structure 3")

\{

First("start Structure 3");

R_Date("Beta-346184", 460, 30);

R_Date("GX-7750", 610, 120)

\{

Outlier("Charcoal", 1);

; ;

R_Date("GX-7755", 440, 120)

\{

Outlier("Charcoal", 1);

\};

Last("end Structure 3");

; ;

Phase("Structure 1")

\{

First("start Structure 1");

R_Date("UGa-2004", 525, 55)

\{

Outlier("Charcoal", 1);

;

R_Date("UGa-2005", 695, 50)

\{

Outlier("Charcoal", 1);

\} 


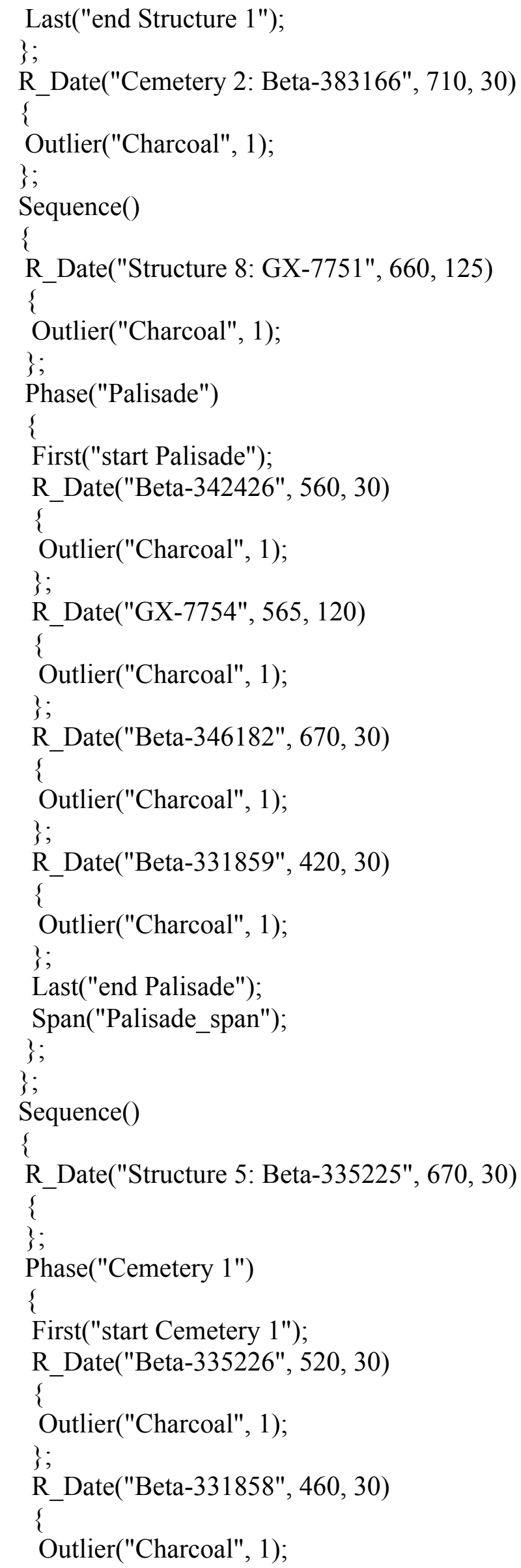


\}

Last("end Cemetery 1");

\}

;

R_Date("Structure 15: Beta-342425", 480, 30);

\}

Boundary("Primary Model: end Averbuch");

Span("Primary Model: span Averbuch");

\}

\} 


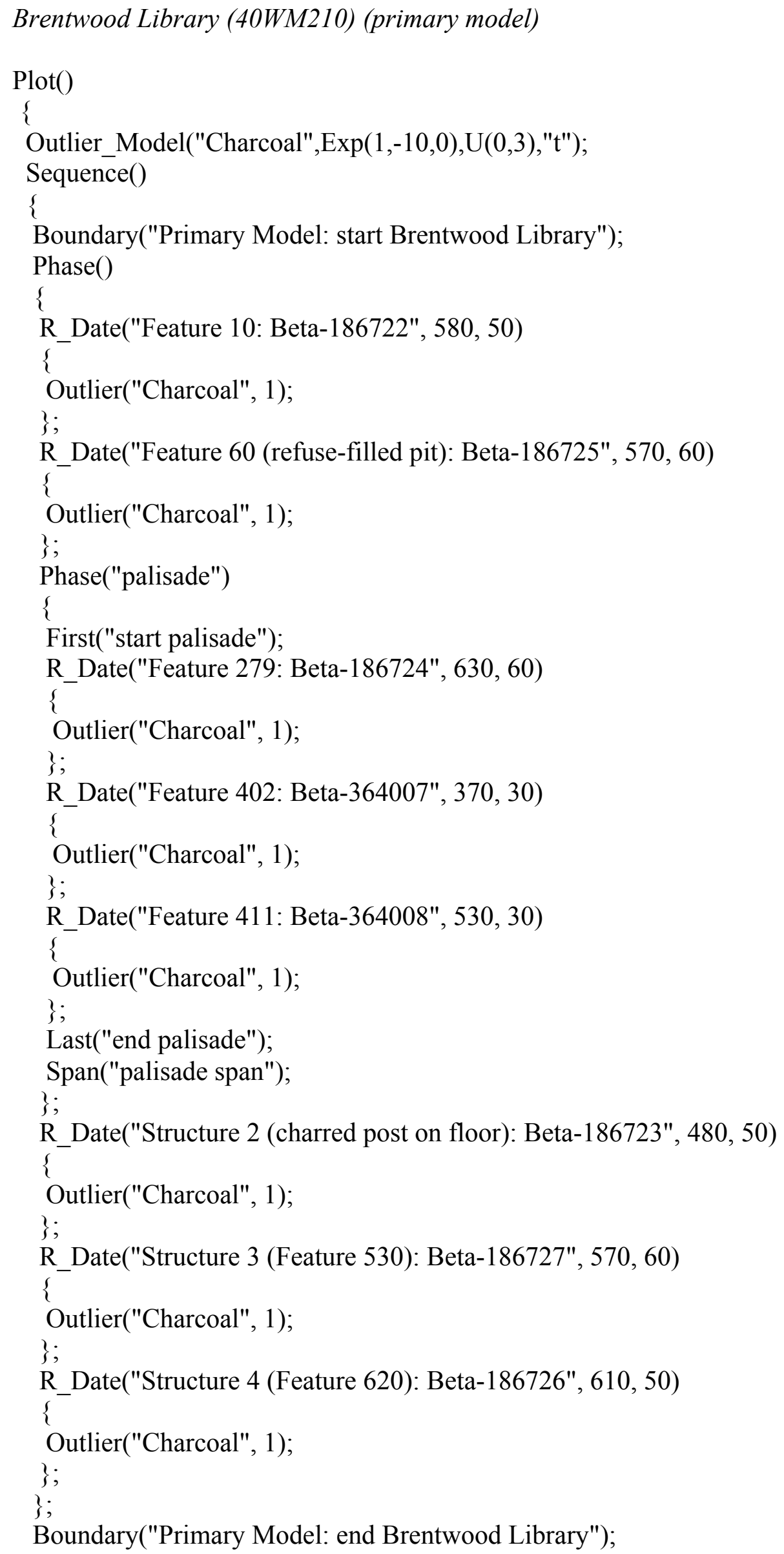


Span("Primary Model: Brentwood Library span");

;

\} 


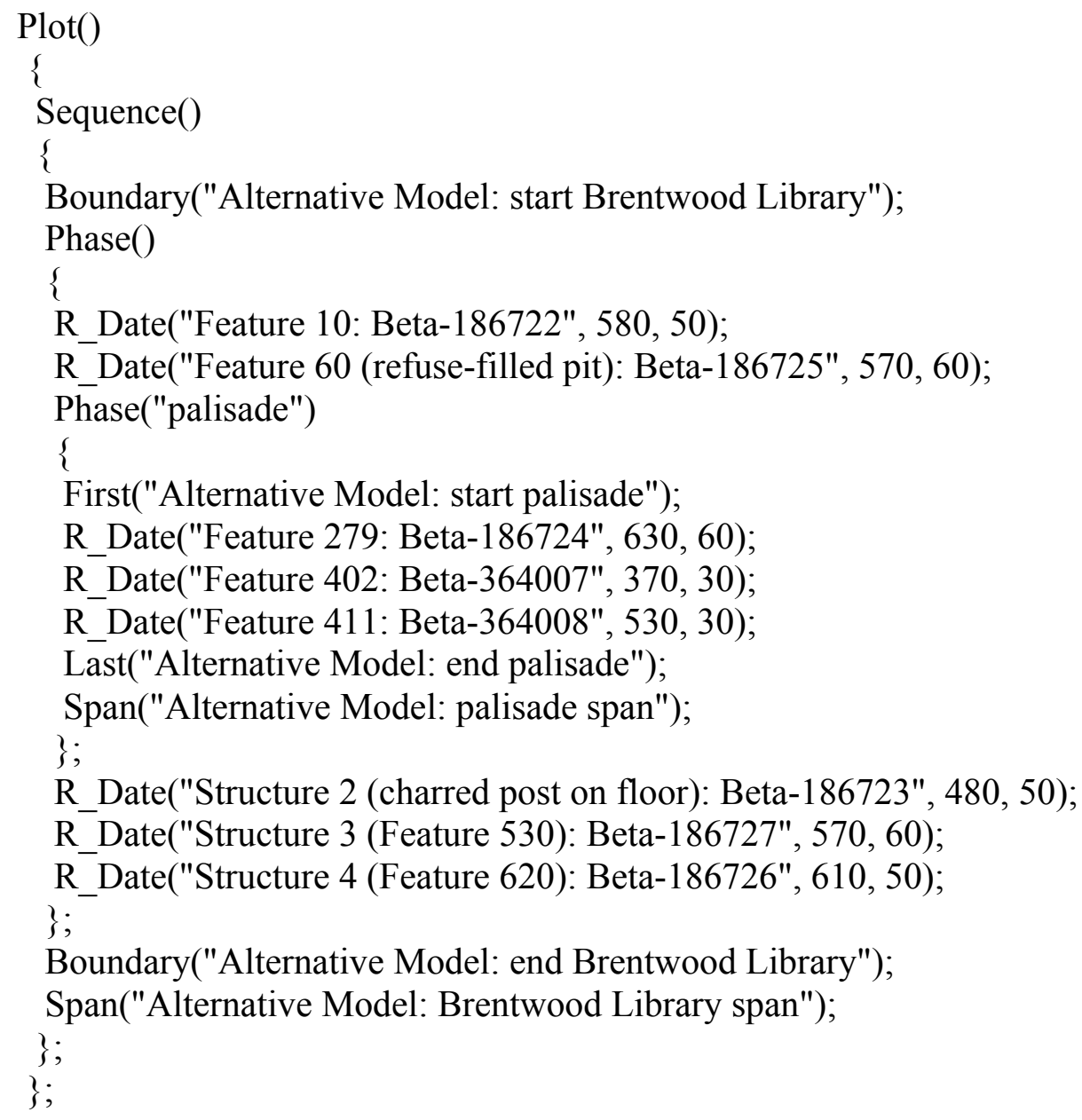


Brentwood Library (40WM210) (primary model with minimum number of simulated dates needed to achieve the desired result in the simulation experiment at $68 \%$ probability)

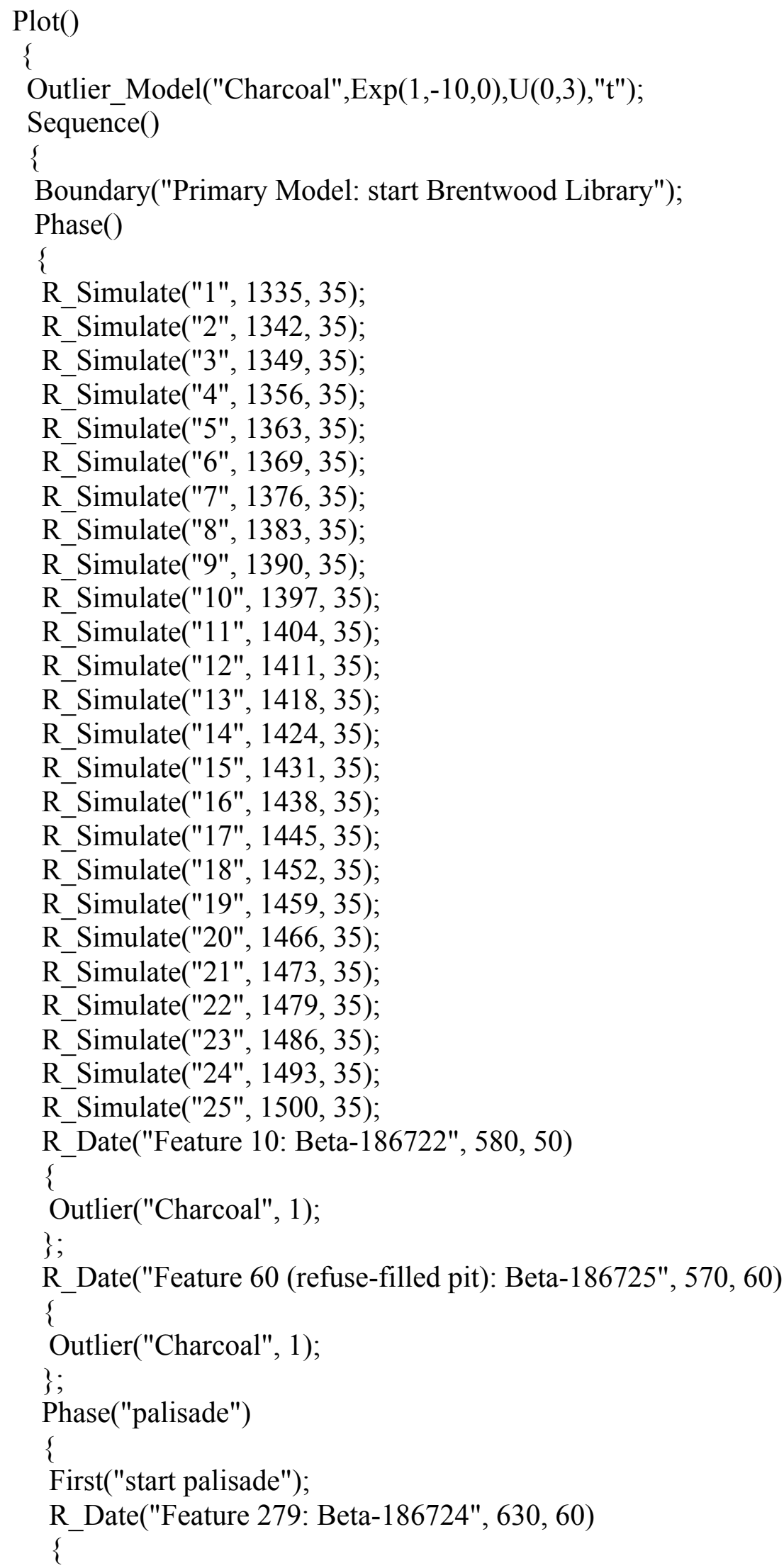




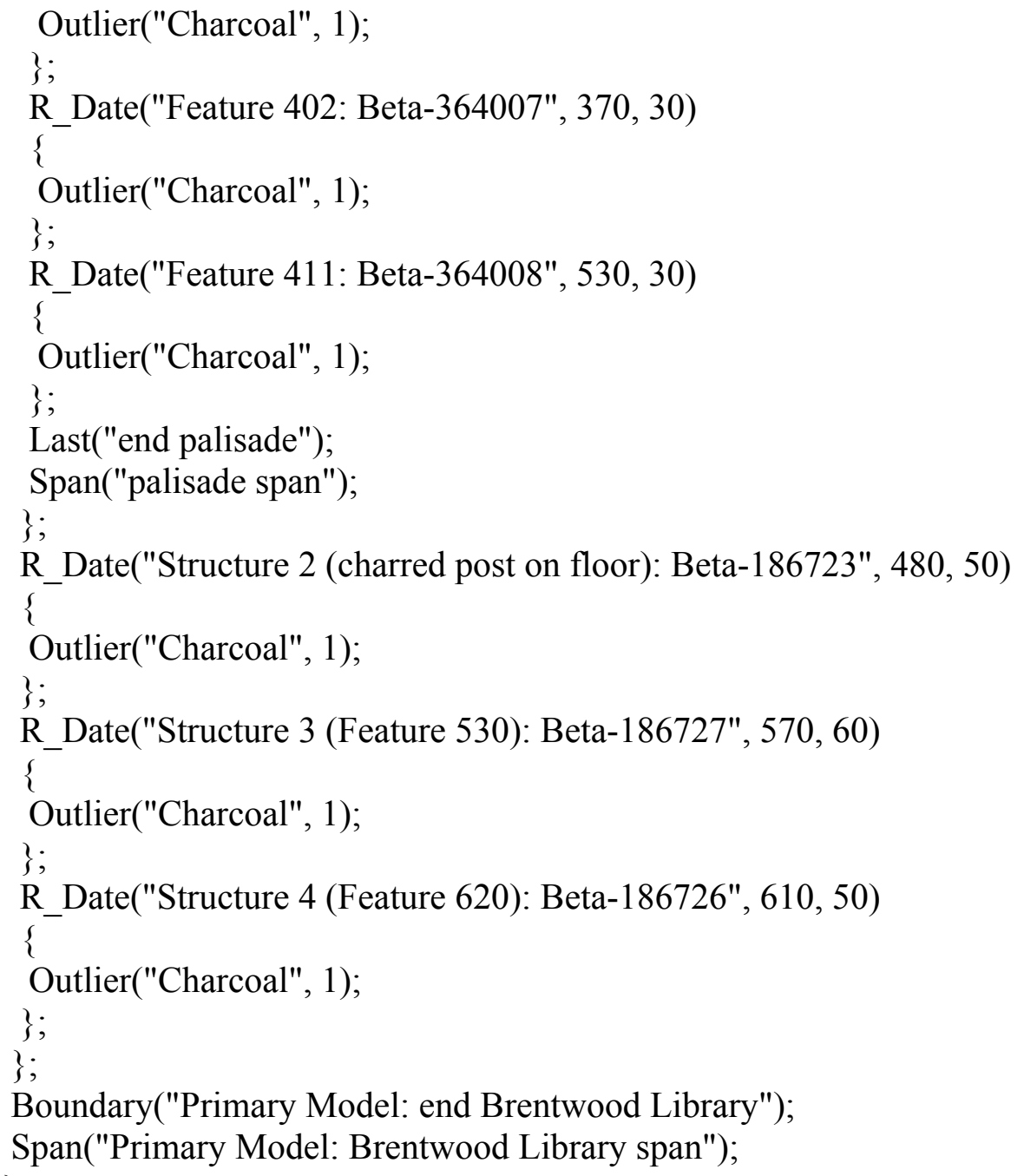


Brentwood Library (40WM210) (primary model with minimum number of simulated dates needed to achieve the desired result in the simulation experiment at 95\% probability)

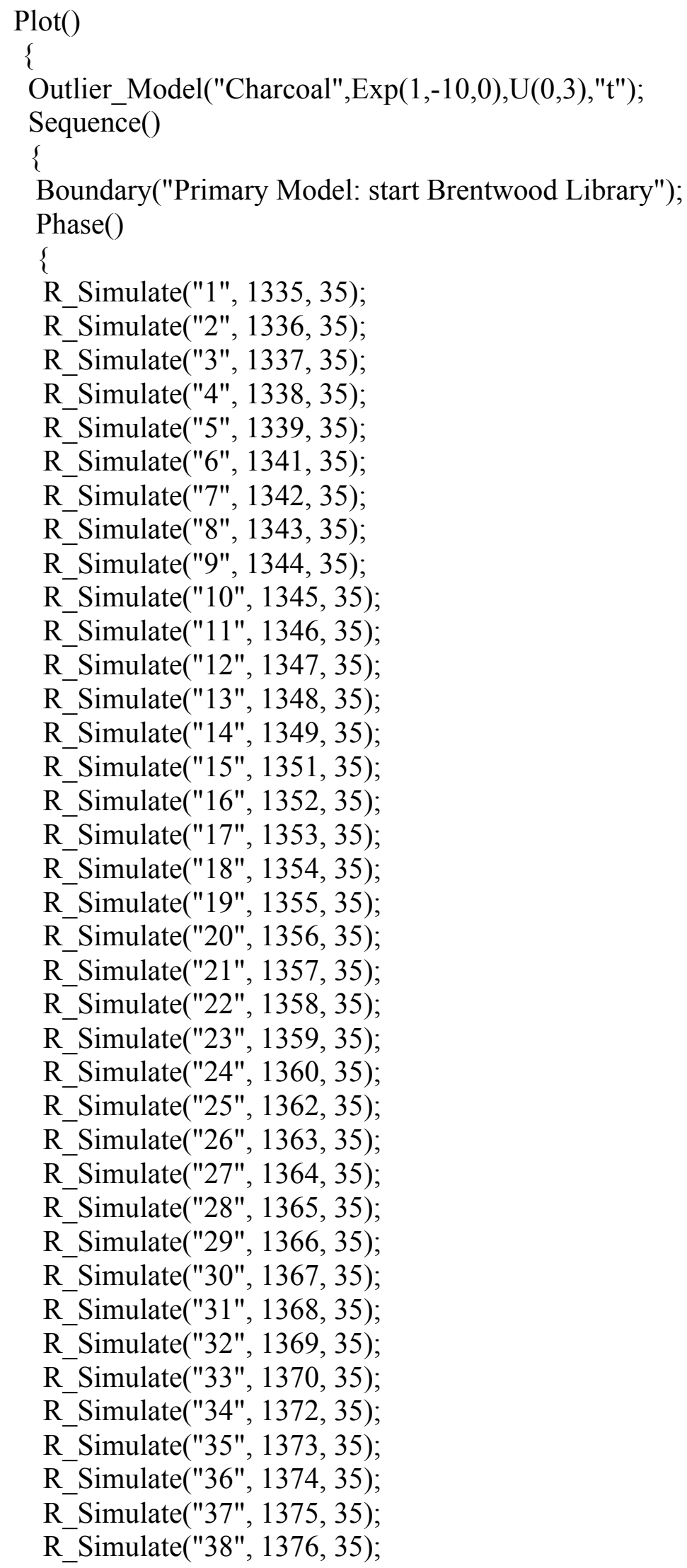


R_Simulate("39", 1377, 35);

R_Simulate("40", 1378, 35);

R_Simulate("41", 1379, 35);

R_Simulate("42", 1380, 35);

R_Simulate("43", 1382, 35);

R_Simulate("44", 1383, 35);

R_Simulate("45", 1384, 35);

R_Simulate("46", 1385, 35);

R_Simulate("47", 1386, 35);

R_Simulate("48", 1387, 35);

R_Simulate("49", 1388, 35);

R_Simulate("50", 1389, 35);

R_Simulate("51", 1390, 35);

R_Simulate("52", 1391, 35);

R_Simulate("53", 1393, 35);

R_Simulate("54", 1394, 35);

R_Simulate("55", 1395, 35);

R_Simulate("56", 1396, 35);

R_Simulate("57", 1397, 35);

R_Simulate("58", 1398, 35);

R_Simulate("59", 1399, 35);

R_Simulate("60", 1400, 35);

R_Simulate("61", 1401, 35);

R_Simulate("62", 1403, 35);

R_Simulate("63", 1404, 35);

R_Simulate("64", 1405, 35);

R_Simulate("65", 1406, 35);

R_Simulate("66", 1407, 35);

R_Simulate("67", 1408, 35);

R_Simulate("68", 1409, 35);

R_Simulate("69", 1410, 35);

R_Simulate("70", 1411, 35);

R_Simulate("71", 1413, 35);

R_Simulate("72", 1414, 35);

R_Simulate("73", 1415, 35);

R_Simulate("74", 1416, 35);

R_Simulate("75", 1417, 35);

R_Simulate("76", 1418, 35);

R_Simulate("77", 1419, 35);

R_Simulate("78", 1420, 35);

R_Simulate("79", 1421, 35);

R_Simulate("80", 1422, 35);

R_Simulate("81", 1424, 35);

R_Simulate("82", 1425, 35);

R_Simulate("83", 1426, 35);

R_Simulate("84", 1427, 35);

R_Simulate("85", 1428, 35);

R_Simulate("86", 1429, 35);

R_Simulate("87", 1430, 35);

R_Simulate("88", 1431, 35); 
R_Simulate("89", 1432, 35);

R_Simulate("90", 1434, 35);

R_Simulate("91", 1435, 35);

R_Simulate("92", 1436, 35);

R_Simulate("93", 1437, 35);

R_Simulate("94", 1438, 35);

R_Simulate("95", 1439, 35);

R_Simulate("96", 1440, 35);

R_Simulate("97", 1441, 35);

R_Simulate("98", 1442, 35);

R_Simulate("99", 1444, 35);

R_Simulate("100", 1445, 35);

R_Simulate("101", 1446, 35);

R_Simulate("102", 1447, 35);

R_Simulate("103", 1448, 35);

R_Simulate("104", 1449, 35);

R_Simulate("105", 1450, 35);

R_Simulate("106", 1451, 35);

R_Simulate("107", 1452, 35);

R_Simulate("108", 1453, 35);

R_Simulate("109", 1455, 35);

R_Simulate("110", 1456, 35);

R_Simulate("111", 1457, 35);

R_Simulate("112", 1458, 35);

R_Simulate("113", 1459, 35);

R_Simulate("114", 1460, 35);

R_Simulate("115", 1461, 35);

R_Simulate("116", 1462, 35);

R_Simulate("117", 1463, 35);

R_Simulate("118", 1465, 35);

R_Simulate("119", 1466, 35);

R_Simulate("120", 1467, 35);

R_Simulate("121", 1468, 35);

R_Simulate("122", 1469, 35);

R_Simulate("123", 1470, 35);

R_Simulate("124", 1471, 35);

R_Simulate("125", 1472, 35);

R_Simulate("126", 1473, 35);

R_Simulate("127", 1475, 35);

R_Simulate("128", 1476, 35);

R_Simulate("129", 1477, 35);

R_Simulate("130", 1478, 35);

R_Simulate("131", 1479, 35);

R_Simulate("132", 1480, 35);

R_Simulate("133", 1481, 35);

R_Simulate("134", 1482, 35);

R_Simulate("135", 1483, 35);

R_Simulate("136", 1484, 35);

R_Simulate("137", 1486, 35);

R_Simulate("138", 1487, 35); 
R_Simulate("139", 1488, 35);

R_Simulate("140", 1489, 35);

R_Simulate("141", 1490, 35);

R_Simulate("142", 1491, 35);

R_Simulate("143", 1492, 35);

R_Simulate("144", 1493, 35);

R Simulate("145", 1494, 35);

R_Simulate("146", 1496, 35);

R Simulate("147", 1497, 35);

R Simulate("148", 1498, 35);

R_Simulate("149", 1499, 35);

R_Simulate("150", 1500, 35);

R_Date("Feature 10: Beta-186722", 580, 50)

\{

Outlier("Charcoal", 1);

; ;

R_Date("Feature 60 (refuse-filled pit): Beta-186725", 570, 60)

\{

Outlier("Charcoal", 1);

;

Phase("palisade")

\{

First("start palisade");

R Date("Feature 279: Beta-186724", 630, 60)

\{

Outlier("Charcoal", 1);

\};

R_Date("Feature 402: Beta-364007", 370, 30)

\{

Outlier("Charcoal", 1);

\};

R_Date("Feature 411: Beta-364008", 530, 30)

\{

Outlier("Charcoal", 1);

; ;

Last("end palisade");

Span("palisade span");

;

R_Date("Structure 2 (charred post on floor): Beta-186723", 480, 50)

\{

Outlier("Charcoal", 1);

\} ;

R Date("Structure 3 (Feature 530): Beta-186727", 570, 60)

\{

Outlier("Charcoal", 1);

\} ;

R_Date("Structure 4 (Feature 620): Beta-186726", 610, 50)

\{

Outlier("Charcoal", 1);

; 
\}

Boundary("Primary Model: end Brentwood Library");

Span("Primary Model: Brentwood Library span");

;

\} 
East Nashville Mounds (40DV4) (primary model)

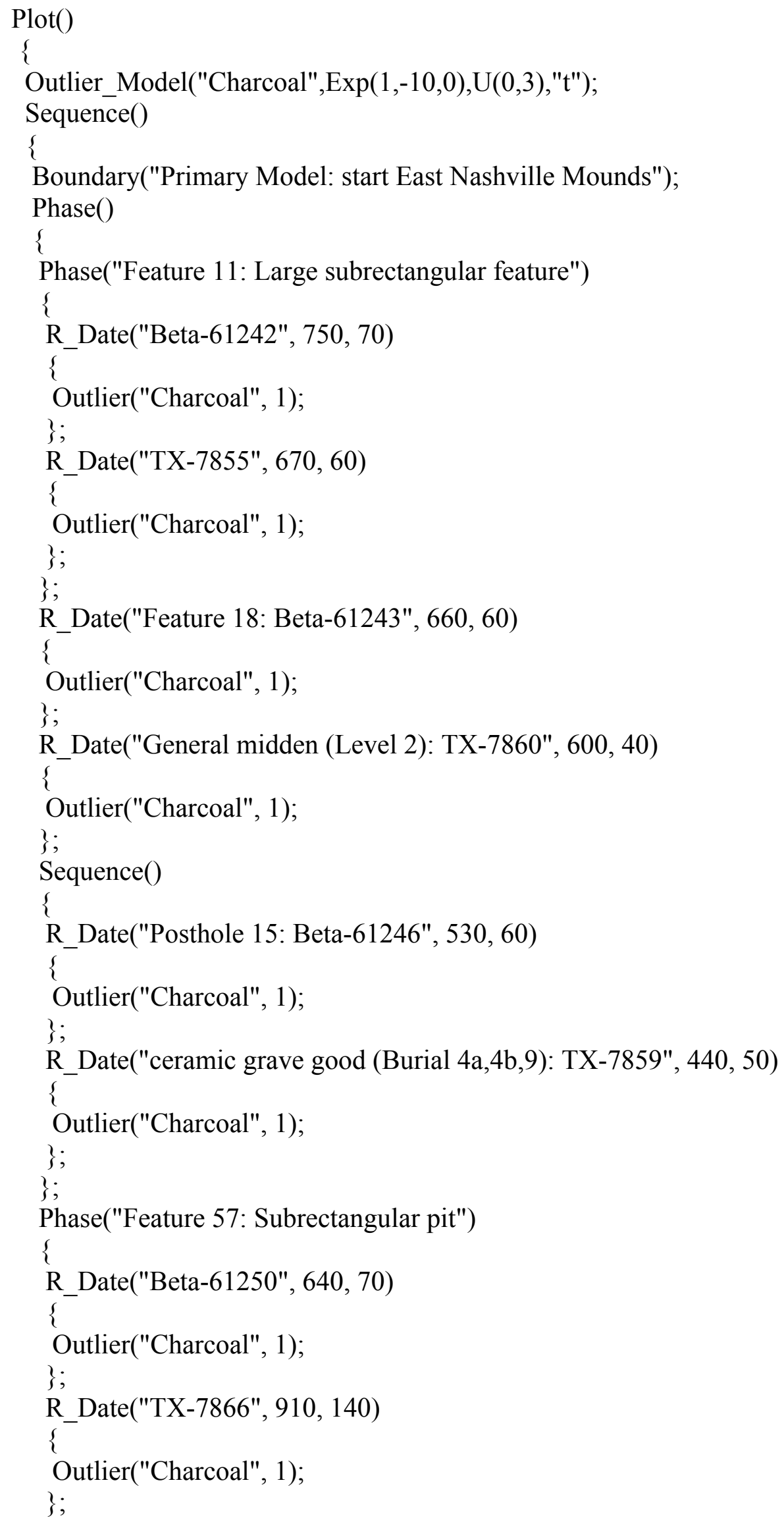


\} ;

R_Date("Possible house floor (Feature 36): TX-7856", 890, 100)

\{

Outlier("Charcoal", 1);

;

R_Date("Feature 37: TX-7857", 580, 50)

\{

Outlier("Charcoal", 1);

;

Phase("Feature 58: Subrectangular pit")

\{

R_Date("Beta-61245", 530, 50)

\{

Outlier("Charcoal", 1);

;

R_Date("TX-7858", 380, 50)

\{

Outlier("Charcoal", 1);

;

\}

R_Date("Feature 24: Beta-61244", 550, 50)

\{

Outlier("Charcoal", 1);

\};

\}

Boundary("Primary Model: end East Nashville Mounds");

Span("Primary Model: East Nashville Mounds span");

\} ;

; 


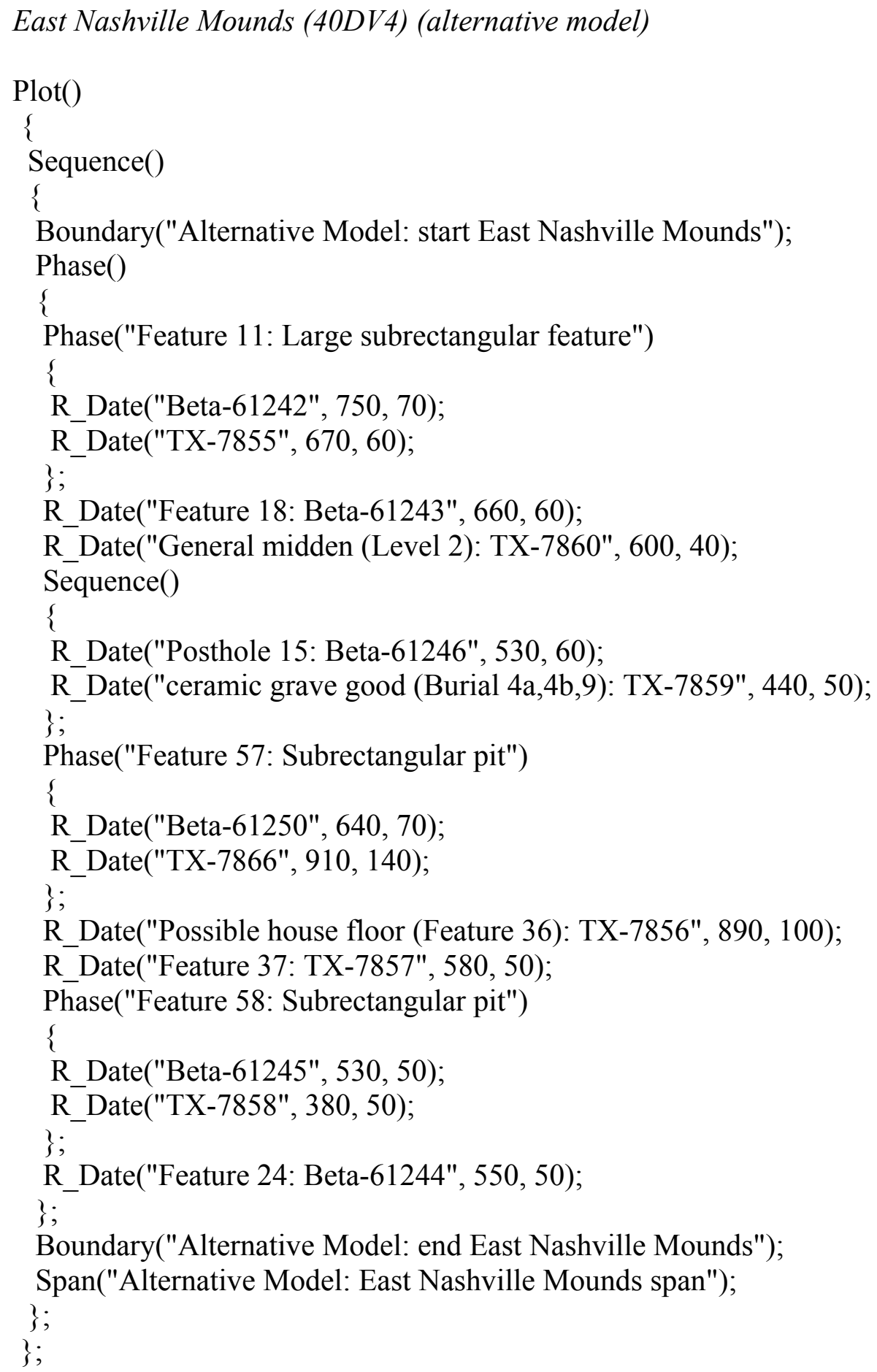


East Nashville Mounds (40DV4) (primary model with minimum number of simulated dates needed to achieve the desired result in the simulation experiment at $68 \%$ probability)

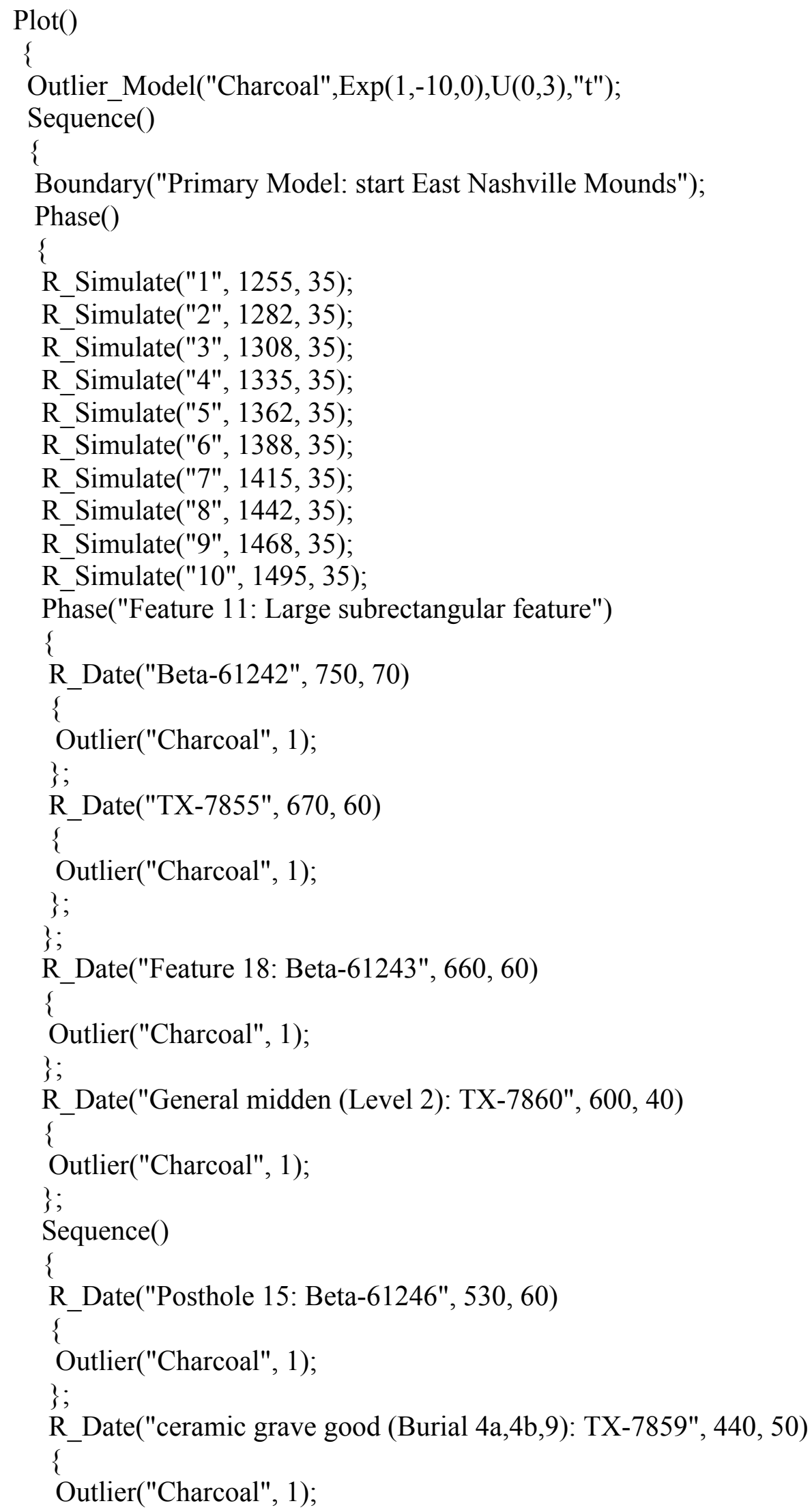




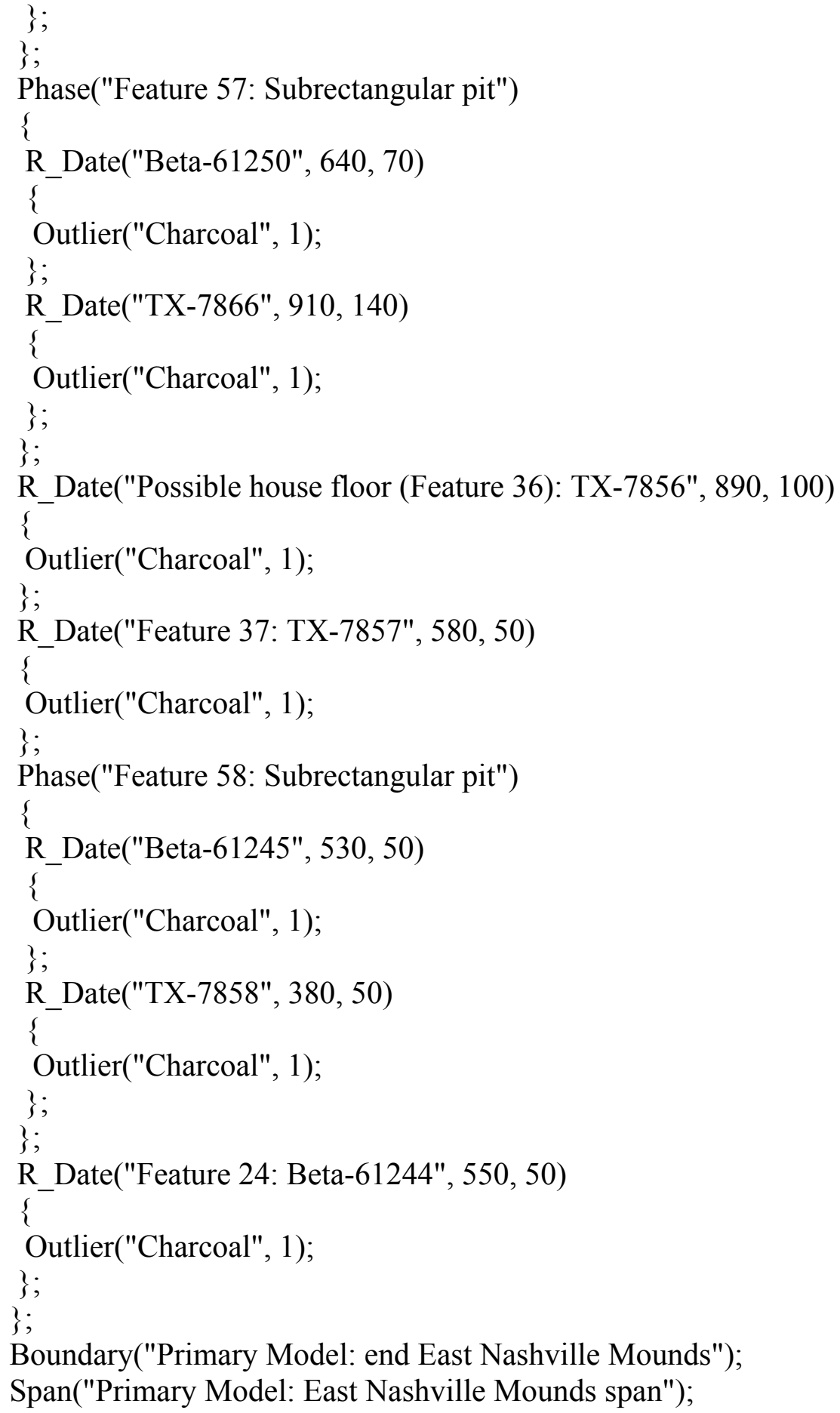


East Nashville Mounds (40DV4) (primary model with minimum number of simulated dates needed to achieve the desired result in the simulation experiment at 95\% probability)

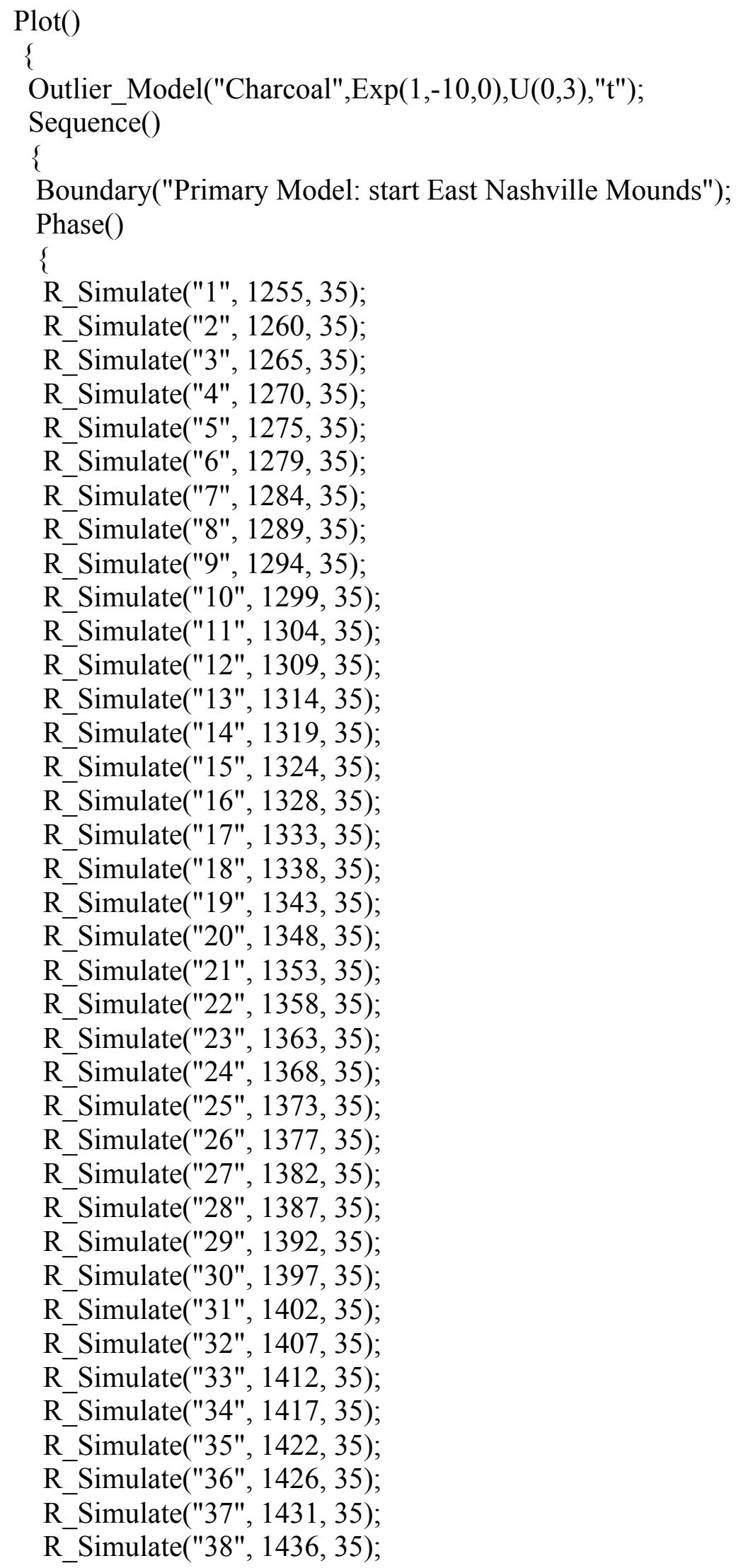


R_Simulate("39", 1441, 35);

R_Simulate("40", 1446, 35);

R_Simulate("41", 1451, 35);

R_Simulate("42", 1456, 35);

R_Simulate("43", 1461, 35);

R_Simulate("44", 1466, 35);

R_Simulate("45", 1471, 35);

R_Simulate("46", 1475, 35);

R_Simulate("47", 1480, 35);

R_Simulate("48", 1485, 35);

R_Simulate("49", 1490, 35);

R_Simulate("50", 1495, 35);

Phase("Feature 11: Large subrectangular feature")

\{

R_Date("Beta-61242", 750, 70)

\{

Outlier("Charcoal", 1);

;

R Date("TX-7855", 670, 60)

\{

Outlier("Charcoal", 1);

;

;

R_Date("Feature 18: Beta-61243", 660, 60)

\{

Outlier("Charcoal", 1);

\};

R_Date("General midden (Level 2): TX-7860", 600, 40)

\{

Outlier("Charcoal", 1);

\};

Sequence()

\{

R_Date("Posthole 15: Beta-61246", 530, 60)

\{

Outlier("Charcoal", 1);

\} ;

R_Date("ceramic grave good (Burial 4a,4b,9): TX-7859", 440, 50)

\{

Outlier("Charcoal", 1);

;

;

Phase("Feature 57: Subrectangular pit")

\{

R_Date("Beta-61250", 640, 70)

\{

Outlier("Charcoal", 1);

; ;

R_Date("TX-7866", 910, 140)

\{ 


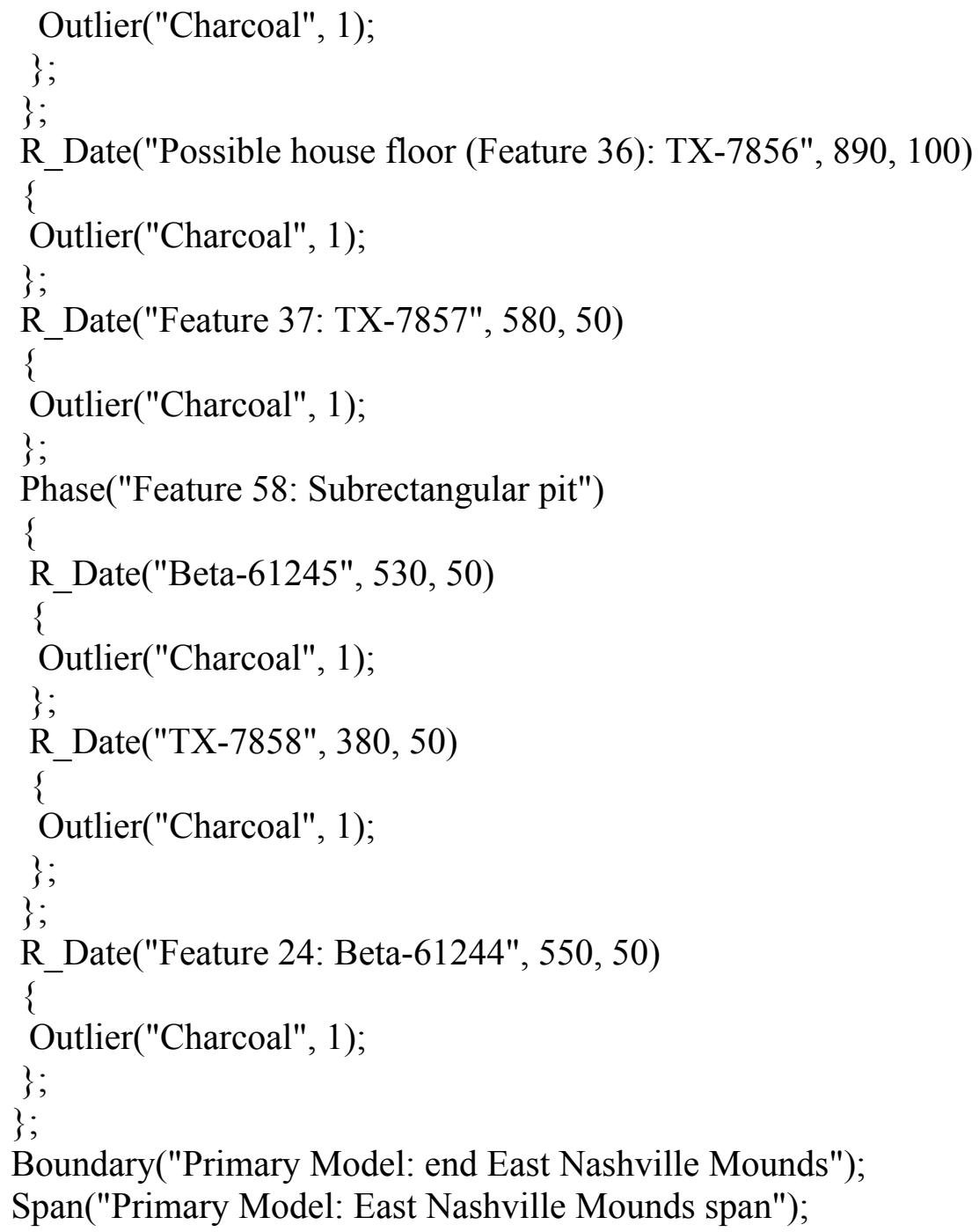


Gordontown (40DV4) (primary model with minimum number of simulated dates to achieve the desired result in the simulation experiment at $68 \%$ probability)

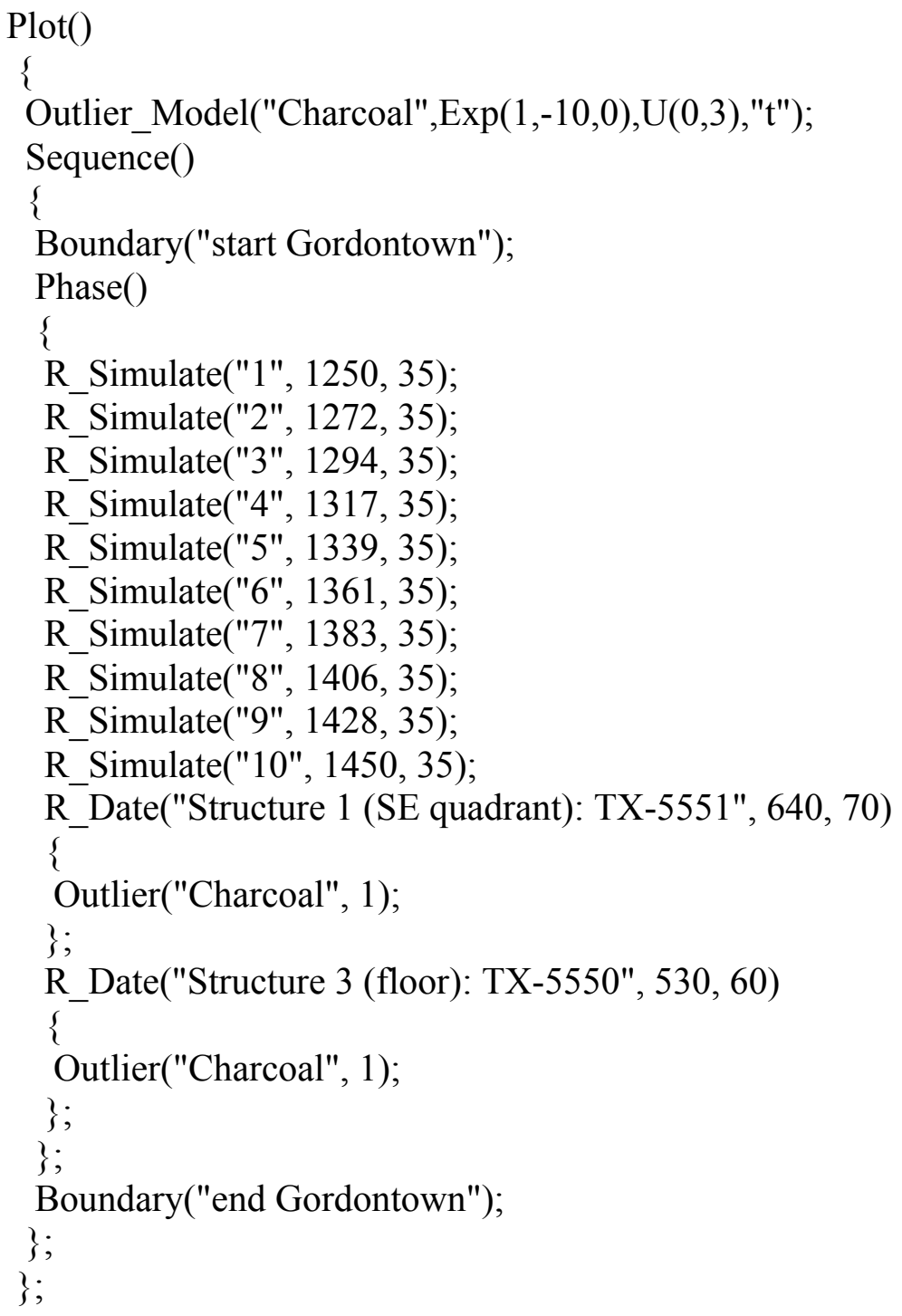


Gordontown (40DV4) (primary model with minimum number of simulated dates needed to achieve the desired result in the simulation experiment at 95\% probability)

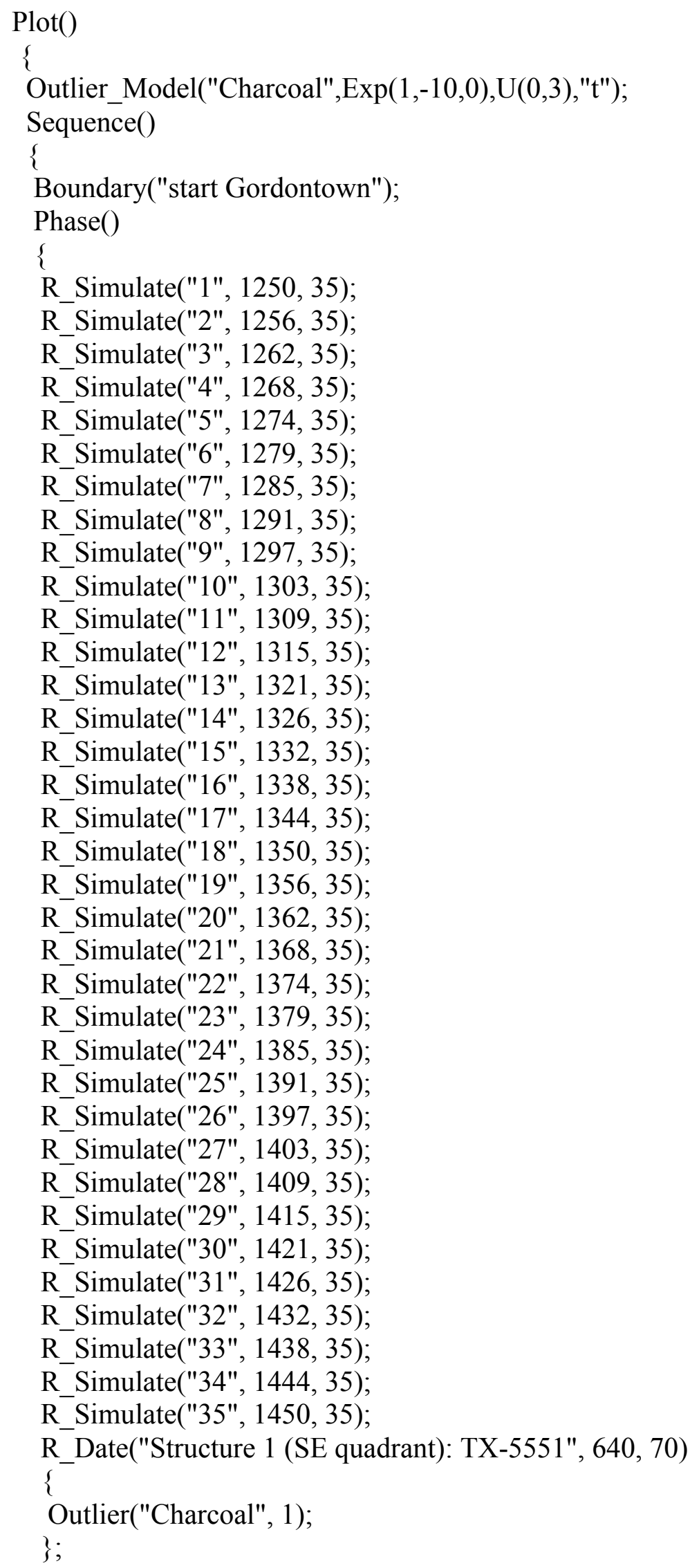


R_Date("Structure 3 (floor): TX-5550", 530, 60)

\{

Outlier("Charcoal", 1);

;

;

Boundary("end Gordontown");

\} ;

\} 
Rutherford-Kizer (40SU15) (primary model)

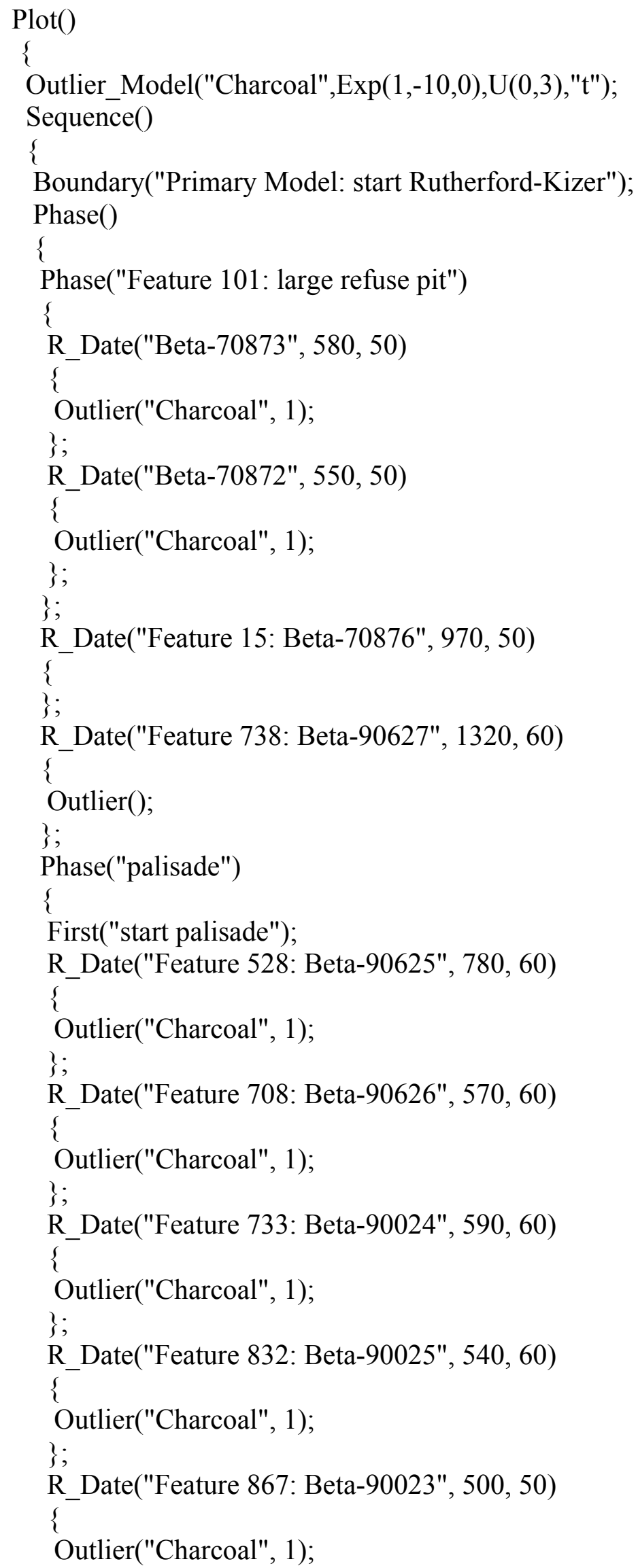




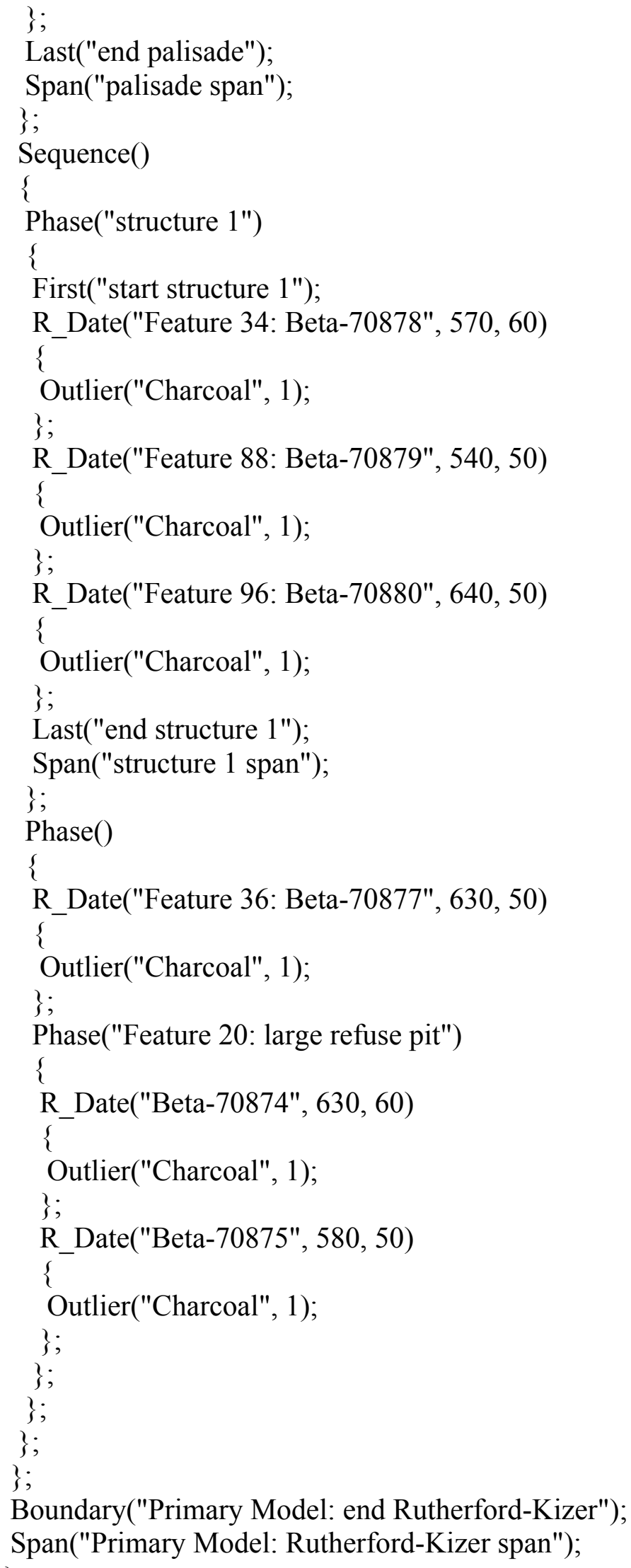


Rutherford-Kizer (40SU15) (alternative model)

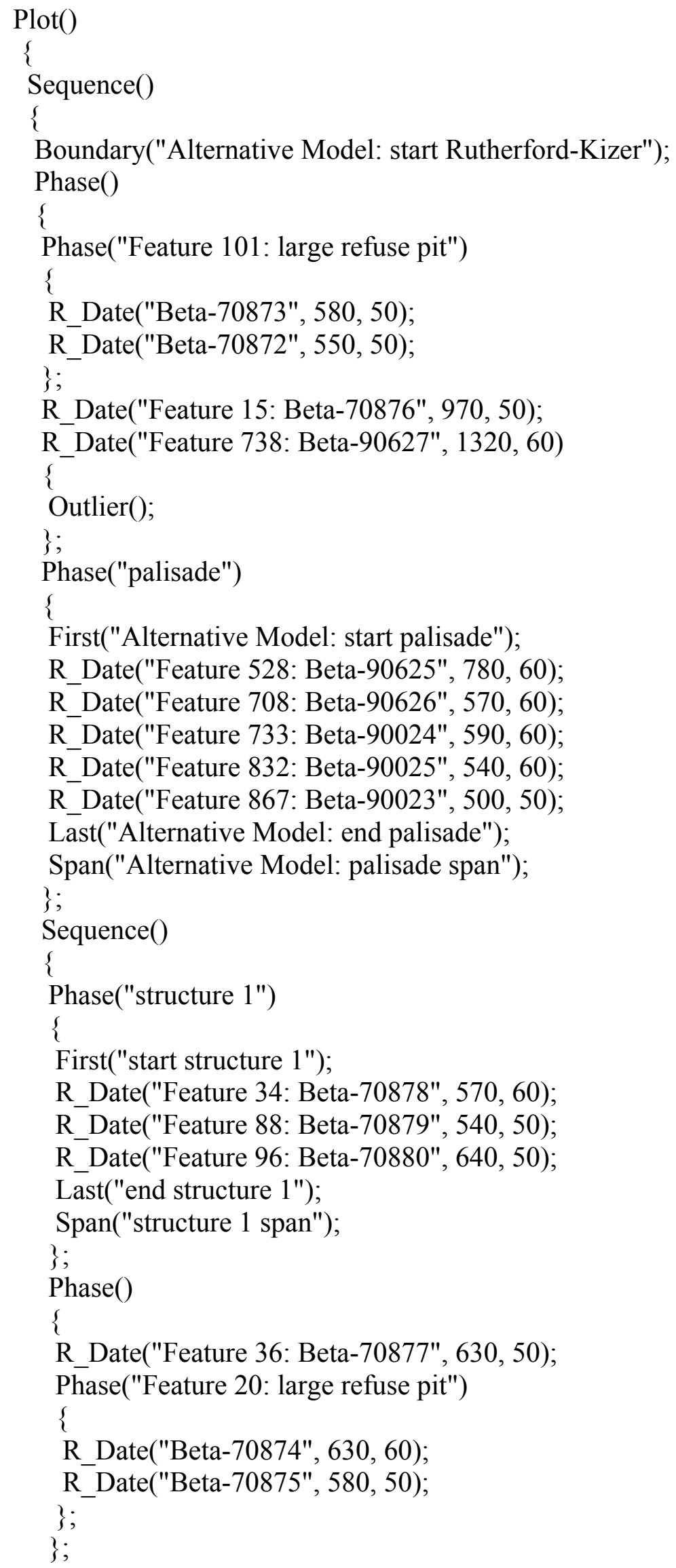


;

\}

Boundary("Alternative Model: end Rutherford-Kizer");

Span("Alternative Model: Rutherford-Kizer span"); ;

\} 
Rutherford-Kizer (40SU15) (primary model with minimum number of simulated dates needed to achieve the desired result in the simulation experiment at $68 \%$ probability)

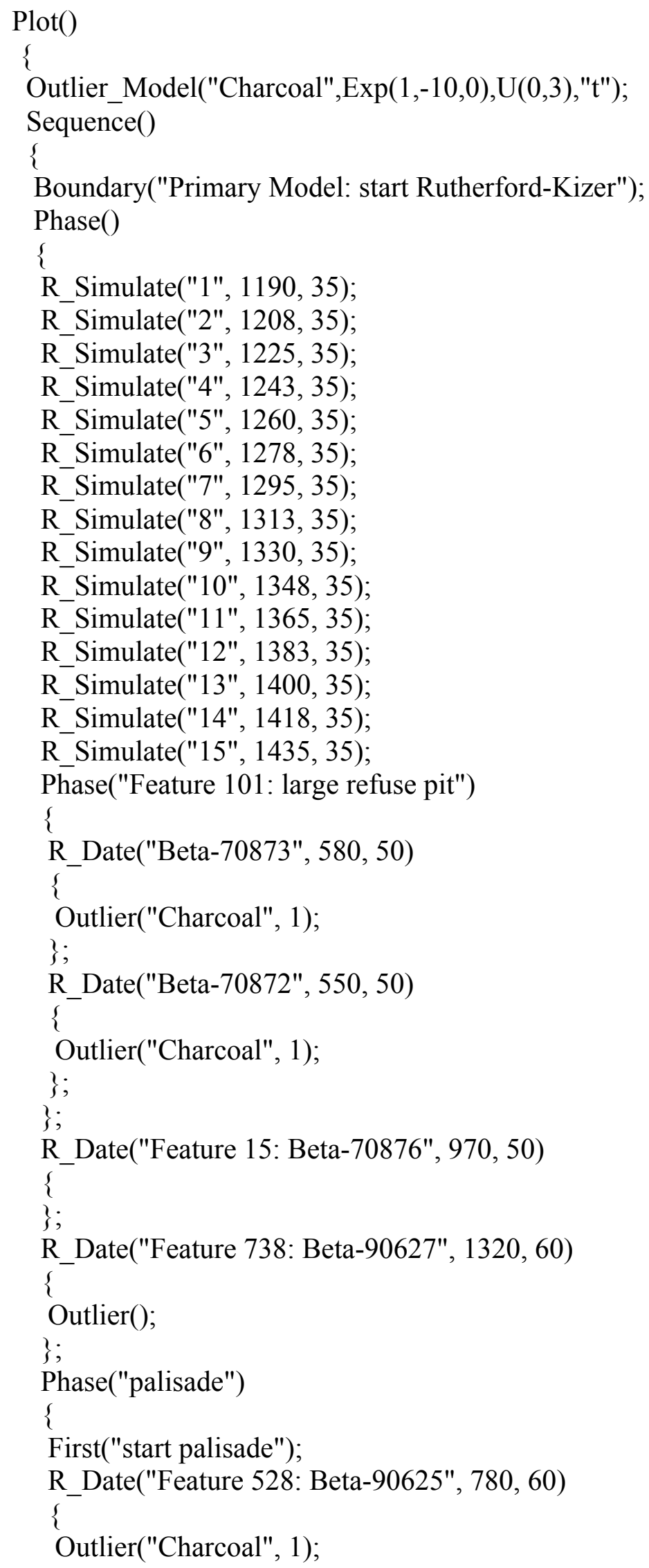


\} ;

R_Date("Feature 708: Beta-90626", 570, 60)

\{

Outlier("Charcoal", 1);

; ;

R_Date("Feature 733: Beta-90024", 590, 60)

\{

Outlier("Charcoal", 1);

\};

R_Date("Feature 832: Beta-90025", 540, 60)

\{

Outlier("Charcoal", 1);

\};

R_Date("Feature 867: Beta-90023", 500, 50)

\{

Outlier("Charcoal", 1);

;

Last("end palisade");

Span("palisade span");

; ;

Sequence()

\{

Phase("structure 1")

\{

First("start structure 1");

R_Date("Feature 34: Beta-70878", 570, 60)

\{

Outlier("Charcoal", 1);

; ;

R_Date("Feature 88: Beta-70879", 540, 50)

\{

Outlier("Charcoal", 1);

; ;

R_Date("Feature 96: Beta-70880", 640, 50)

\{

Outlier("Charcoal", 1);

; ;

Last("end structure 1");

Span("structure 1 span");

; ;

Phase()

\{

R Date("Feature 36: Beta-70877", 630, 50)

\{

Outlier("Charcoal", 1);

; ;

Phase("Feature 20: large refuse pit")

\{

R_Date("Beta-70874", 630, 60)

\{ 
Outlier("Charcoal", 1);

\};

R_Date("Beta-70875", 580, 50)

\{

Outlier("Charcoal", 1);

;

\}

\}

;

\}

Boundary("Primary Model: end Rutherford-Kizer");

Span("Primary Model: Rutherford-Kizer span");

;

; 
Rutherford-Kizer (40SU15) (primary model with minimum number of simulated dates needed to achieve the desired result in the simulation experiment at 95\% probability)

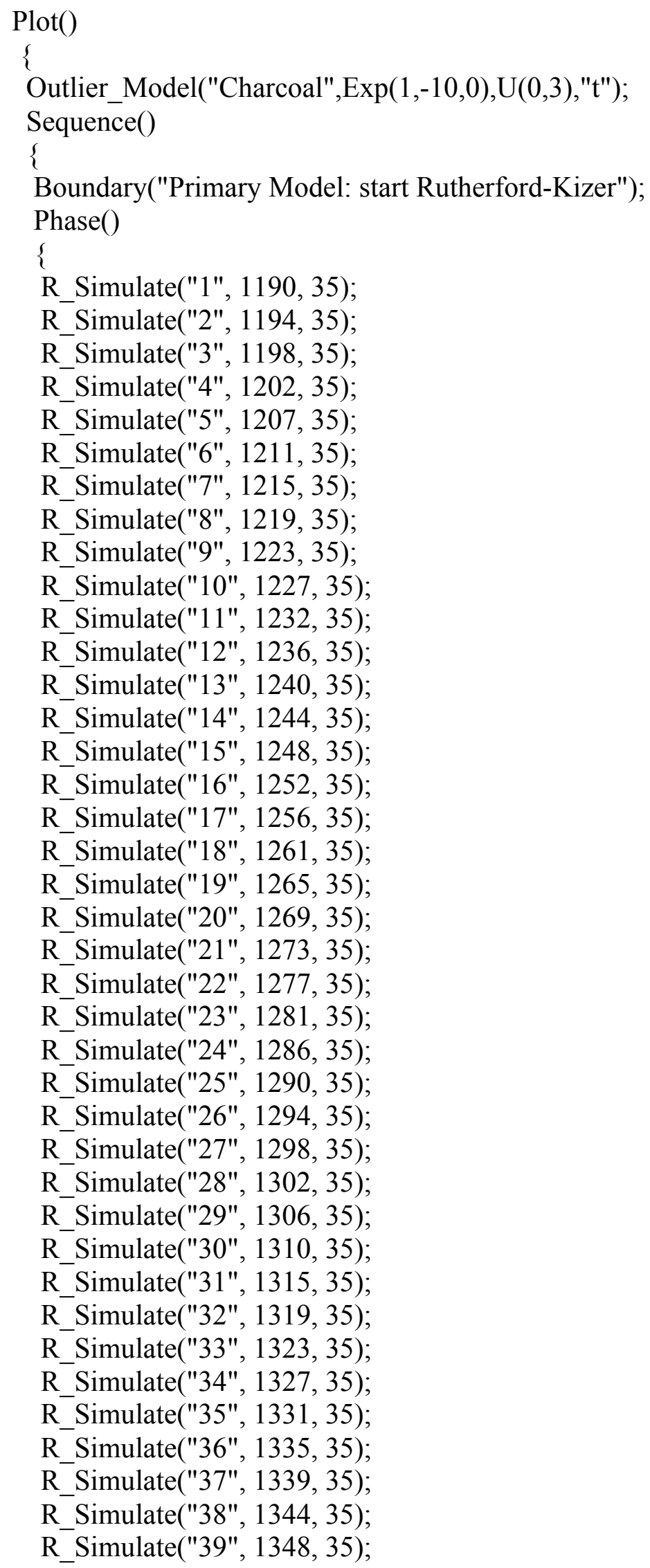


R_Simulate("40", 1352, 35);

R_Simulate("41", 1356, 35);

R_Simulate("42", 1360, 35);

R_Simulate("43", 1364, 35);

R_Simulate("44", 1369, 35);

R_Simulate("45", 1373, 35);

R_Simulate("46", 1377, 35);

R_Simulate("47", 1381, 35);

R_Simulate("48", 1385, 35);

R_Simulate("49", 1389, 35);

R_Simulate("50", 1393, 35);

R_Simulate("51", 1398, 35);

R_Simulate("52", 1402, 35);

R_Simulate("53", 1406, 35);

R_Simulate("54", 1410, 35);

R_Simulate("55", 1414, 35);

R_Simulate("56", 1418, 35);

R_Simulate("57", 1423, 35);

R_Simulate("58", 1427, 35);

R_Simulate("59", 1431, 35);

R Simulate("60", 1435, 35);

Phase("Feature 101: large refuse pit")

\{

R_Date("Beta-70873", 580, 50)

\{

Outlier("Charcoal", 1);

\};

R_Date("Beta-70872", 550, 50)

\{

Outlier("Charcoal", 1);

\}

;

R Date("Feature 15: Beta-70876", 970, 50)

\{

\} ;

R_Date("Feature 738: Beta-90627", 1320, 60)

\{

Outlier();

; ;

Phase("palisade")

\{

First("start palisade");

R_Date("Feature 528: Beta-90625", 780, 60)

\{

Outlier("Charcoal", 1);

;

R_Date("Feature 708: Beta-90626", 570, 60)

\{

Outlier("Charcoal", 1);

\}; 


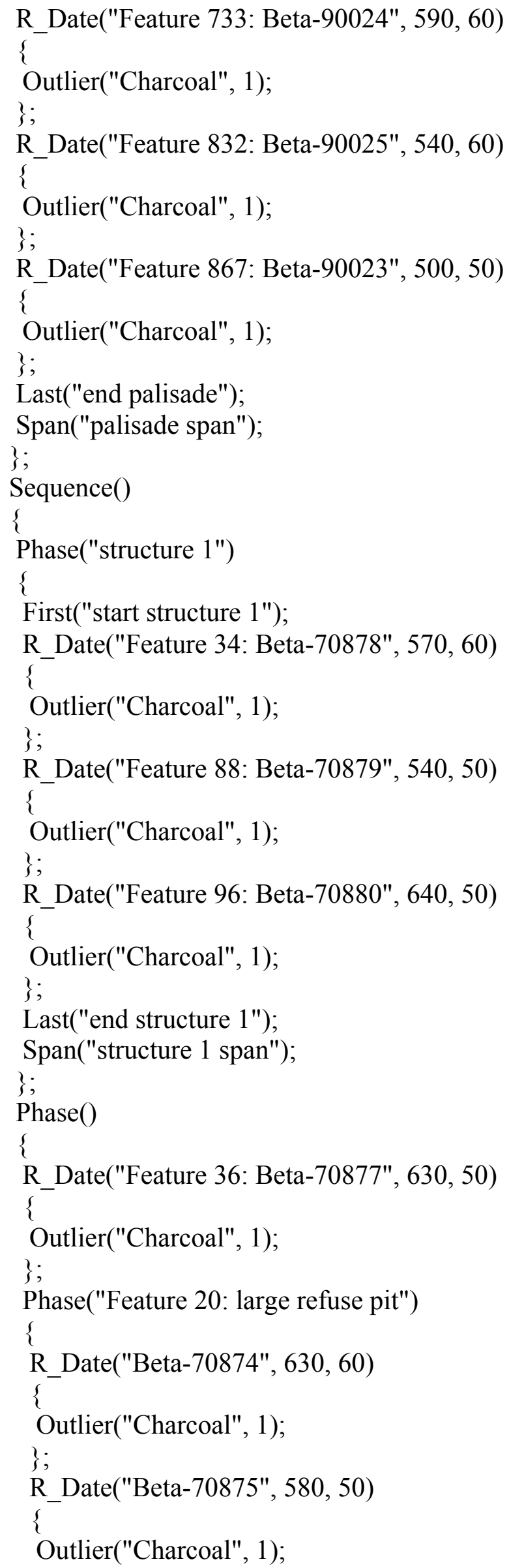




$$
\begin{aligned}
& 3 ; \\
& \} ; \\
& \xi
\end{aligned}
$$

\}

Boundary("Primary Model: end Rutherford-Kizer");

Span("Primary Model: Rutherford-Kizer span"); \}

\} 


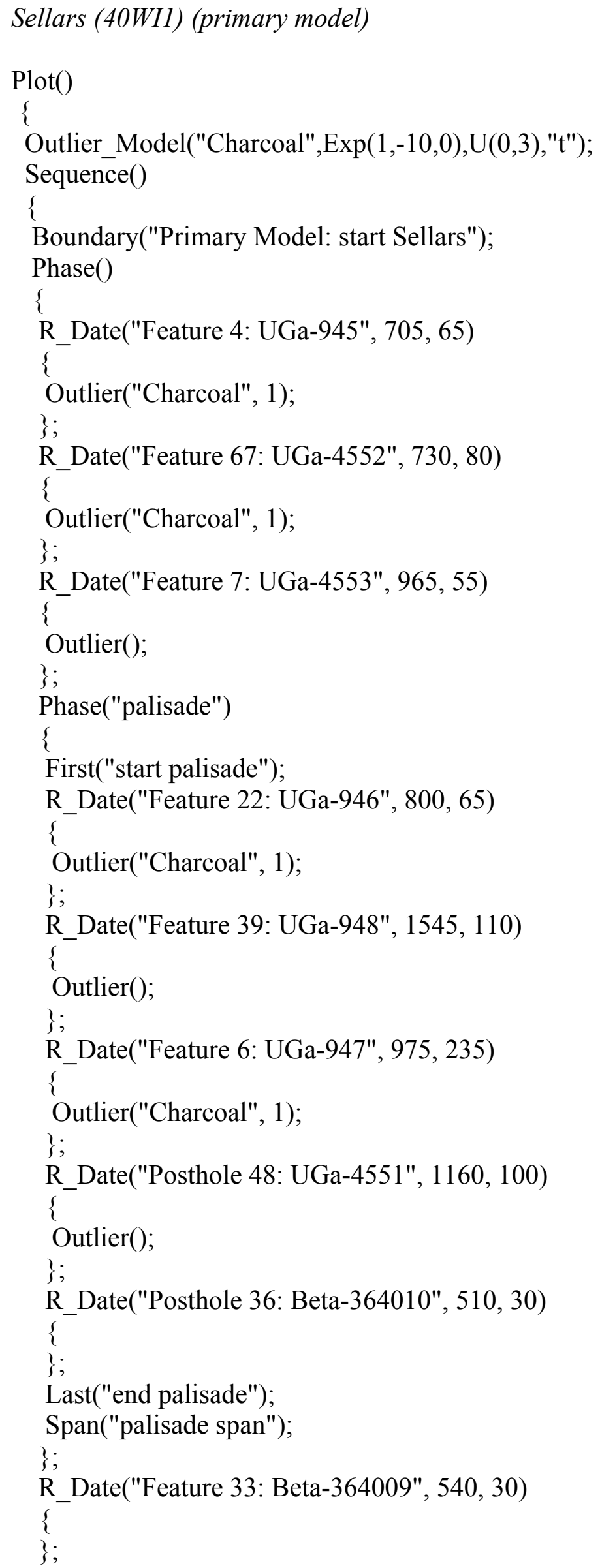


R_Date("Structure 1 (Feature 2): UGa-944", 900, 110)

\{

Outlier("Charcoal", 1);

;

\}

Boundary("Primary Model: end Sellars");

Span("Primary Model: Sellars span");

\}

\} 


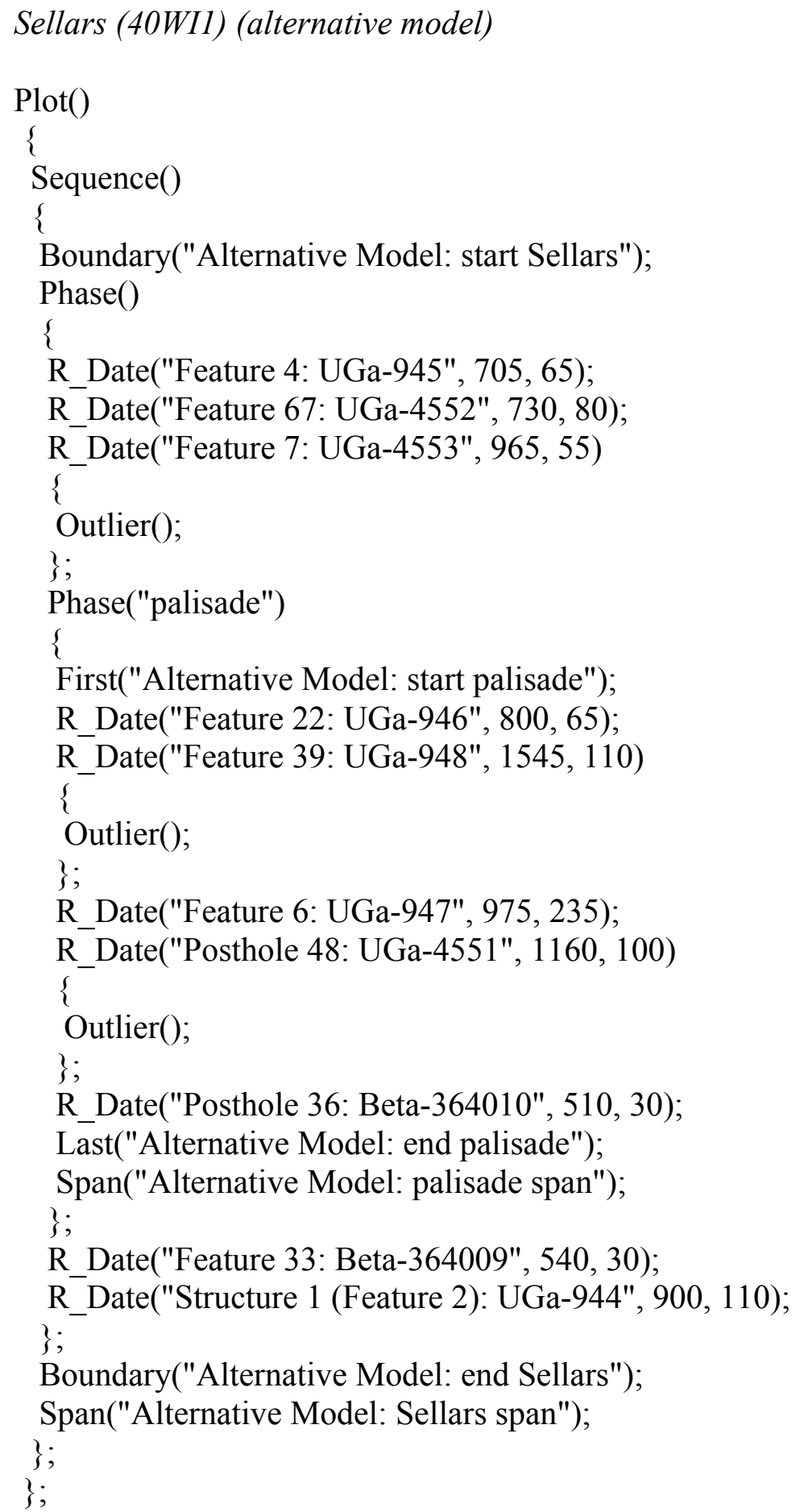


Sellars (40WI1) (primary model with minimum number of simulated dates needed to achieve the desired result in the simulation experiment at $68 \%$ probability)

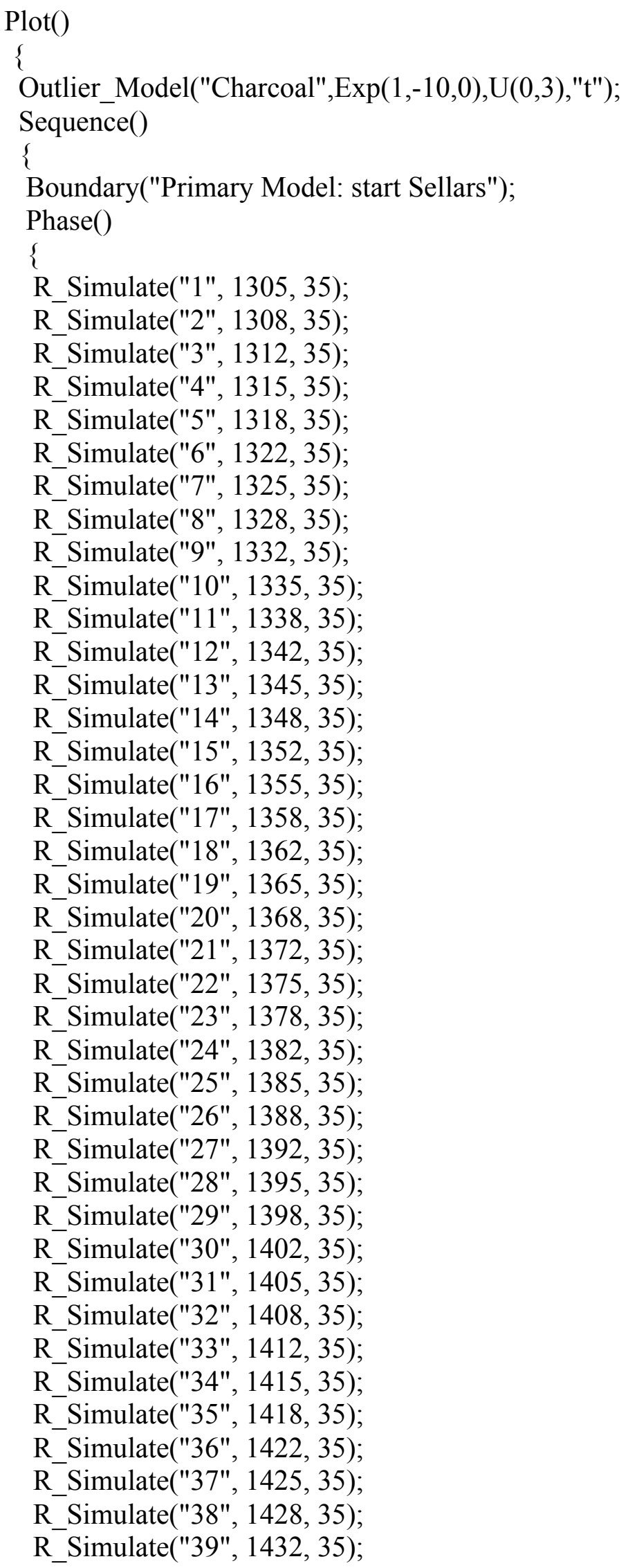


R_Simulate("40", 1435, 35);

R_Date("Feature 4: UGa-945", 705, 65)

\{

Outlier("Charcoal", 1);

; ;

R_Date("Feature 67: UGa-4552", 730, 80)

\{

Outlier("Charcoal", 1);

;

R_Date("Feature 7: UGa-4553", 965, 55)

\{

Outlier();

; ;

Phase("palisade")

\{

First("start palisade");

R_Date("Feature 22: UGa-946", 800, 65)

\{

Outlier("Charcoal", 1);

; ;

R_Date("Feature 39: UGa-948", 1545, 110)

\{

Outlier();

; ;

R_Date("Feature 6: UGa-947", 975, 235)

\{

Outlier("Charcoal", 1);

;

R_Date("Posthole 48: UGa-4551", 1160, 100)

\{

Outlier();

; ;

R_Date("Posthole 36: Beta-364010", 510, 30)

\{

;

Last("end palisade");

Span("palisade span");

; ;

R_Date("Feature 33: Beta-364009", 540, 30)

\{

\} ;

R_Date("Structure 1 (Feature 2): UGa-944", 900, 110)

\{

Outlier("Charcoal", 1);

;

\}

Boundary("Primary Model: end Sellars");

Span("Primary Model: Sellars span");

\}

\} 
Sellars (40WI1) (primary model with minimum number of simulated dates needed to achieve the desired result in the simulation experiment at 95\% probability)

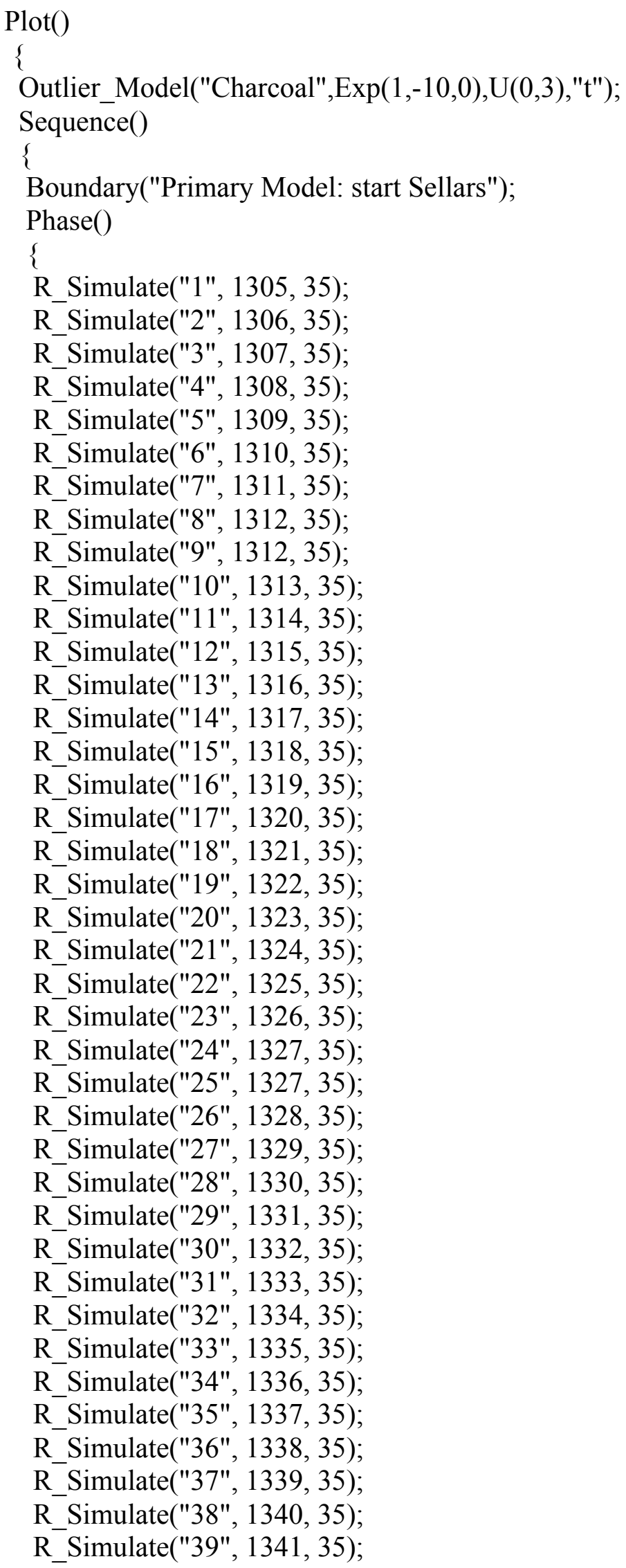


R_Simulate("40", 1341, 35);

R_Simulate("41", 1342, 35);

R_Simulate("42", 1343, 35);

R_Simulate("43", 1344, 35);

R_Simulate("44", 1345, 35);

R_Simulate("45", 1346, 35);

R_Simulate("46", 1347, 35);

R_Simulate("47", 1348, 35);

R_Simulate("48", 1349, 35);

R_Simulate("49", 1350, 35);

R_Simulate("50", 1351, 35);

R_Simulate("51", 1352, 35);

R_Simulate("52", 1353, 35);

R_Simulate("53", 1354, 35);

R_Simulate("54", 1355, 35);

R_Simulate("55", 1356, 35);

R_Simulate("56", 1356, 35);

R_Simulate("57", 1357, 35);

R_Simulate("58", 1358, 35);

R_Simulate("59", 1359, 35);

R_Simulate("60", 1360, 35);

R_Simulate("61", 1361, 35);

R_Simulate("62", 1362, 35);

R_Simulate("63", 1363, 35);

R_Simulate("64", 1364, 35);

R_Simulate("65", 1365, 35);

R_Simulate("66", 1366, 35);

R_Simulate("67", 1367, 35);

R_Simulate("68", 1368, 35);

R_Simulate("69", 1369, 35);

R_Simulate("70", 1370, 35);

R_Simulate("71", 1370, 35);

R_Simulate("72", 1371, 35);

R_Simulate("73", 1372, 35);

R_Simulate("74", 1373, 35);

R_Simulate("75", 1374, 35);

R_Simulate("76", 1375, 35);

R_Simulate("77", 1376, 35);

R_Simulate("78", 1377, 35);

R_Simulate("79", 1378, 35);

R_Simulate("80", 1379, 35);

R_Simulate("81", 1380, 35);

R_Simulate("82", 1381, 35);

R_Simulate("83", 1382, 35);

R_Simulate("84", 1383, 35);

R_Simulate("85", 1384, 35);

R_Simulate("86", 1384, 35);

R_Simulate("87", 1385, 35);

R_Simulate("88", 1386, 35);

R_Simulate("89", 1387, 35); 
R_Simulate("90", 1388, 35);

R_Simulate("91", 1389, 35);

R_Simulate("92", 1390, 35);

R_Simulate("93", 1391, 35);

R_Simulate("94", 1392, 35);

R_Simulate("95", 1393, 35);

R_Simulate("96", 1394, 35);

R_Simulate("97", 1395, 35);

R_Simulate("98", 1396, 35);

R_Simulate("99", 1397, 35);

R_Simulate("100", 1398, 35);

R_Simulate("101", 1399, 35);

R_Simulate("102", 1399, 35);

R_Simulate("103", 1400, 35);

R_Simulate("104", 1401, 35);

R_Simulate("105", 1402, 35);

R_Simulate("106", 1403, 35);

R_Simulate("107", 1404, 35);

R_Simulate("108", 1405, 35);

R_Simulate("109", 1406, 35);

R_Simulate("110", 1407, 35);

R_Simulate("111", 1408, 35);

R_Simulate("112", 1409, 35);

R_Simulate("113", 1410, 35);

R_Simulate("114", 1411, 35);

R_Simulate("115", 1412, 35);

R_Simulate("116", 1413, 35);

R_Simulate("117", 1413, 35);

R_Simulate("118", 1414, 35);

R_Simulate("119", 1415, 35);

R_Simulate("120", 1416, 35);

R_Simulate("121", 1417, 35);

R Simulate("122", 1418, 35);

R_Simulate("123", 1419, 35);

R_Simulate("124", 1420, 35);

R_Simulate("125", 1421, 35);

R_Simulate("126", 1422, 35);

R_Simulate("127", 1423, 35);

R_Simulate("128", 1424, 35);

R_Simulate("129", 1425, 35);

R_Simulate("130", 1426, 35);

R_Simulate("131", 1427, 35);

R_Simulate("132", 1428, 35);

R_Simulate("133", 1428, 35);

R_Simulate("134", 1429, 35);

R_Simulate("135", 1430, 35);

R_Simulate("136", 1431, 35);

R_Simulate("137", 1432, 35);

R_Simulate("138", 1433, 35);

R_Simulate("139", 1434, 35); 
R_Simulate("140", 1435, 35);

R_Date("Feature 4: UGa-945", 705, 65)

\{

Outlier("Charcoal", 1);

; ;

R_Date("Feature 67: UGa-4552", 730, 80)

\{

Outlier("Charcoal", 1);

;

R_Date("Feature 7: UGa-4553", 965, 55)

\{

Outlier();

; ;

Phase("palisade")

\{

First("start palisade");

R_Date("Feature 22: UGa-946", 800, 65)

\{

Outlier("Charcoal", 1);

; ;

R_Date("Feature 39: UGa-948", 1545, 110)

\{

Outlier();

\};

R_Date("Feature 6: UGa-947", 975, 235)

\{

Outlier("Charcoal", 1);

; ;

R_Date("Posthole 48: UGa-4551", 1160, 100)

\{

Outlier();

; ;

R_Date("Posthole 36: Beta-364010", 510, 30)

\{

;

Last("end palisade");

Span("palisade span");

; ;

R_Date("Feature 33: Beta-364009", 540, 30)

\{

\} ;

R_Date("Structure 1 (Feature 2): UGa-944", 900, 110)

\{

Outlier("Charcoal", 1);

;

\}

Boundary("Primary Model: end Sellars");

Span("Primary Model: Sellars span");

\}

\} 


\section{Supplemental Material References Cited}

Bayliss, Alex

2009 Rolling out revolution: using radiocarbon dating in archaeology. Radiocarbon 51(1):123-147.

Bayliss, Alex, Christopher Bronk Ramsey, Johannes van der Plicht and Alasdair Whittle

2007 Bradshaw and Bayes: Towards a Timetable for the Neolithic. Cambridge Archaeological Journal 17(1):1-28.

Beahm, Emily Lynne

2013 Mississippian polities in the Middle Cumberland Region of Tennessee. Ph.D. Dissertation, Department of Anthropology, University of Georgia.

Butler, Brian M.

1981 Sellars: A small mound center in the hinterlands. Tennessee Anthropologist $6: 37-60$

Cobb, Charles R., Anthony M. Krus, and Dawnie W. Steadman

2015 Bayesian Modeling of the Occupation Span of the Averbuch Site in the Middle Cumberland Drainage. Tennessee. Southeastern Archaeology 34:4656.

Griffiths, Seren 
2014 Simulations and Outputs. Radiocarbon 56(2):871-876.

Klippel, Walter E., and William M. Bass (editors)

1984 Averbuch: A Late Mississippian Manifestation in the Nashville Basin. Two volumes. Department of Anthropology, University of Tennessee, Knoxville. Submitted to the National Park Service, Atlanta.

Moore, Michael C.

2005 The Brentwood Library Site: A Mississippian Town on the Little Harpeth River, Williamson County, Tennessee. Research Series No. 15, Tennessee Division of Archaeology, Nashville.

Moore, Michael C., and Emanuel Breitburg

1998 Gordontown: Salvage Archaeology at a Mississippian Town in Davidson County, Tennessee. Research Series No. 11. Tennessee Division of Archaeology, Nashville.

Moore, Michael C., Emanuel Breitburg, Kevin E. Smith, and Mary Beth Trubitt 2006 One Hundred Years of Archaeology at Gordontown: a Fortified Mississippian Town in Middle Tennessee. Southeastern Archaeology 25:89-109.

Moore, Michael C., and Kevin E. Smith (editors)

2001 Archaeological Excavations at the Rutherford-Kizer Site: A Mississippian Mound Center in Sumner County, Tennessee. Research Series No. 13. 
Tennessee Department of Environment and Conservation Division of Archaeology, Nashville

Reed, A.

1984 Radiocarbon dates. In Averbuch: A Late Mississippian Manifestation in the Nashville Basin, edited by Walter E. Klippel and William M. Bass, pp. 2.12.8. Department of Anthropology, University of Tennessee, Knoxville. Submitted to the National Park Service, Atlanta.

Smith, Kevin E.

2002 Tennessee Radiocarbon Dates (List Version 1.00). Tennessee Anthropologist 24(1-2):1-46.

Walling, Richard

2000 Radiocarbon Dates. In The Jefferson Street Bridge Project: Archaeological Investigations at the East Nashville Mounds Site (40DV4) and the French Lick / Sulphur Dell Site (40DV5) in Nashville, Davidson County, Tennessee, Volume I: Text. edited by Richard Walling, Lawrence S. Alexander, and Evan Peacock, pp. 481-490. Publication in Archaeology 1. Tennessee Department of Transportation, Nashville, TN. 